ALICE RAMOS DE FREITAS PEREIRA

Avaliação clínica de implantes restaurados com conectores de titânio ou zircônia: estudo longitudinal de 3 anos 

ALICE RAMOS DE FREITAS PEREIRA

\title{
Avaliação clínica de implantes restaurados com conectores de titânio ou zircônia: estudo longitudinal de 3 anos
}

\author{
Versão Corrigida
}

Dissertação apresentada à Faculdade de Odontologia de Ribeirão Preto da Universidade de São Paulo para a obtenção do título de Mestre em Odontologia.

Área de Concentração: Reabilitação Oral.

Orientador: Prof. Dr. Cássio do Nascimento

Ribeirão Preto 
Autorizo a reprodução e divulgação total ou parcial deste trabalho, por qualquer meio convencional ou eletrônico, para fins de estudo e pesquisa, desde que citada a fonte.

\section{FICHA CATALOGRÁFICA}

Pereira, Alice Ramos de Freitas

Avaliação clínica de implantes restaurados com conectores de titânio ou zircônia: estudo longitudinal de 3 anos. Ribeirão Preto, 2017.

126p. : il. ; $30 \mathrm{~cm}$

Dissertação de Mestrado, apresentada à Faculdade de Odontologia de Ribeirão Preto/USP. Área de concentração: Reabilitação Oral.

Versão corrida da Dissertação. A versão original se encontra disponível na Unidade que aloja o Programa.

Orientador: Prof. Dr. Cássio do Nascimento.

1. Implante dentário. 2. Zircônia. 3. Titânio. 4. Conectores. 5. Avaliação clínica. 


\section{FOLHA DE APROVAÇÃO}

Pereira, ARF. Avaliação clínica de implantes restaurados com conectores de titânio ou zircônia: estudo longitudinal de 3 anos.

Dissertação apresentada à Faculdade de Odontologia de Ribeirão Preto da Universidade de São Paulo para obtenção do título de Mestre em Odontologia. Área de concentração: Reabilitação Oral.

Aprovado em

\section{Banca Examinadora}

Prof. (a). Dr. (a).:

Instituição:

Julgamento:

Prof. (a). Dr. (a).:

Instituição:

Julgamento:

Prof. (a). Dr. (a).:

Instituição:

Julgamento:

Prof. (a). Dr. (a).:

Instituição:

Julgamento: 

Dedicatária 



\title{
Dedicatória
}

\begin{abstract}
A Deus
Pelo dom da vida e por esta vitória, por estar sempre presente nas alegrias e me dar forças nos momentos difíceis. Por guiar meus passos quando me sinto sem orientação. E por me mostrar todos os dias que as barreiras colocadas no meu caminho, sou capaz de ultrapassá-las.
\end{abstract}

\section{Aos meus pais}

Célio Carvalho de Freitas e Maria Avani Ramos de Freitas, meus exemplos de vida, companheirismo, amor e principais incentivadores. Obrigada por mesmo a distância nunca me deixarem só, pelas orações, incentivo, por me amarem tanto e por sempre cuidarem tão bem de mim! Minha eterna gratidão, pois sem os ensinamentos de vocês, jamais teria chegado até aqui. Amo muito vocês!

\section{Ao meu marido}

Samuel Mateus, minha vida, meu melhor amigo, meu confidente e meu porto seguro, você foi o maior incentivador para que eu realizasse esse sonho, muito obrigada! O seu amor, a sua paciência, o seu cuidado infinito, o seu incentivo constante e o seu conforto foram fundamentais para que essa fase fosse realizada da melhor maneira possível. Obrigada por sempre acreditar em mim e buscar tornar os meus sonhos os teus também! Amo muito você!

\section{Aos meus irmãos}

Aline e Saulo, meus amigos, com quem eu posso sempre contar. Apesar da distância física se fazem sempre presente, no apoio, conselhos e cuidados. Obrigada por sempre acreditarem em mim, e me incentivarem nessa caminhada! 

Agradecimentas Especiais 



\section{Agradecimentos Especiais}

Ao Professor. Dr. Cássio do Nascimento, agradeço a Deus por ter me dado a honra de ser sua orientada. Sua competência profissional, humildade, paciência e apoio foram fundamentais para que eu não desistisse nos momentos de dificuldade. Agradeço por toda dedicação, pelos valiosos conhecimentos transmitidos, incentivo e conselhos. Muito obrigada por tudo!!!

Ao pós-graduando Thalisson Saymo, meu amigo, parceiro de lab, serei eternamente grata por sua amizade, você foi um presente de Deus em Ribeirão. Obrigada por me ajudar em todos os experimentos como se fossem seus, por torná-los mais divertidos, por todas risadas e momentos de descontração. Mesmo a distância, tenha em mente que sempre pode contar comigo! Certamente a vida tem reservado o de melhor pra você, e estarei na primeira fileira para aplaudir! Valeu parceria!

Aos voluntários da pesquisa, pela confiança e compromisso com o estudo. 

Agradecimentas 



\section{Agradecimentos}

À Faculdade de Odontologia de Ribeirão Preto da Universidade de São Paulo (FORP-USP), que me acolheu e foi essencial para o meu crescimento profissional.

Ao Programa de Pós-Graduação em Reabilitação Oral da FORP - USP, representada pelo coordenador Professor Dr. Ricardo Faria Ribeiro, pelo empenho em oferecer um programa de excelente qualidade.

Ao Conselho Nacional de Desenvolvimento Científico e Tecnológico (CNPq) e Fundação de Amparo à Pesquisa do estado de São Paulo (FAPESP) pelos suportes financeiros para o desenvolvimento da pesquisa, nas modalidades de Auxílio à Pesquisa (Processo MCTI/CNPq/Universal 457941/2014-6; e Processo FAPESP 2014/22876-8) e Bolsa de Estudos no País - Mestrado (Processo FAPESP 2016/13203-5).

Aos Docentes do Departamento de Materiais Dentários e Prótese da FORP - USP, sou encantada com a competência, paciência, dedicação e amor com que exercem a profissão. Obrigada por todos os ensinamentos.

Aos Professores da Disciplina de Materiais Dentários, Cássio do Nascimento e Alma Blásida Concepcion Elizaur Benitez Catirse que através do Programa PAE, pude aprender sobre as responsabilidades e vida diária na docência.

Aos Funcionários do Departamento de Materiais Dentários e Prótese, pela inestimável disponibilidade, eficiência e colaboração durante o período do mestrado em Reabilitação Oral.

Aos funcionários das Clínicas da FORP-USP, Fernando, Karina, Gledson, Sr. José, Roberta, Verinha, Dani e Silvia, pela organização, amabilidade, e pelo trabalho incrível que é desenvolvido todos os dias.

Ao Emerson de Souza Santos, técnico do Laboratório de Sequenciamento de Ácidos Nucleicos, ao Prof. Sérgio Akira Uyemura, responsável pelo laboratório, e a Viviane de 
Cássia Oliveira, técnica do Laboratório de Pesquisa em Reabilitação Oral, muito obrigada por sempre não medir esforços para ajudar.

Aos meus amigos do Mestrado, Bruna, Cecília, Livia, Marília, Milena, Michelli e Geyson. Nunca imaginei que encontraria pessoas tão especiais nessa trajetória, amigos sinceros e sempre dispostos a ajudar, ensinar e compartilhar. A amizade, a união, o apoio e o companheirismo de vocês amenizaram a saudade de casa, tornaram a trajetória mais fácil e me fizeram crescer como ser humano e profissional. A vocês desejo todo sucesso do mundo, estarei sempre na torcida! Muito obrigada!

À toda minha família e amigos de Fortaleza e Sobral. Apesar da distância, vocês se fizeram presentes e me abençoaram através das palavras de ânimo, e carinho. $O$ apoio sincero, o braço de suporte, a saudade apertada e o incentivo de vocês foi a minha base para realizar este trabalho da melhor maneira possível!

À todos que direta ou indiretamente contribuíram para a realização deste trabalho, 
"Bendize, ó minha alma, ao Senhor e NÃO esqueças nenhum de seus beneficios"

Salmos 103:2 

Resuma 

Pereira, ARF. Avaliação clínica de implantes restaurados com conectores de titânio ou zircônia: estudo longitudinal de 3 anos. [Dissertação]. Ribeirão Preto: Universidade de São Paulo, Faculdade de Odontologia de Ribeirão Preto; 2017.

\section{RESUMO}

Os implantes dentários representam uma opção de tratamento com alta previsibilidade de sucesso e sobrevivência. Os excelentes resultados geralmente estão relacionados à estabilidade da crista óssea e à saúde dos tecidos peri-implantares de suporte. O material utilizado para confecção do conector protético parece ter papel importante no resultado clínico dos implantes em longo prazo. O objetivo deste estudo foi avaliar longitudinalmente parâmetros clínicos dos tecidos peri-implantares em pacientes reabilitados com próteses unitárias cimentadas sobre conectores de titânio ou zircônia. Foram selecionados 20 participantes que foram reabilitados com implantes dentários e coroas protéticas unitárias cimentadas sobre conectores de zircônia ( $n=10$; região anterior da maxila) ou conectores de titânio ( $\mathrm{n}=10$; região posterior da maxila/mandíbula). Os parâmetros clínicos: profundidade de sondagem, nível clínico de inserção, recessão gengival, sangramento à sondagem e reabsorção óssea marginal foram coletados nos períodos $\mathrm{T} 0=$ baseline (instalação da prótese), T1 = 12 meses, T2 = 24 meses e T3 = 36 meses de função mastigatória. Nenhuma complicação clínica foi observada para ambos os conectores, com taxa de sucesso de $100 \%$. Tanto os materiais avaliados quanto os períodos de investigação propostos apresentaram efeito relativo significante nos parâmetros clínicos avaliados $(p<0,05)$. Não houve diferença significante em relação à reabsorção óssea marginal total, entre os dois materiais, após 36 meses. Os resultados sugerem manutenção da saúde peri-implantar ao longo do tempo, em ambos os grupos.

Palavras-chave: Implantes dentários, Conectores, Titânio, Zircônia, Avaliação clínica. 

Alstract 

Pereira, ARF. Clinical evaluation of restored implants with titanium or zirconia abutments: longitudinal study of 3 years. [Dissertation]. Ribeirão Preto: Universidade de São Paulo, Faculdade de Odontologia de Ribeirão Preto; 2017.

\begin{abstract}
Dental implants represent a treatment option with high success and survival predictability. The great results usually are related to bone crest stability and peri-implant supporting tissues health. The material used to produce the prosthetic connector seems to play an important role on the long term of implant clinical outcome. The objective of this study was to evaluate longitudinal clinical parameters of peri-implant tissues in patients rehabilitated with unitary prostheses cemented on titanium or zirconia connectors. Were selected twenty participants rehabilitated with dental implants and cemented crowns on zirconia connectors $(\mathrm{n}=10$, anterior maxilla) or titanium connectors $(\mathrm{n}=10$, posterior maxilla/ mandible). The clinical parameters: probing depth, connective tissue attachment level, gingival recession, bleeding on probing and marginal bone resorption, were collected in the periods of masticatory function: $\mathrm{T} 0=$ baseline (prosthesis installation), $\mathrm{T} 1=12$ months, $\mathrm{T} 2=24$ months and T $3=36$ months . No clinical complication was observed in both connectors, with a $100 \%$ success rate. The evaluated materials and the investigated periods had a significant relative effect on the clinical parameters evaluated $(\mathrm{p}<0.05)$. There was no significant difference on the total marginal bone resorption between the two materials, after 36 months. The results suggests maintenance of peri-implant health over time, in both groups.
\end{abstract}

Key-words: Dental Implants. Abutments. Titanium. Zirconia. Clinical assessment. 

Lista de Figuras 



\section{LISTA DE FIGURAS}

Figura 1- Fluxograma do estudo

66

Figura 2- Guias cirúrgicos confeccionados para auxílio no posicionamento correto dos implantes.

Figura 3- Sistema computadorizado de sondas periodontais Florida Probe ${ }^{\circledR}$

Figura 4- Aferição da profundidade de sondagem e nível clínico de inserção por meio do sistema Florida Probe ${ }^{\circledR}$

Figura 5- Técnica do paralelismo para obtenção de radiografias periapicais

Figura 6- Mensuração da reabsorção óssea marginal (região mesial e distal) com o auxílio do software Image J.

Figura 7- Radiografias periapicais ilustrando a osseointegração dos implantes

Figura 8- Gráfico Box Plot com os valores de mediana, intervalo interquartil e valores mínimo e máximo de profundidade de sondagem $(\mathrm{mm})$ e gráfico do intervalo de confiança de $95 \%$ para o efeito relativo dos fatores investigados.

Figura 9- Mediana, intervalo interquartil e valores mínimo e máximo de profundidade de sondagem (mm) após os testes de múltiplas comparações de Friedman-Conover corrigido por Benjamini-Hockberg FDR

Figura 10- Gráfico Box Plot com os valores de mediana, intervalo interquartil e valores mínimo e máximo de nível clínico de inserção $(\mathrm{mm})$ e gráfico do intervalo de confiança de $95 \%$ para o efeito relativo dos fatores investigados.

Figura 11- Mediana, intervalo interquartil e valores mínimo e máximo de nível clínico de inserção (mm) após os testes de múltiplas comparações de Friedman-Conover corrigido por Benjamini-Hockberg FDR

Figura 12- Gráfico Box Plot com os valores de mediana, intervalo interquartil e valores mínimo e máximo de sangramento à sondagem e gráfico do intervalo de confiança de $95 \%$ para o efeito relativo dos fatores investigados.

Figura 13- Mediana, intervalo interquartil e valores mínimo e máximo de sangramento à sondagem após os testes de múltiplas comparações de Friedman-Conover corrigido por Benjamini-Hockberg FDR

Figura 14- Gráfico Box Plot com os valores de mediana, intervalo interquartil e valores mínimo e máximo de recessão gengival $(\mathrm{mm})$ e gráfico do intervalo de confiança de $95 \%$ para o efeito relativo dos fatores investigados 
Figura 15- Mediana, intervalo interquartil e valores mínimo e máximo de recessão gengival (mm) após os testes de múltiplas comparações de FriedmanConover corrigido por Benjamini-Hockberg FDR 
Lista de Tabelas 



\section{LISTA DE TABELAS}

Tabela 1- Distribuição de participantes, gênero, idade e número de sítios avaliados por grupo nos tempos investigado.

Tabela 2- Análise dos efeitos relativos dos fatores substrato, tempo e suas interações na profundidade de sondagem.

Tabela 3- Valores de $p$ para as múltiplas comparações por meio do método de Friedman-Conover corrigido pelo pós-teste de Benjamini-Hochberg FDR na profundidade de sondagem.

Tabela 4- Mean ranks (Rj) após múltiplas comparações na profundidade de sondagem......

Tabela 5- Análise dos efeitos relativos dos fatores substrato, tempo e suas interações no nível clínico de inserção

Tabela 6- Valores de $p$ para as múltiplas comparações realizadas por meio do método de Friedman-Conover corrigido pelo pós-teste de Benjamini-Hochberg FDR no nível clínico de inserção

Tabela 7- Mean ranks (Rj) após múltiplas comparações no nível clínico de inserção....

Tabela 8- Análise dos efeitos relativos dos fatores substrato, tempo e suas interações no sangramento à sondagem.

Tabela 9- Valores de $p$ para as múltiplas comparações por meio do método de Friedman-Conover corrigido pelo pós-teste de Benjamini-Hochberg FDR no sangramento à sondagem.

Tabela 10- Mean ranks (Rj) após múltiplas comparações no sangramento à sondagem...

Tabela 11- Análise dos efeitos relativos dos fatores substrato, tempo e suas interações na recessão gengival.

Tabela 12- Valores de $p$ para as múltiplas comparações por meio do método de Friedman-Conover corrigido pelo pós-teste de Benjamini-Hochberg FDR na recessão gengival...

Tabela 13- Mean ranks ( $\quad$ Rj) após múltiplas comparações na recessão gengival.

Tabela 14- Reabsorção óssea marginal $(\mathrm{mm}$, média $\pm \mathrm{Dp})$ ao redor dos implantes restaurados com pilares de titânio ou zircônia após 1,2 e 3 anos de função. 

Sumária 



\section{SUMÁRIO}

1. INTRODUÇÃ

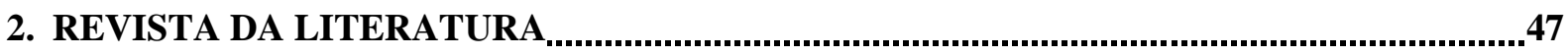

2.1 Sucesso na Implantodontia e doença peri-implantar

2.2 Desempenho clínico dos conectores de titânio e zircônia

3. PROPOSIÇÃO

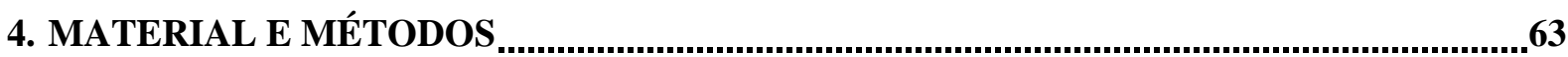

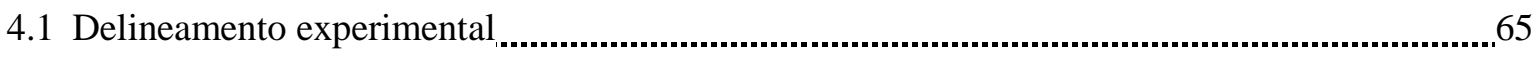

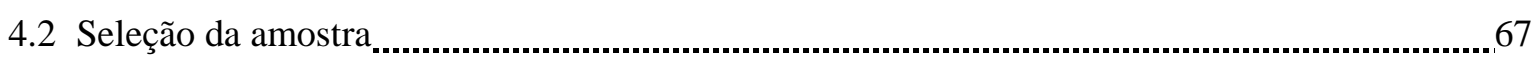

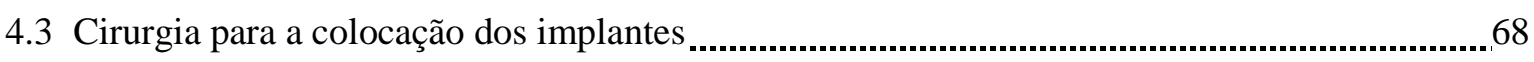

4.4 Avaliação dos indicadores clínicos e radiográficos................................................................ 69

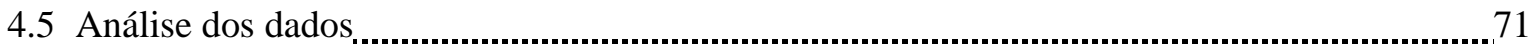

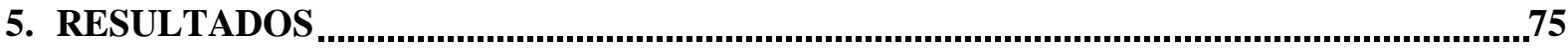

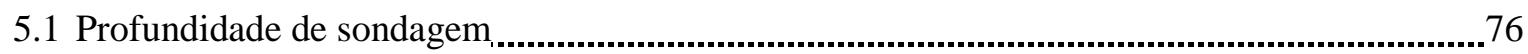

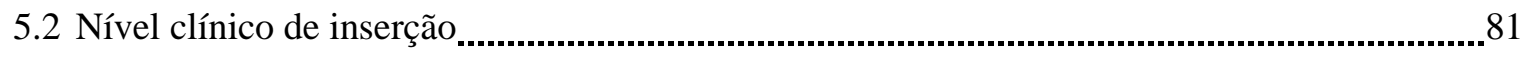

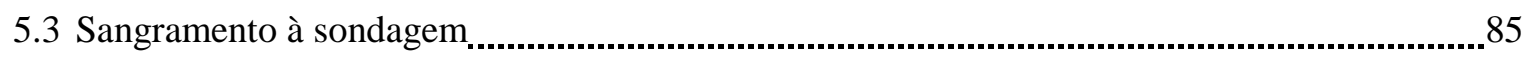

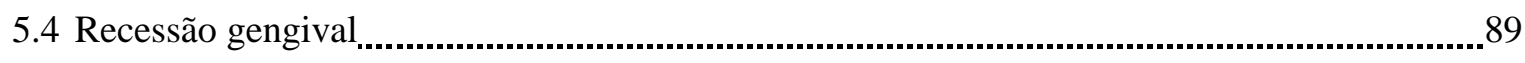

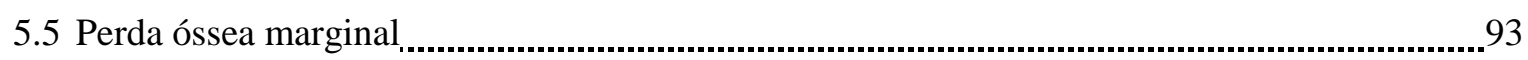

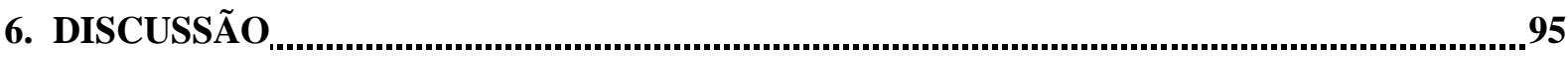

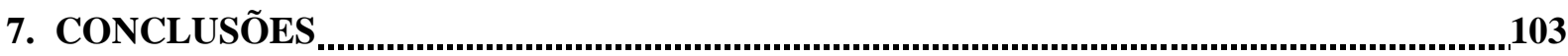

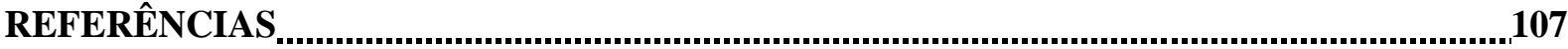

ANEXO

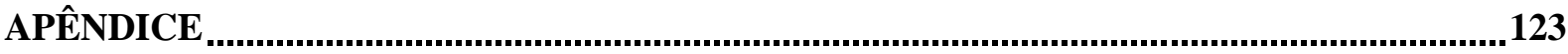



1. Intraduçãa 



\section{INTRODUÇÃO}

Os implantes dentários são considerados como uma opção de tratamento com alta previsibilidade de sucesso para restaurações de áreas edêntulas pequenas e extensas, tanto do ponto de vista funcional quanto estético, apresentando taxa de sobrevivência superior a 95\%, ocorrendo cerca de 500 mil cirurgias realizadas todos os anos (RUSTEMEYER et al., 2007 ELEMAN et al., 2011; BUSENLECHNER et al., 2014; MORASCHINI et al., 2015; ALTUNA et al., 2016; POL et al., 2017). Eles são ancorados aos ossos maxilares por um processo de osseointegração e conectados à restauração protética por meio de um componente transmucoso, o conector protético, que além de servir como estrutura de apoio e suporte para a restauração protética, é o responsável pela transmissão das forças mastigatórias para os tecidos de suporte (SALVI et al., 2008). Além disso, a estética ganhou grande valorização na sociedade contemporânea, tornando-se critério adicional para obter sucesso no tratamento, sendo, portanto, um dos maiores desafios da odontologia, onde deve-se obter uma restauração harmoniosa com a dentição remanescente (ZEMBIC et al., 2015).

Os excelentes resultados associados à longevidade dos tratamentos com implantes estão, geralmente, relacionados com a estabilidade primária em função da qualidade da cortical óssea e à saúde dos tecidos ósseos peri-implantares. Entretanto, mesmo com a alta taxa de sobrevivência, número significativo de implantes ainda apresentam falhas em longo prazo. Nesse contexto, os diversos micro-organismos presentes na cavidade oral, em especial os relacionados à doença periodontal, são indicados como os principais responsáveis por esta falha tardia, além de fatores oclusais desfavoráveis (ONG et al., 1992; SBORDONE et al., 1995; CHRCANOVIC et al., 2014; ESQUIVEL-UPSHAW et al., 2014). A presença de bactérias periodonto-patogênicas nos sulcos peri-implantares e a presença de dentes com periodontite próximos a implantes dentais são considerados fatores de risco para o insucesso dos implantes (GOUVOUSSIS et al., 1997; SAITO et al., 1997; JERVOE-STORM et al. 2015).

O sistema de implantes de dois componentes é amplamente utilizado na prática clínica, porém, na região de união entre o implante e o conector protético, é inevitável a presença de pequenos espaços (muitas vezes microscópicos), denominados microgaps, que funcionam como abrigo para os diversos micro-organismos presentes na cavidade oral, muitos dos quais são potencialmente capazes de provocar reações inflamatórias nos tecidos periimplantares (do NASCIMENTO et al., 2011, 2012; LIU; WANG, 2017). Na maioria desses sistemas, a plataforma do implante é posicionada ao nível da crista alveolar, o que expõe o 
tecido ósseo adjacente ao risco de contaminação/infecção microbiana (WELANDER et al., 2008; MERHEB et al., 2017). A colonização microbiana dos sulcos e próteses peri-implantes ocorre em aproximadamente 60\% dos pacientes reabilitados (LINDHE; MEYLE, 2008) e, portanto, consiste em uma das principais preocupações relacionadas ao sucesso em longo prazo dos implantes dentários (PALMA-CARRIÓ et al., 2011; SAKKA et al., 2012; DABDOUD et al., 2013).

A conexão dos tecidos moles ao redor dos implantes e restaurações atua como barreira de proteção entre o ambiente da cavidade oral e o tecido ósseo peri-implantar, funcionando como uma espécie de "selamento natural" (ATSUTA et al., 2016). Desta forma, o material utilizado para a fabricação do conector protético parece ter um papel importante na adesão dos micro-organismos e, consequentemente, na qualidade final do selamento entre a mucosa e o conjunto implante/conector (ABRAHAMSSON et al., 1998). Ligas de metais preciosos, ligas de metais básicos e materiais cerâmicos, como a zircônia, têm sido relatados para a fabricação dos conectores protéticos (ABRAHAMSSON et al., 1998, do NASCIMENTO et al., 2013; 2014). Os conectores de titânio são os mais utilizados e os que têm sido mais investigados e descritos na literatura ao longo dos anos. A interface entre a mucosa peri-implantar e os conectores de titânio é composta de um tecido epitelial e conjuntivo (ABRAHAMSSON et al. 1998). A estrutura e a função desta barreira foram previamente descritas por diversos estudos, com resultados satisfatórios com relação à biocompatibilidade, resistência mecânica e corrosão do metal (VAN BRAKEL et al., 2012). Entretanto, o potencial citotóxico celular relacionado à liberação de nanopartículas do metal e, principalmente, a alta implicação estética de restaurações anteriores levou ao surgimento de materiais alternativos aos metais para a confecção dos conectores protéticos (VAN BRAKEL et al., 2012).

Materiais cerâmicos, como a zircônia, têm ganhado popularidade pela semelhança de cor com as estruturas dentais e potenciais vantagens biológicas, o que tem difundido sua utilização nas restaurações dentárias anteriores. Conectores de zircônia surgiram em 1995 e apresentam estabilidade superior às cerâmicas convencionais e têm sido largamente utilizados na região anterior da maxila com resultados estéticos superiores aos obtidos com conectores de titânio (BRODBECK, 2003; WATKIN; KERSTEIN, 2008; SAILER et al., 2009a; LINKEVICIUS; VAITELIS, 2015) e, potencialmente, com menor adesão de microorganismos (do NASCIMENTO et al., 2013, 2014). Além disso, diversos estudos relataram excelentes taxas de sobrevivência após acompanhamento de até 12 anos (GLAUSER et al., 2004; SAILER et al., 2009; ZEMBIC et al., 2009, ZEMBIC et al, 2015, PASSOS et al., 2016, 
EKFELDT et al., 2017), e estudos in vitro e in vivo demonstraram baixo risco de fratura destes materiais (GLAUSER et al 2004, GEHRKE et al 2006, ALTUNA et al., 2016).

Os estudos reportados na literatura mostram que a colonização microbiana no sulco peri-implantar e a consequente contaminação do implante e seus componentes, associados ao trauma crônico, podem levar a uma reação inflamatória nos tecidos peri-implantares de suporte que, se não controlada, podem comprometer o sucesso em longo prazo dos implantes. A constante busca por novos materiais e técnicas que reduzam esta colonização é frequentemente reportada na literatura. Os resultados microbiológicos descritos sugerem que a colonização microbiana parece ser sítio-específica, dependente do tipo de material/superfície usada para a confecção do componente protético, sugerindo que componentes cerâmicos podem reduzir a formação do biofilme microbiano e, consequentemente, extensão da inflamação dos tecidos peri-implantares. Da mesma forma, os achados clínicos reportados parecem refletir esta condição, uma vez que os implantes reabilitados com componentes de titânio apresentam, de forma geral, maior colonização microbiana e reabsorção óssea marginal ao longo do tempo (ESPOSITO et al., 1998; AVILA et al., 2016; do NASCIMENTO et al., 2016; SASADA; COCHRAN, 2017; LIU; WANG, 2017).

A relevância do tema se evidencia pela extensão e velocidade com que se difundiu e consagrou o tratamento com implantes dentários na Odontologia, pelo constante desenvolvimento de novos materiais e técnicas de tratamento, e pela escassez de informações conclusivas sobre o impacto do uso de componentes cerâmicos na formação do biofilme microbiano ao redor dos implantes e das próteses e o comportamento clínico destes implantes em longo prazo. Desta forma, com base nas limitações do conhecimento atual, este estudo objetivou abordar a seguinte questão de pesquisa: Qual a implicação clínica (avaliada por meio dos parâmetros clínicos de inflamação dos tecidos moles e duros), em longo prazo (12, 24 e 36 meses), da colonização microbiana associada ao trauma oclusal em restaurações protéticas confeccionadas sobre conectores de titânio ou zircônia? Os resultados clínicos observados em longo prazo contribuirão para melhor compreensão do papel do biofilme formado em cada componente na manutenção da saúde ou no desenvolvimento de potenciais lesões inflamatórias nos tecidos suportes peri-implantares, podendo orientar no desenvolvimento de recomendações clínicas que possam evitar ou minimizar a proliferação dos micro-organismos, desenvolvimento de doenças e consequente perda dos implantes. Os resultados obtidos neste estudo também poderão fornecer bases científicas para futuras investigações envolvendo a avaliação do impacto do biofilme microbiano no sucesso, em longo prazo, das restaurações implantossuportadas que utilizam componentes cerâmicos. 

2. Revista da Literatura 



\section{REVISTA DA LITERATURA}

\subsection{Sucesso da Implantodontia e Doença Peri-Implantar}

A implantodontia ganhou impulso a partir das publicações de BRANEMARK et al. (1969) que definiram a osseointegração como a conexão direta, estrutural e funcional entre o osso vital e a superfície de titânio do implante, capaz de receber carga funcional, sem a presença de tecido conjuntivo entre as duas estruturas. A descoberta aconteceu ao acaso após a tentativa da retirada de uma peça de titânio utilizada em tíbia de uma cobaia. Foi observado que a peça se integrou ao osso e, a partir desse fenômeno, começaram outros estudos e pesquisas relacionados à união entre osso e titânio e desde então, muitos estudos têm relatado o sucesso do implante em longo prazo, sendo atualmente uma forma de tratamento muito procurada para a substituição dos dentes naturais ausentes, visando tanto o restabelecimento funcional quanto estético do sistema estomatognático (DAWSON; JASPER, 2015; VALENTE; ANDREANA, 2016).

Diante dos avanços tecnológicos, da melhora da qualidade de vida da população e da redução dos custos dos materiais envolvidos, a busca por reabilitação com implantes dentários apresenta crescente procura, sendo observado um número superior a 500 mil implantes instalados por ano. Apesar da alta taxa de sobrevivência e sucesso deste tratamento, existem alguns fatores que podem levar ao insucesso em curto ou longo prazo. Sendo assim, é essencial conhecermos os tipos de complicações, bem como o seu percentual de ocorrência e buscar meios de prevenir ou solucionar esses problemas (SRIDHAR et al., 2015).

O sucesso do implante depende fundamentalmente da remodelação óssea formada ao redor do implante imediatamente após sua inserção no leito ósseo, tendo como objetivo obter a osseointegração. A excessiva perda óssea ao redor do implante não é aceitável, pois leva a um aumento no desenvolvimento de bolsas, favorecendo o acúmulo de biofilme bacteriano subgengival, aumentando, desta forma, o risco de infecção na porção cervical do implante, o que comprometeria o sucesso da implantação. Mesmo em implantes considerados satisfatoriamente osseointegrados é possível observar que há, com o passar do tempo, reabsorção óssea progressiva, principalmente nos casos onde não há controle efetivo do biofilme formado. No entanto, para que seja considerado um processo fisiológico, há limites para essa perda óssea. Alguns autores definiram como limites aceitáveis perda óssea de aproximadamente 1,3 milímetros no primeiro ano e 0,1 a 0,2 milímetro por ano nos anos subsequentes (COX; ZARB, 1987; PAPASPYRIDAKOS et al., 2012). 
Alguns critérios foram definidos por Smith e Zarb (1998) para a avaliação do tratamento com implantes, baseados em evidências científicas. A revisão da literatura e a análise dos resultados de pesquisas indicam que seis critérios deveriam ser observados para que o tratamento com implantes apresente sucesso clínico: 1) ausência de mobilidade do implante quando avaliado individualmente; 2) não haver radioluscência ao redor do implante; 3) a perda óssea média vertical anual não deve ser maior que $0,2 \mathrm{~mm}$ após o primeiro ano de função; 4) deve haver ausência de dor, desconforto ou infecção frequente na região do implante; 5) o tratamento não deve comprometer a estética; 6) taxas de sucesso de $85 \%$ após 5 anos e $80 \%$ para dez anos de observação são os níveis mínimos aceitáveis para o tratamento com implantes osseointegrados.

Misch et al. (2008) na Conferência de Consenso de Pisa que ocorreu no Congresso Internacional de Implantodontistas Orais (ICOI), apresentaram quatro categorias clínicas que definem as condições de sucesso do implante, sobrevivência e falha. A sobrevivência pode estar dividida em duas diferentes categorias: a sobrevivência satisfatória descreve implantes abaixo das condições ideais, mas que não há necessidade de intervenção clínica; e a sobrevivência comprometida que inclui implantes abaixo da condição ideal que requerem tratamento clínico para reduzir o risco de falha do implante. A falha do implante é o termo utilizado para implantes que requerem remoção ou que já foram perdidos. O sucesso do implante é um termo utilizado para descrever condições clínicas e deve incluir um período de doze meses em que o implante serve como pilar protético. O sucesso precoce é sugerido para implantes que ficam por um período de um a três anos, sucesso intermediário para três a sete anos e sucesso de longo prazo para um período acima de sete anos. Nessa nova escala são avaliados: dor, mobilidade, perda óssea radiográfica, profundidade de sondagem e doença peri-implantar.

Segundo Emecen-Huja et al. (2015), a falha dos implantes pode ocorrer de forma precoce ou tardia. A forma precoce ocorre antes do implante ser colocado em função, não ocorrendo a osseointegração. Esses fracassos precoces podem estar relacionados ao trauma cirúrgico, superaquecimento do osso durante a cirurgia de implante, formação óssea insuficiente ao redor do implante, à carga inicial do implante ou infecção bacteriana durante o transoperatório. Além disso, investigações anteriores identificaram outras possíveis causas para falha do implante de forma precoce, incluindo hábitos de fumo, condição sistêmica, a qualidade óssea, número de implantes colocados e a distribuição desses implantes (PALMACARRIÓ et al., 2011; MALO et al., 2011). A falha tardia ocorre após a reabilitação protética e indica que a osseointegração instituída não foi mantida e geralmente pode ter como fator 
causal mudanças na carga imposta ao implante, a qualidade e o volume das relações ósseas e peri-implantite.

Dentre as causas de falha tardia dos implantes, a patologia peri-implantar se destaca. Pode ser classificada como mucosite ou peri-implantite, sendo ambas comumente assintomáticas e diagnosticadas em consultas de rotina (PASSONI et al. 2014; NEVES et al., 2016). A mucosite é descrita como uma lesão inflamatória na mucosa ao redor dos implantes, enquanto que a peri-implantite pode ser definida como uma condição potencialmente progressiva envolvendo infecção, inflamação, destruição do tecido conjuntivo e a reabsorção óssea do tecido de suporte. A condição é caracterizada por infecção microbiana, elevada profundidade de sondagem, sangramento à sondagem, supuração e reabsorção óssea marginal (EMECEN-HUJA et al., 2015).

Pacientes comprometidos sistêmicamente apresentam maior risco de falha no implante por terem maior propenção à doença peri-implantar, sendo apontados por alguns autores como contra-indicação relativa à reabilitação com implantes. Neves et al. (2016) avaliaram por meio de um estudo clínico retrospectivo os possíveis fatores de risco para a falha do implante e doença peri-implantar numa população de pacientes comprometidos sistemicamente. Um total de 721 pacientes (422 mulheres, 299 homens), com idade média de 51 anos (intervalo: 20 a 87), reabilitados com implantes dentários foram acompanhados durante 7 anos e 3 meses. Com os resultados observados ao fim do estudo, os autores sugerem que o aumento da idade, condição reumatológica, condição cardiovascular e hepatite devem ser considerados quando se realiza reabilitações implantossuportadas devido à sua negativa influência sobre os resultados clínicos. Outros estudos semelhantes corroboram com estes resultados (COATES et al., 2000; BALAJI, 2008, OATES et al., 2000.; WEINLANDER et al., 2010; SLOGASTRA et al., 2015).

Dentre os possíveis fatores de risco para o aparecimento de doenças peri-implantares temos o acúmulo de biofilme dental, principalmente em decorrência de uma má higiene oral (FERREIRA et al., 2006; KAROUSSIS et al., 2007), história prévia de doença periodontal, diabetes, consumo de álcool, tabagismo e predisposição genética (DAUBERT et al., 2015).

Como os resultados das terapias para doenças peri-implantares ainda não são considerados conclusivos, é inprescindível que se trabalhe na prevenção da doença. Para a elaboração de estratégias preventivas para doenças peri-implantares, a compreensão completa da epidemiologia é necessária, mas devido às diferentes formas de definições clínicas e à falta de padronização no diagnóstico para peri-implantite, a prevalência dessa condição é relatada de forma bastate variada na literatura (DERKS; TOMASI, 2015). 
Heitz-Mayfield (2011) publicou uma revisão baseada nas duas conferências realizadas pela Federação Europeia de Periodontontia (EFP), em 2008 e 2011. De acordo com esta revisão, sondagem e avaliação radiográfica são os meios diagnósticos primários da doença periodontal. A sondagem deve ser realizada utilizando força inferior a $0,25 \mathrm{~N}$, a fim de não danificar os tecidos peri-implantares e tem como objetivo avaliar a presença de sangramento à sondagem, o que indica a presença de inflamação na mucosa peri-implantar e é um preditor para a perda de tecido ósseo. A profundidade de sondagem deve ser avaliada regularmente para a detecção de sangramento à sondagem e possível supuração, e para determinar qualquer aumento em profundidade ao longo do tempo, que é geralmente associado com a perda de inserção clínica e reabsorção do osso de suporte. As radiografias também devem ser realizadas regularmente para avaliar o possível aumento da reabsorção óssea marginal ao longo do tempo.

Ferreira et al. (2006) realizaram um estudo retrospectivo para avaliar a prevalência da doença peri-implantar em uma determinada população e analisar os possíveis fatores de risco associados à mucosite peri-implantar e/ou peri-implantite. Duzentos e doze pacientes parcialmente desdentados e reabilitados com implantes osseointegrados foram examinados clínica e radiograficamente para avaliar a saúde dos tecidos peri-implantares. O grau de associação entre doença peri-implantar e diversas variáveis independentes foi investigado por meio de uma análise de regressão multinomial. As prevalências de mucosite peri-implantar e peri-implantite foram $64,6 \%$ e $8,9 \%$, respectivamente. Os indivíduos saudáveis apresentaram menor índice de placa e menor sangramento à sondagem. As variáveis de risco associadas à maior chance de ter a doença peri-implantar foram: sexo, índice de placa, sangramento à sondagem e profundidade de sondagem. Presença de periodontite e diabetes foram significativamente associadas com risco aumentado de peri-implantite. Os autores sugerem que indivíduos com periodontite, diabetes e má higiene oral são mais propensos a desenvolverem peri-implantite.

Atieh et al. (2013) realizaram uma revisão sistemática para avaliar a frequência de mucosite e peri-implante em pacientes gerais e de alto risco. De 504 estudos identificados a partir de quatro bases de dados, foram incluídos nove estudos com 1.497 participantes e 6.283 implantes. De forma geral, a freqüência de mucosite peri-implantar foi encontrada em $63,4 \%$ dos participantes e $30,7 \%$ dos implantes, e de peri-implantite foi encontrada em $18,8 \%$ dos participantes e 9,6\% dos implantes. A maior frequência de ocorrência de doenças periimplantares foi encontrada em pacientes fumantes, com estimativa de prevalência de 36,3\%. Este estudo mostrou que a ocorrência de doenças peri-implantares não é incomum após a 
reabilitação com implantes, principalmente nos casos onde os fatores de risco estão presentes. Além disso, segundo os autores, a terapia periodontal de suporte parece reduzir a taxa de ocorrência de doenças peri-implantares, sendo recomendados cuidados de manutenção em longo prazo, principalmente para os grupos de alto risco.

Derks e Tomasi (2015), em uma revisão sistemática por meio de metanálise, avaliaram a literatura científica, a fim de avaliar a prevalência, extensão e severidade das doenças peri-implantares. Quinze artigos descrevendo 11 estudos foram incluídos. A prevalência de mucosite peri-implantar e peri-implantite variou de 19 a $65 \%$ e de 1 a $47 \%$, respectivamente. A metanálise estimou a prevalência média de mucosite peri-implantar e periimplantite de $43 \%$ e $22 \%$, respectivamente. A metanálise mostrou relação positiva entre a prevalência de peri-implantite e o tempo de função dos implantes, e relação negativa entre a prevalência de peri-implantite e limiar para a perda óssea. Extensão e gravidade das doenças peri-implantares raramente foram relatadas. Os autores concluíram que há a necessidade que estudos futuros avaliem a epidemiologia das doenças peri-implantares com amostras de tamanho adequado, de forma aleatória e levem em consideração o tempo de função do implante.

Gurgel et al. (2017), por meio de estudo transversal, avaliaram a frequência de doenças peri-implantares e os fatores associados à sua ocorrência. Cento e ciquenta e cinco pacientes com implantes dentários foram avaliados neste estudo. Os implantes dentários foram avaliados clínica e radiograficamente para diagnosticar as condições dos tecidos periimplantares. Foram avaliadas as associações entre doenças peri-implantares e variáveis independentes (características socioeconômicas, demográficas e periodontal). As frequiências de doenças peri-implantares, mucosite e peri-implantite, foram $54 \%$ e $28 \%$, respectivamente. A amostra foi quase exclusivamente de pacientes com doença periodontal não tratada (93\%). Os autores observaram correlação entre as doenças peri-implantares com pacientes do sexo masculino, uso de medicamentos, doenças sistêmicas, número de implantes, índice de placa visível e índice de sagramento gengival.

Sendo a inflamação dos tecidos peri-implantares a causa mais frequente de comprometimento da estabilidade dos implantes osseointegrados e consequente falha do tratamento reabilitador (SCHAUMANN et al., 2014), o conhecimento da causa e o imediato diagnóstico da doença peri-implantar, apoiados pelos conceitos estabelecidos na literatura aplicada, permitirão ao cirurgião-dentista a melhor compreensão do processo saúde/doença peri-implantar, possibilitando, desta forma, ação mais efetiva na prevenção do desenvolvimento e progressão da doença. 


\subsection{Desempenho clínico dos conectores de titânio e zircônia}

A longevidade dos implantes dentários depende da ausência de inflamação nos tecidos peri-implantares. Semelhante aos dentes, bactérias patogênicas presentes na cavidade oral podem aderir à superfície do conector protético, colonizar os espaços existentes entre os componentes dos implantes e invadir os espaços biológicos, podendo causar doença periimplantar e aumentar o risco de perda precoce do implante dental. O desenvolvimento da inflamação em torno dos implantes está associado ao acúmulo de biofilmes bacterianos. Estima-se que mais de 700 espécies bacterianas possam colonizar a cavidade oral, sendo que vários deles são potenciais agentes patogênicos para o desenvolvimento da doença periodontal (MOORE; MOORE, 1994;; HAFFAJEE, 2005; PASTER et al., 2001; AVILA et al., 2016).

De acordo com a literatura, a colonização da superfície do implante por espécies microbianas já se inicia 30 minutos após a colocação do implante. O perfil bacteriano permanece inalterado na primeira semana. Entre a primeira e décima segunda semana após a cirurgia, há alteração do perfil bacteriano e a concentração de micro-organismos torna-se significativamente mais elevada para várias espécies, dentre as quais destacam-se Porphyromonas gingivalis, Tannerella forsythia e Treponema denticola, considerados como os principais patógenos das doenças periodontais e peri-implantares (SALVI et al., 2008). Após um ano, a carga bacteriana parece ser significativamente maior para algumas espécies, T. Forsythia e, em menor grau, P. gingivalis (FURST et al., 2007).

A união entre os conectores protéticos e a mucosa peri-implantar atua como barreira de proteção contra a passagem de micro-organismos em direção ao implante e seus componentes. Esta junção peri-implantar é composta por três tipos de epitélio: epitélio periimplantar (PIE), epitélio sulcular peri-implantar e epitélio oral. O PIE executa a função de anexação epitelial semelhante ao epitélio juncional nos dentes, e provém do epitélio oral dentro de 2-3 semanas após a implantação. O PIE é composto por uma fina camada de 3-4 células e possui imunoglobulinas, neutrófilos, linfócitos e células plasmáticas, em um amplo espaço intercelular, que juntos protegem o tecido subjacente de fatores exógenos deletérios. $\mathrm{O}$ PIE tem capacidade de vedação funcional muito menor do que epitélio juncional, apesar de ter estruturas epiteliais muito similares (ATSUNA et al., 2016).

Uma forma de potencializar essa união (selamento gengival) e minimizar a passagem de micro-organismos para o implante dentário é por meio de variações na superfície dos conectores protéticos, as quais podem alterar a união com o tecido conjuntivo adjacente (BLÁZQUEZ-HINAREJOS et al., 2017). Diferenças nas propriedades físicas superficiais dos componentes utilizados, como composição quimica, rugosidade superficial, molhabilidade e 
energia livre de superfície podem afetar a adesão microbiana e o crescimento do biofilme em formação (AVILA et al., 2016; WASSMANN et al., 2017).

O titânio é considerado o material de referência devido às suas características físicas, incluindo biocompatibilidade, estabilidade e resistência à corrosão. Porém, a elevada demanda por tratamento estético tem favorecido a introdução de conectores fabricados com zircônia (KIM et al., 2015). Além das vantagens estéticas, os materiais cerâmicos apresentam excelente resistência à corrosão, biocompatibilidade e altos valores de resistência à aplicação de cargas (PICONI e MACCAURO, 1999), tendo mostrado excelente prognóstico em região anterior e de pré-molares (ZEMBIC et al., 2015; PASSOS et al., 2016). Apesar das vantagens dos conectores de zircônia, seu uso em região posterior ainda é questionável. Vechiato-Filho et al. (2016), em uma revisão sistemática e meta-análise, avaliaram a taxa de sobrevivência e eficácia dos conectores de zircónia em relação aos conectores de titânio em reabilitações implantossuportadas unitárias na região posterior de maxila e mandíbula. Os autores concluíram que apesar de alguns estudos em curto prazo mostrarem que não existe diferença significativa do uso de conectores de titânio ou zircônia em região posterior, é necessário cautela devido à ausência de dados relacionados à avaliação clínica em longo prazo. Além disso, evidências científicas sugerem que a zircônia pode sofrer espontânea e descontrolada transformação de sua estrutura tetragonal em monoclínica, o que afeta drasticamente suas propriedades mecânicas, resultando em fratura e consequente falha do tratamento (ZEMBIC et al., 2009; MOLIN et al., 2008).

Sailer et al. (2009a) realizaram uma revisão sistemática com o objetivo de avaliar a taxa de sobrevivência e complicações associadas a conectores cerâmicos e metálicos após 5 anos de função. Os autores selecionaram 29 ensaios clínicos controlados e randomizados e 22 estudos laboratoriais que acompanharam o desempenho clinico dos conectores por um tempo mínimo de 3 anos. Os autores observaram que após 5 anos a taxa de sobrevivência dos conectores cerâmicos $(99,1 \%)$ foi superior à dos conectores metálicos $(97,4 \%)$. A incidência de complicações técnicas foi de $6,9 \%$ para conectores cerâmicos e $15,9 \%$ para os metálicos. O afrouxamento do parafuso do conector foi o problema técnico mais freqüente, ocorrendo em incidência estimada de $5,1 \%$ após 5 anos. A incidência de complicações biológicas foi estimada em 5,2\% para cerâmicos e 7,7\% para metálicos. As complicações estéticas tendem a ser mais frequentes em conectores metálicos. Os autores concluíram não haver diferenças significativas no desempenho clínico entre conectores cerâmicos e metálicos, pois a taxa de sobrevivência e incidência de complicações tanto técnicas quanto biológicas foram semelhantes ao longo do tempo avaliado. 
Sailer et al. (2009b) avaliaram, por meio de um estudo clínico ranzomizado, a taxa de sobrevivência e o resultado estético de conectores de titânio e zircônia instalados em regiões canina e posteriores. Vinte e dois pacientes com 40 implantes foram incluídos no estudo e instalados 20 conectores de zircônia $(\mathrm{Zr})$ e 20 de titânio (Ti). Sobre os conectores foram cimentadas, utilizando resina ou cimento de ionômero de vidro, coroas totalmente cerâmicas ou metalocerâmicas, exceto em dois casos, onde as coroas foram retidas por parafuso. As restaurações foram examinadas quanto a presença problemas técnicos e biológicos no momento da instalação do pilar, após 6 e 12 meses. Profundidade de sondagem, índice de placa e sangramento à sondagem foram avaliados nesses períodos e comparados com dentes contra-laterais. Além disso, a diferença de cor da mucosa peri-implantar e da gengiva dos dentes controle foi avaliada por meio de um espectrofotômetro. Após 12 meses de acompanhamento, não foram encontrados problemas técnicos ou biológicos nos grupos teste e controle, a taxa de sobrevivência para as restaurações e conectores foi de $100 \%$. Nenhuma diferença foi encontrada em relação à profundidade de sondagem $(\mathrm{Zr}=3,4 \pm 0.7 \mathrm{~mm}, \mathrm{Ti}=3,3$ $\pm 0.6 \mathrm{~mm})$, índice de placa $(\mathrm{Zr}=0,2 \pm 0,3, \mathrm{Ti}=0,1 \pm 1,8)$, sangramento à sondagem $(\mathrm{Zr}=60$ $\pm 30 \%, \mathrm{Ti}=60 \pm 40 \%$ ) entre os grupos investigados. Além disso, não foi observada diferença significativa na alteração de cor do tecido mole em relação à gengiva de dentes naturais $(\mathrm{Zr}=$ $8,1 \pm 3,9, \mathrm{Ti}=7,8 \pm 4,3)$. Dessa forma, os autores concluíram que após um ano os conectores de zircônia apresentaram resultados semelhantes aos de titânio mesmo posicionados em regiões posteriores, onde ocorre maior incidência de cargas mastigatórias.

Ekfeldt et al. (2011) avaliaram de forma retrospectiva o desempenho clínico, em longo prazo, de restaurações unitárias sobre conectores personalizados de zircônia. Foram avaliados registros clínicos e radiográficos de 130 pacientes tratados com 185 restaurações unitárias sobre conectores de zircônia e exame clínico de 25 pacientes com 40 restaurações realizadas há mais de 3 anos. Os conectores de zircônia foram bem sucedidos durante o período avaliado. As taxas de complicações técnicas e biológicas foram baixas, e os pacientes apresentaram-se de forma geral satisfeitos com as restaurações. Além disso, não houve alterações significativas no nível do osso marginal peri-implantar entre o período de 3 a 5 anos de função (média 0,29 mm, $\pm 0,87 \mathrm{~mm}$ ). Diante dos resultados observados, os autores sugerem que os conectores de zircônia para coroas unitárias parecem demonstrar bons resultados técnicos e biológicos, no entanto, são necessários mais estudos para avaliar seu desempenho em longo prazo. Este resultado foi semelhante ao apresentado por estudos anteriores que mostraram taxa de sobrevivência dos conectores de zircônia de 100\% após 3-4 anos de função (GLAUSER et al., 2004; CANULLO, 2007). 
Hosseini et al (2012) em um estudo clínico prospectivo de 3 anos, descreveram o desempenho clínico de 98 restaurações unitárias anteriores suportadas por implante. Foram utilizados 52 conectores de zircônia, 21 de titânio e 25 de liga de ouro. No momento de instalação dos conectores e após 3 anos os autores registraram variáveis biológicas, como a taxa de sobrevivência de implantes, nível ósseo marginal, índice de placa modificado, índice de sangramento modificado e as complicações biológicas. As variáveis de resultado técnico incluíram o conector e a taxa de sobrevivência da coroa, a adaptação marginal das coroas, o excesso de cimento e complicações técnicas. O resultado estético foi avaliado de forma subjetiva, usando o índice de Copenhague e os resultados relatados pelo paciente foram registrados por meio de um questionário. Os resultados mostraram taxa de sobrevivência de $100 \%$ para os implantes e $97 \%$ para conectores e coroas. Não houve diferença para o nível de placa e sangramento à sondagem para os três tipos de conectores. Observou-se perda óssea marginal significativamente maior em conectores de ligas de ouro em relação aos pilares de zircônia $(p=0,040)$. A complicação técnica encontrada mais frequente foi a perda de retenção da coroa. Os conectores de zircônia apresentaram descoloração menor, porém sem diferença significativa com os pilares metálicos e, em geral, os pacientes relataram satisfação estética das restaurações. Os resultados obtidos só vieram a corroborar com outros estudos que comprovam a possibilidade de manutenção da saúde peri-implantar e do sucesso clínico, em longo prazo, de conectores de zircônia instalados sobre implantes osseointegrados e bem planejados.

Van Brakel et al. (2012) compararam a saúde dos tecidos moles associados a conectores de titânio ou zircônia por meio de análise histológica. Vinte pacientes receberam 2 implantes mandibulares, posicionados em arcos diferentes, onde foram instalados um conector de titânio e um de zircônia. Após 3 meses foram realizadas biópsias do tecido mole peri-implantar para avaliação histológica. A análise revelou, em ambos tipos de conectores, a presença de fibras colágenas orientadas paralelamente à superfície do conector, epitélio escamoso estratificado bem queratinizado, contínuo com o epitélio juncional, com proporções normais, variando entre 0,2 e 0,5 , e a presença de pequeno infiltrado inflamatório. Dessa forma, não foram observadas diferenças entre os diferentes conectores na saúde da mucosa peri-implantar. No entanto, um estudo anterior, ao comparar a análise histológica de tecido mucoso peri-implantar associado a cicatrizadores de titânio e zircônia após 6 meses instalados, observou maior infiltrado inflamatório associado ao material de titânio, mas devese levar em consideração que esse estudo foi realizado com amostra relativamente pequena $(\mathrm{n}=5)(\mathrm{DEGIDI}$ et al., 2006).

Lops et al. (2013) acompanharam durante 5 anos o desempenho clínico de conectores de titânio e zircônia na região posterior. Foram instalados 47 conectores de titânio e 38 de 
zircônia em implantes unitários localizados na região posterior de 85 pacientes. Após 5 anos de função 4 pacientes não puderam ser acompanhados, dessa forma, foram coletados parâmetros biológicos (índice de placa, profundidade de sondagem e índice de sangramento modificado) e radiográficos (perda óssea mesial e distal) de 44 conectores de titânio e 37 de zircônia. Nenhuma falha nos implantes, restaurações ou conectores foi relatada após 5 anos. Não foram encontradas diferenças significativas entre os grupos para profundidade de sondagem $(\mathrm{Zr} 2,6 \pm 0,5 \mathrm{~mm}$, Ti 2,7 $\pm 0,4 \mathrm{~mm}$, dentes 2,5 $\pm 0,7)$, sangramento à sondagem ( $\mathrm{Zr}$ $0,5 \pm 0,3$, Ti 0,4 $\pm 0,2$ ) e controle de placa (Implantes 0,4 $\pm 0,2$, dentes 0,4 $\pm 0,3$ ). Além disso, o nível ósseo foi semelhante nos sítios relacionados aos conectores de zircônia e titânio (Zrmesial 0,1 $\pm 0,1, \mathrm{Zr}$-distal 0,4 $\pm 0,2$; Ti-mesial 0,2 $\pm 0,1$, Ti-distal 0,5 $\pm 0,3$ ). Com base nesses resultados, pode-se afirmar que os conectores de zircônia apresentam desempenho satisfatório em região posterior, no entanto são necessários mais estudos clínicos em longo prazo para confirmar este achado.

Numa revisão sistemática e meta-análise publicada recentemente por Sanz-Martín et al. (2017), os autores investigaram a influência do material do conector, macrogeometria do implante, topografia de superfície e método de limpeza na saúde do tecido peri-implantar. Foram incluídos ensaios clínicos controlados e randomizados que realizaram acompanhamento mínimo de 6 meses dos implantes, 19 publicações foram selecionados ao final da busca bibliográfica. Os resultados da meta-análise indicaram que os pilares de zircônia apresentaram menor aumento nos valores de profundidade de sondagem e sangramento à sondagem ao longo do tempo [n = 3; WMD = -26,96; IC de 95\% (-45,00; 8,92); $p=0,003$ ] e menor acúmulo de biofilme [ $\mathrm{n}=1$; WMD = -20,00; IC 95\% (-41,47; 1,47); $p=0,068$ ] quando comparado com conectores de titânio. A perda óssea marginal foi influenciada pelo método de descontaminação da superfície do pilar [n = 1; MD = -0,44; IC $95 \%(-0,65 ;-0,23) ; p<0,001]$, mas não foi influenciada pelo tipo de material e macrogeometria do implante. Esses resultados, portanto, levaram os autores a concluirem que o macrogeometria do implante, a topografia de superfície e o método de limpeza do conector não influenciaram na inflamação em torno do implante. Em contrapartida, o material do conector apresentou impacto significativo, com aumento nos valores de profundidade de sondagem e sangramento à sondagem ao longo do tempo para os conectores de titânio em relação aos de zircônia. Os autores ressaltaram a necessidade de mais estudos em longo prazo. 
3. Propasicãa 



\section{PROPOSIÇÃO}

\section{Objetivo geral}

O objetivo deste estudo foi realizar avaliação clínica longitudinal de próteses implantossuportadas unitárias cimentadas sobre conectores de titânio ou zircônia.

\section{Objetivos específicos}

$\checkmark$ Observar se há diferença significante na profundidade de sondagem, nível clínico de inserção, sangramento à sondagem e recessão gengival entre os conectores de titânio e zircônia após 3 anos de função mastigatória.

$\checkmark$ Observar se há diferença significante na reabsorção óssea marginal entre os conectores de titânio e zircônia após 3 anos de função.

\section{Hipótese nula}

A hipótese nula testada neste estudo foi de que os diferentes substratos utilizados para a confecção dos conectores protéticos (titânio e zircônia) e o tempo de avaliação não afetam os parâmetros clínicos investigados. 

4. Material e Métodos 



\section{MATERIAL E MÉTODOS}

\subsection{Delineamento experimental}

Este é um estudo clínico longitudinal prospectivo que propõe investigar a influência do tipo de material do conector protético (titânio e zircônia) na adesão e manutenção do biofilme oral nos tecidos de suporte ao redor do implante e consequente impacto na saúde dos tecidos peri-implantares, em longo prazo. O presente trabalho constitui a segunda fase de um estudo inicial financiado pela FAPESP (2010/12830-0 Auxílio Regular Pesquisa) onde os objetivos propostos acima foram avaliados desde a instalação dos implantes/próteses nos participantes até o período de 6 meses de função. Para esta segunda fase do estudo, foram recrutados todos os 20 participantes portadores de implantes dentários reabilitados com coroas protéticas unitárias cimentadas sobre conectores de zircônia (Grupo 1; n=10; região anterior da maxila) e conectores de titânio (Grupo 2; n=10; região posterior da mandíbula), selecionados na primeira fase da investigação. Esta segunda etapa, também financiada pela FAPESP (2014/22876-8), teve duração de três anos, com coletas dos parâmetros clínicos realizadas nos períodos $\mathrm{T} 0$ = baseline (instalação da prótese), $\mathrm{T} 1=12$ meses, $\mathrm{T} 2=24$ meses e T3 = 36 meses após instalação da prótese. O desenho experimental do estudo está ilustrado na Figura 1. 
Figura 1 - Fluxograma do estudo.

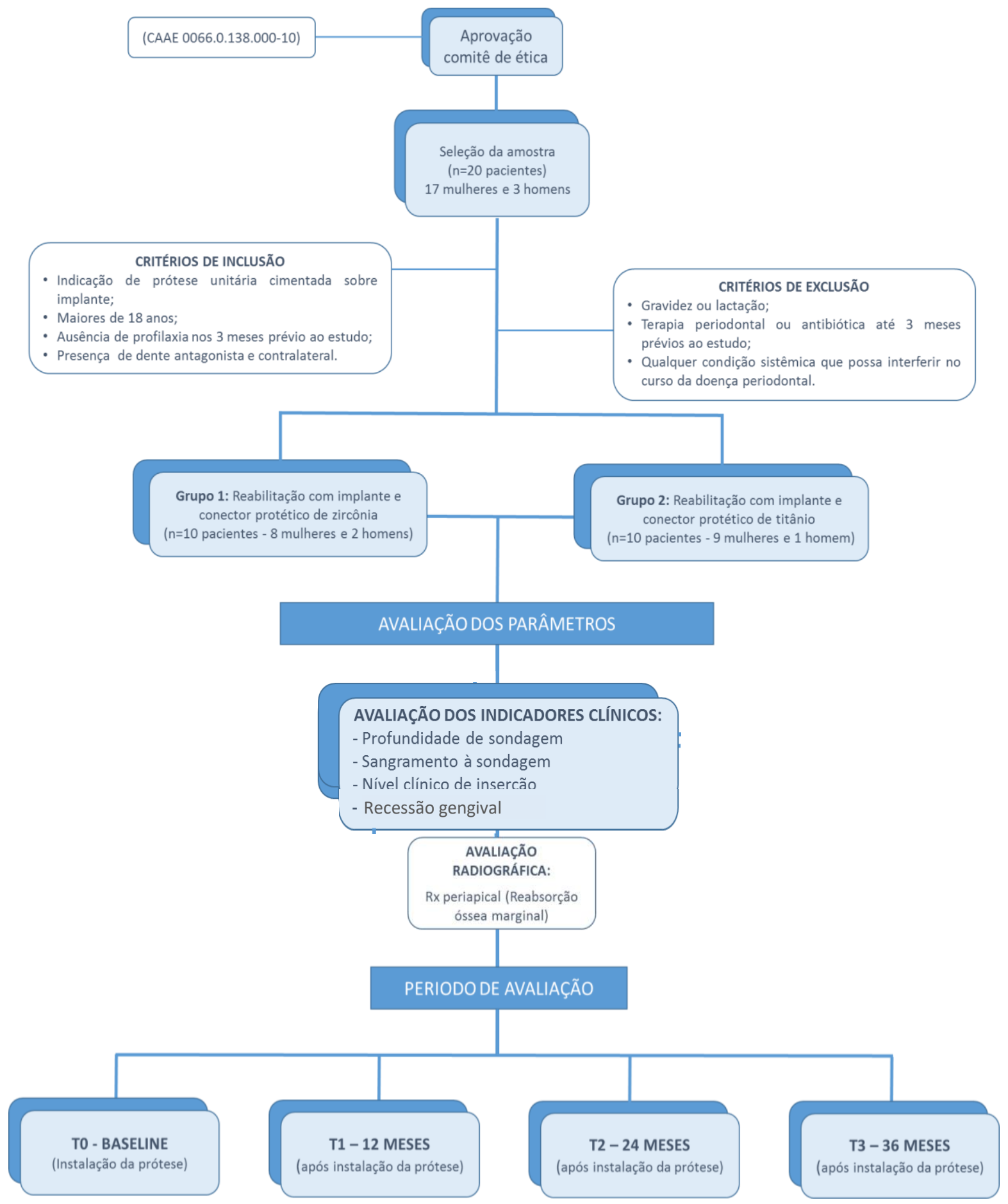




\subsection{Seleção da amostra}

Os participantes incluídos neste estudo foram selecionados dentre os pacientes das Clínicas de atendimento da Faculdade de Odontologia de Ribeirão Preto-USP. Na primeira fase do estudo, foram selecionados 20 indivíduos que receberam um sistema de implantes de dois estágios cirúrgicos na região anterior da maxila ou na região posterior da maxila/mandíbula (de acordo com o conector protético selecionado) e que seguiam os seguintes critérios de inclusão: (a) idade acima de 18 anos; (b) ausência de profilaxia nos 3 meses prévios ao início do estudo; (c) presença de dente antagonista e contra-lateral; indicação de prótese unitária cimentada sobre implante. $\mathrm{O}$ tamanho do $\mathrm{N}$ amostral $(\mathrm{n}=20)$ foi calculado com o auxílio do software PASS 2005 (NCSS, Kaysville, EUA). Foi selecionado o parâmetro contagem de células bacterianas como variável primária para a determinação do $\mathrm{N}$. Para a comparação de dois grupos independentes (titânio e zircônia) com medidas repetidas realizadas em tempos distintos foram considerados um desvio-padrão de 1,26 entre indivíduos e 0,89 nas medidas intra-indivíduo (valores dos desvios estimados a partir da literatura e estudos pilotos). O poder estatístico (power) foi de $84 \%$ para o fator grupo e $96 \%$ para o fator tempo e interação grupo $\mathrm{x}$ tempo, com nível de significância igual a 5\% e magnitude do efeito (effect size) de 0,79 para o fator grupo e 1,12 para o fator tempo e interação grupo x tempo.

Nesta segunda fase do estudo, foram incluídos todos participantes que não apresentavam manifestações bucais de moléstias sistêmicas ou processos infecciosos agudos na cavidade oral. Os critérios de exclusão utilizados foram: gravidez, lactação, tratamento periodontal ou antibiótico nos últimos 3 meses, presença de qualquer condição sistêmica que possa influenciar o curso da doença periodontal ou que exigem pré-medicação para procedimentos, fumantes e pacientes com gengivite ou periodontite. Quando da seleção dos participantes, procurou-se constituir os grupos de estudo com pessoas sob condições ambientais semelhantes, idades próximas, sob tipo de alimentação e cuidados semelhantes, a fim de se obter maior uniformidade da amostra, reduzindo-se a variabilidade. Orientações foram dadas quanto aos procedimentos da pesquisa, e aos voluntários foi novamente facultado o direito de decidir sobre sua participação ou não nesta segunda fase do estudo. Este estudo foi realizado com a devida apreciação e aprovação do Comitê de Ética da Faculdade de Odontologia de Ribeirão Preto (CAAE 0066.0.138.000-10) e todos os participantes assinaram o Termo de Consentimento Livre e Esclarecido. 


\subsection{Cirurgia para colocação dos implantes}

Todos os participantes recrutados foram reabilitados na primeira etapa do estudo com implantes de conexão do tipo cone morse com plataforma de $\varnothing$ 3,5 mm (Ankylos C/X, Dentsply Friadent). Dez indivíduos receberam os implantes na região anterior da maxila; neste grupo, as restaurações protéticas foram cimentadas sobre os conectores protéticos de zircônia (Cercon Balance C/ reto, Ankylos). Os outros 10 indivíduos receberam os implantes na região posterior da maxila ou mandíbula, e as restaurações foram cimentadas sobre conectores protéticos de titânio (Balance posterior C/ reto, Ankylos). Todos os conectores utilizados eram usinados de fábrica, e não sofreram qualquer tipo de tratamento ou acabamento superficial. Para a colocação dos implantes, os pacientes foram previamente submetidos à anestesia local. O tratamento foi realizado em duas fases cirúrgicas, com a cirurgia de inserção dos implantes em uma primeira etapa, e reabertura para instalação dos componentes protéticos e confecção das coroas provisórias após 60 dias da instalação, assim como preconizado pela empresa fabricante. Nenhuma complicação cirúrgica ou pós-cirúrgica foi observada e todos os implantes apresentaram estabilidade primária satisfatória após sua inserção. Na Figura 2 estão representados alguns dos guias cirúrgicos utilizados durante a instalação dos implantes.

Figura 2 - Guias cirúrgicos confeccionados para auxilio no posicionamento correto dos implantes. A: Guia cirúrgico representativo para instalação de implante na região anterior de maxila (Grupo 1 - Zircônia); B: Guia cirúrgico representativo para instalação de implante na região posterior de mandíbula (Grupo 2 - Titânio).
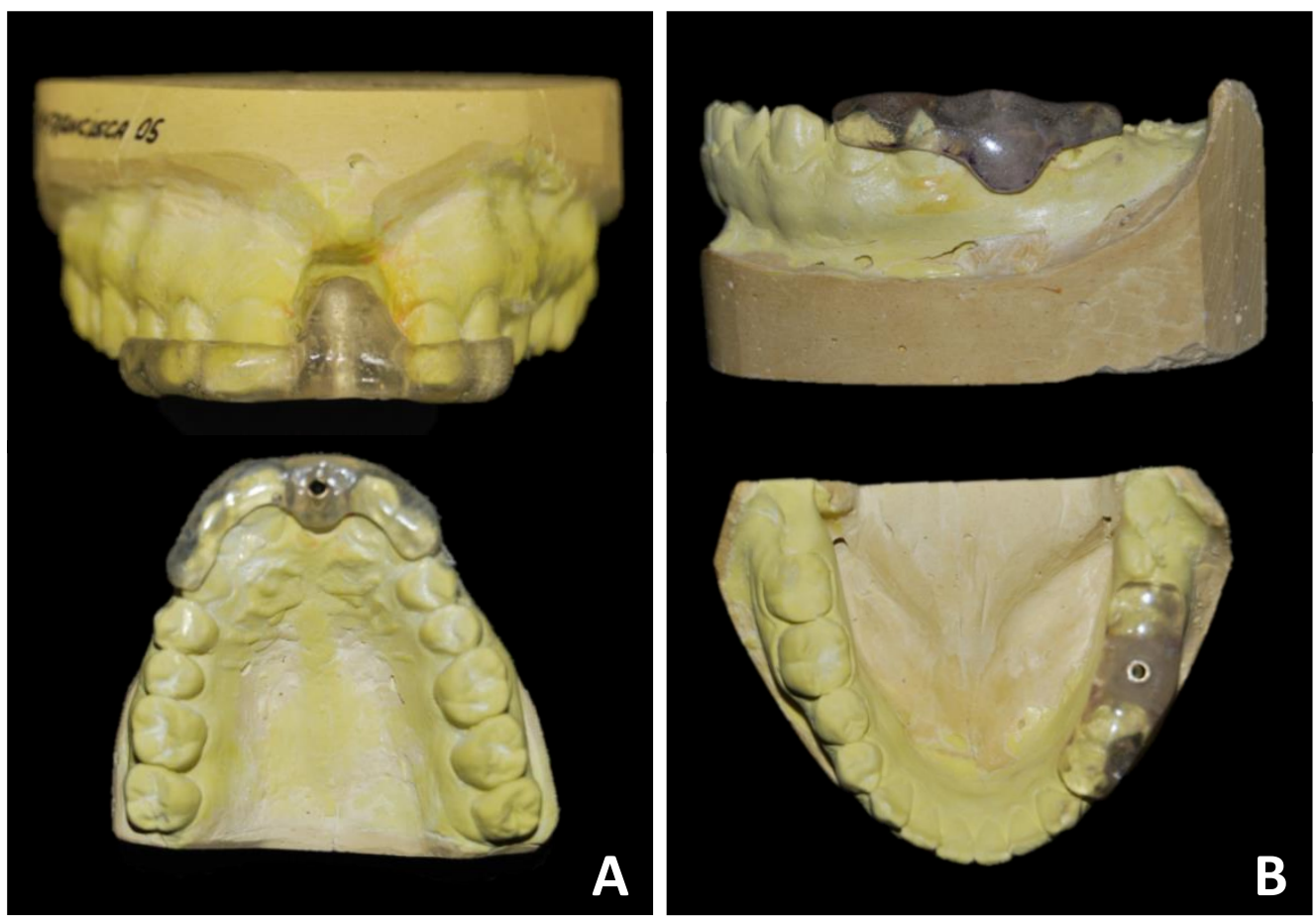


\subsection{Avaliação dos indicadores clínicos e radiográficos}

Um exame clínico peri-implantar e radiográfico foi realizado nos implantes durante os períodos propostos (12, 24 e 36 meses) com o objetivo de avaliar o papel do biofilme microbiano formado ao longo do tempo no processo de manutenção da saúde dos tecidos de suporte ou no possível desenvolvimento de doenças. Os dentes contra-laterais aos sítios experimentais também foram investigados, e constituíram o grupo controle (dente) para os parâmetros clínicos avaliados. As avaliações da profundidade de sondagem, nível clínico de inserção, recessão gengival e sangramento à sondagem foram realizadas por meio do sistema computadorizado de sondas periodontais Florida Probe ${ }^{\circledR}$ (Florida Probe ${ }^{\circledR}$ System, Florida Probe Corporation, Gainesville, FL, EUA) com alta precisão $(0,2 \mathrm{~mm})$ e pressão controlada (15 g) (Figura 3) (GIBBS et al., 1988; RENATUNS et al., 2016). Foram avaliadas as distâncias, em milímetros, entre a margem gengival livre e a porção mais apical sondável do sulco peri-implantar (para a profundidade de sondagem); entre a margem gengival livre e a linha cemento-esmalte (para a recessão gengival); e entre a linha cemento-esmalte e a porção mais apical sondável do sulco (para o nível clínico de inserção). Em cada dente, as medições foram aferidas em seis sítios distintos (mésio-vestibular, vestibular, disto-vestibular, mésiolingual, lingual e disto lingual), conforme ilustrado na Figura 4, e os valores foram apresentados como a média destas seis medições (perfazendo o total de 60 sítios avaliados por participante). Radiografias periapicais foram realizadas com o objetivo de monitorar a reabsorção óssea marginal e, para obtenção das mesmas, utilizou-se a técnica do paralelismo (Figura 5). Após a digitalização das imagens radiográficas, o nível ósseo marginal foi medido com o auxílio do Software ImageJ-Fiji 1.43 (NIH, EUA). As medições foram realizadas nas faces mesial e distal de cada implante e os valores de reabsorção para um determinado período foram apresentados como a média destas duas medidas. Para as medições, um ponto fixo (A) foi aleatoriamente definido sobre a plataforma de cada implante para ser sempre utilizado como o ponto de referência inicial, e um segundo ponto (B) sempre foi posicionado sobre a região mais alta da crista óssea marginal do lado a ser aferido. Desta forma, em todos os períodos, realizou-se a medição da distância A-B em milímetros (SALVI; LANG, 2004) (Figura 6). Os períodos de avaliação clínica e radiográfica nesta segunda fase do estudo foram $\mathrm{T} 0=$ baseline (instalação das próteses), $\mathrm{T} 1=12$ meses, $\mathrm{T} 2=24$ meses e $\mathrm{T} 3=36$ meses após a instalação das próteses. 
Figura 3 - Sistema computadorizado de sondas periodontais Florida Probe ${ }^{\circledR}$ (Florida Probe ${ }^{\circledR}$ System, Florida Probe Corporation, Gainesville, FL, EUA)

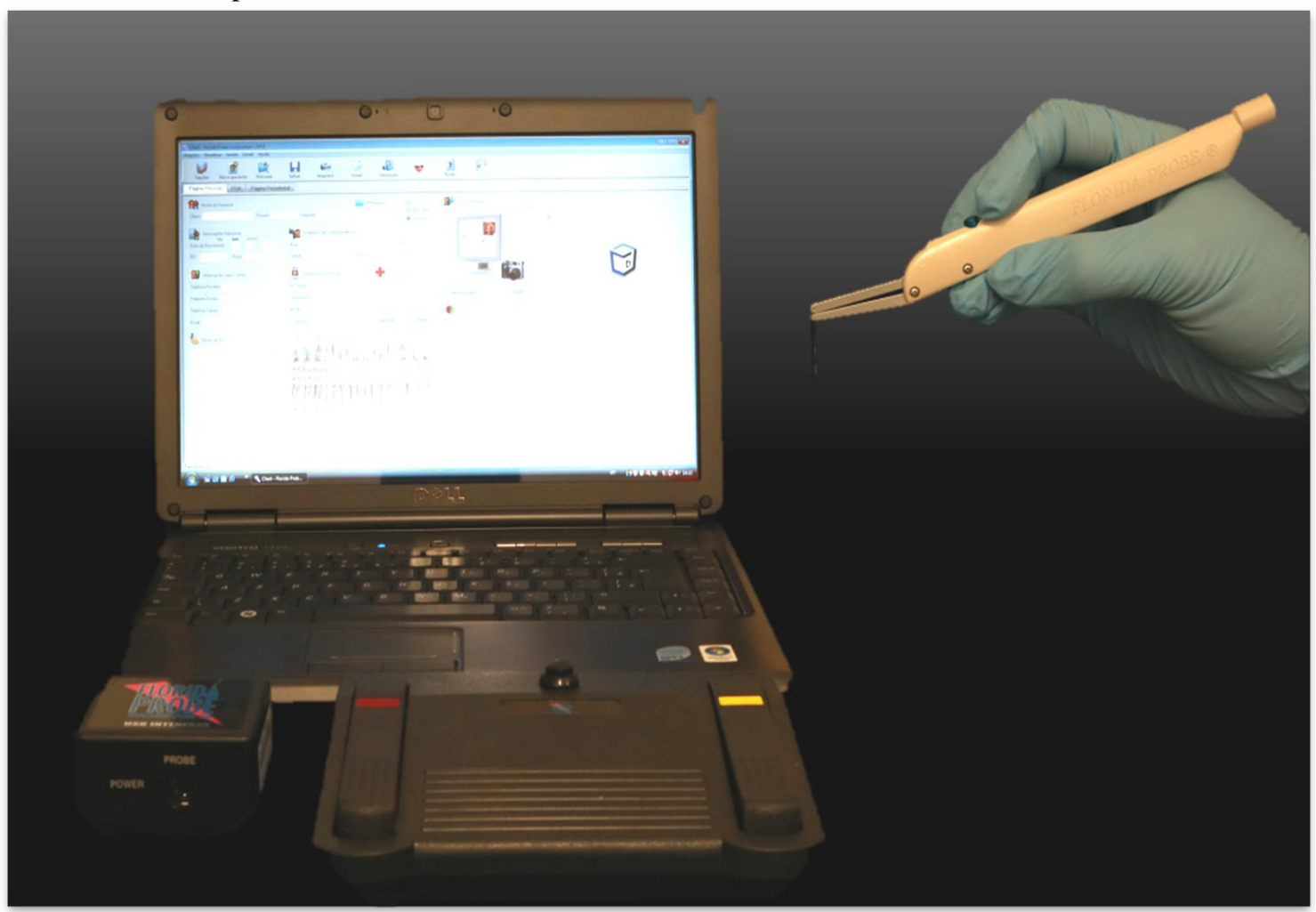

Figura 4 - Aferição da profundidade de sondagem, recessão gengival e nível clínico de inserção por meio do sistema Florida Probe ${ }^{\circledR}$. Em cada dente e implante, as medições foram realizadas em seis sítios distintos (mésio-vestibular, vestibular, disto-vestibular, mésiolingual, lingual e disto lingual).

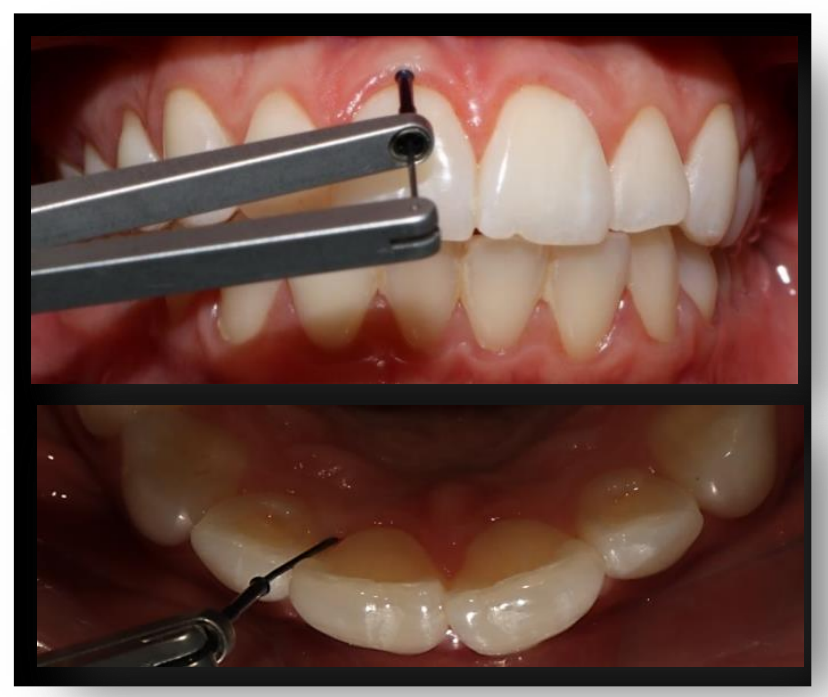

Figura 5 - Técnica do paralelismo para obtenção de radiografias periapicais.

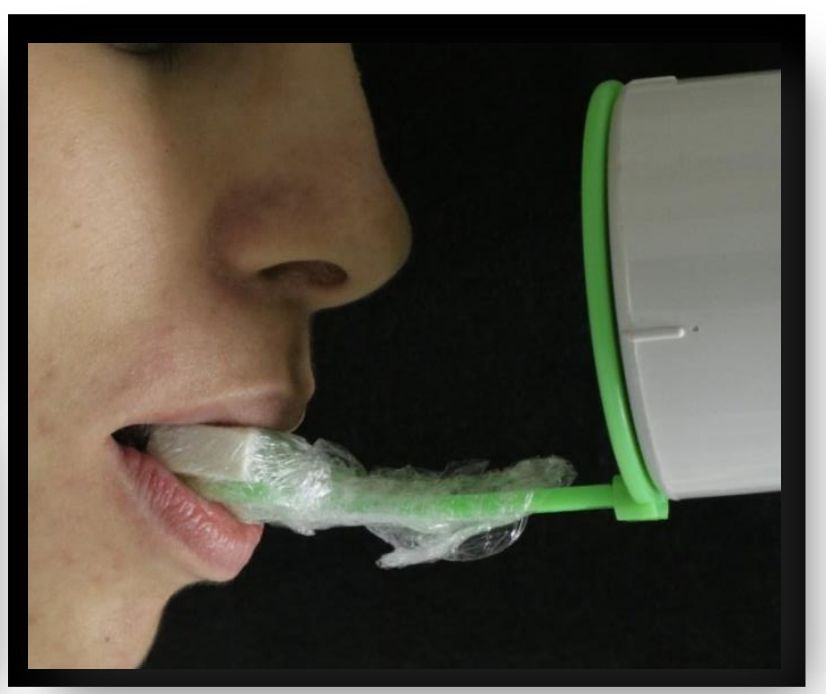


Figura 6 - Mensuração da reabsorção óssea marginal (região mesial e distal) com o auxílio do Software ImageJFiji 1.43 (NIH, EUA). Seta vermelha: calibração da escala (em mm) com um paquímetro digital. A: ponto fixo de referência na plataforma do implante. B: ponto selecionado sobre a região mais alta da crista óssea alveolar.

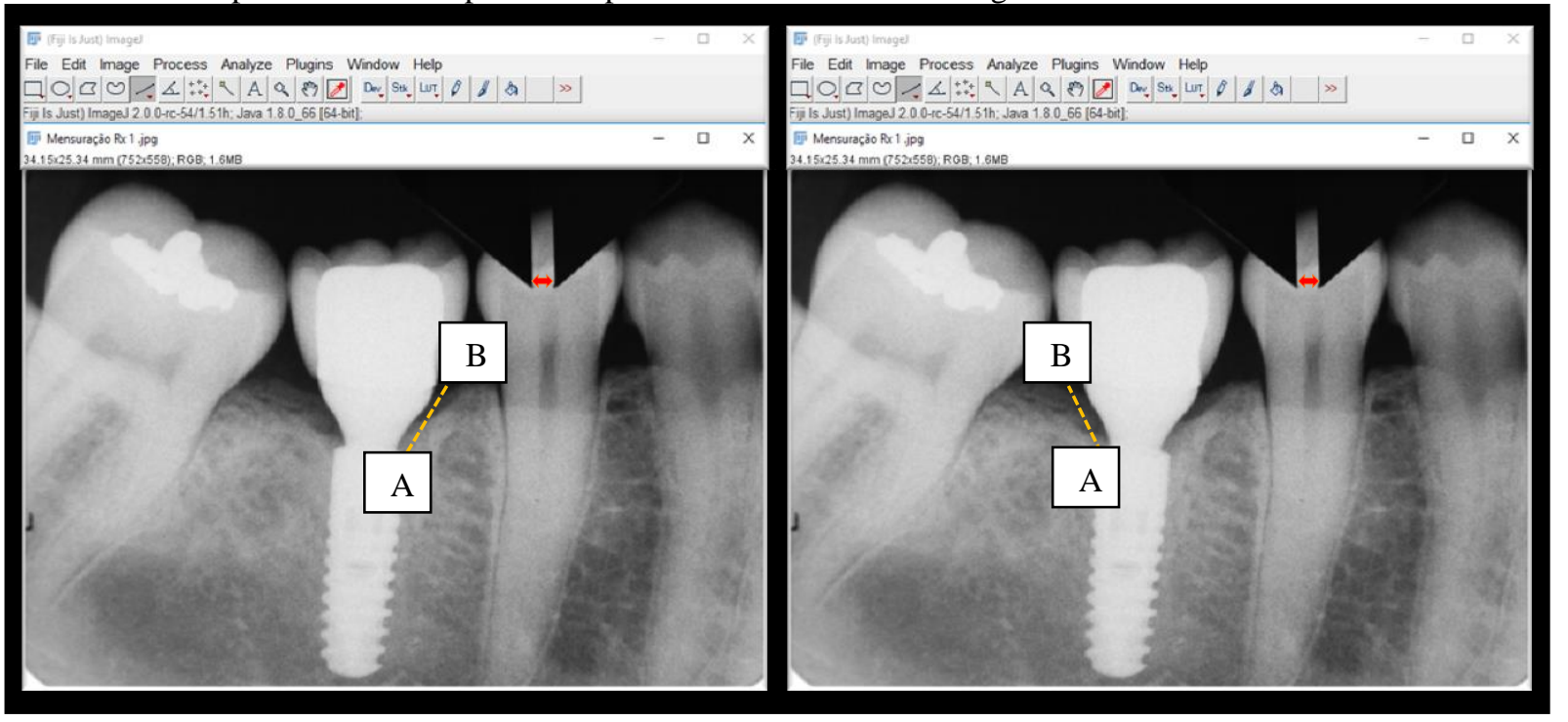

\subsection{Análise dos Dados}

Todos os dados clínicos e radiográficos obtidos ao longo dos períodos de investigação foram submetidos à análise estatística descritiva. Os resultados das variáveis clínicas investigadas foram sumarizados como mediana, intervalo interquartil e valores mínimo e máximo. Para a análise estatística de inferência, foram testados os efeitos dos dois diferentes substratos utilizados para a confecção dos conectores protéticos (titânio e zircônia) e dos períodos (T0, T1, T2, T3) sobre os índices sumários de profundidade de sondagem, recessão gengival, nível clínico de inserção, sangramento à sondagem e reabsorção óssea marginal. Considerando-se o tamanho amostral do estudo e a dependência longitudinal dos fatores de variação, os dados foram inicialmente comparados por um modelo não-paramétrico de regressão liner mista (Brunner and Langer nonparametric analysis of longitudinal data in factorial experiments; BRUNNER \& LANGER, 1999). As variáveis clínicas e os fatores de variação foram tratados como efeitos fixos e o participante como efeito aleatório. Wald-Type Statistic (WTS) e ANOVA-Type Statistic (ATS) foram usados para investigar a hipótese de ausência de interação entre os fatores substrato e tempo. Para investigar se a ausência de interação entre os diferentes substratos deve ser rejeitada em cada período de avaliação, múltiplas comparações foram realizadas por meio do teste de Friedman-Conover, corrigido por Benjamini-Hockberg False Discovery Rate (FDR). Os resultados das análises de reabsorção óssea marginal foram representados como média e desvio-padrão, por apresentarem distribuição normal, e o teste utilizado para a comparação entre os grupos foi o Two-Way ANOVA. Diferenças foram consideradas significantes para valores de $p<0,05$. Os 
dados foram analisados utilizando o software estatístico R (R. software 3.1.0; R Foundation for Statistical Computing, Viena, Áustria). 
5. Resultados 



\section{RESULTADOS}

Os participantes do estudo foram divididos nos dois grupos investigados de acordo com os substratos utilizados para a confecção do conector protético (titânio ou zircônia). Ao final dos 36 meses de investigação, o tamanho amostral foi de 7 indivíduos para cada grupo, com idade média de $44 \pm 16$ anos para o grupo zircônia (5 mulheres e 2 homens) e $37 \pm 16$ anos para o grupo titânio (6 mulheres e 1 homem), conforme Tabela 1. Os participantes perdidos foram por motivo de óbito $(n=1)$ ou impossibilidade de localização $(n=5)$. Os dentes contra-laterais dos sítios investigados foram utilizados como parâmetro de controle para a comparação com os substratos investigados. Os dados das variáveis investigadas foram coletados no momento de instalação das próteses (T0) e nos períodos subsequentes de 12 (T1), 24 (T2) e 36 meses (T3) de função. Todos os implantes estavam osseointegrados e sem presença de mobilidade. Nenhum sinal clínico de complicação foi identificado em todos períodos avaliados, resultando em taxa de sucesso de $100 \%$ para os implantes em ambos os grupos (Figura 7; A-D).

Figura 7 - Figura representativa das radiografias periapicais ilustrando os implantes. A: Radiografia prévia à cirurgia de instalação do implante; B: Radiografia do paciente após 3 anos de função da restauração com coroa metal free sobre o conector de zircônia; C: Radiografia prévia à cirurgia de instalação do implante; D: Radiografia do paciente após 3 anos de função da restauração com coroa metalocerâmica sobre o conector de titânio.

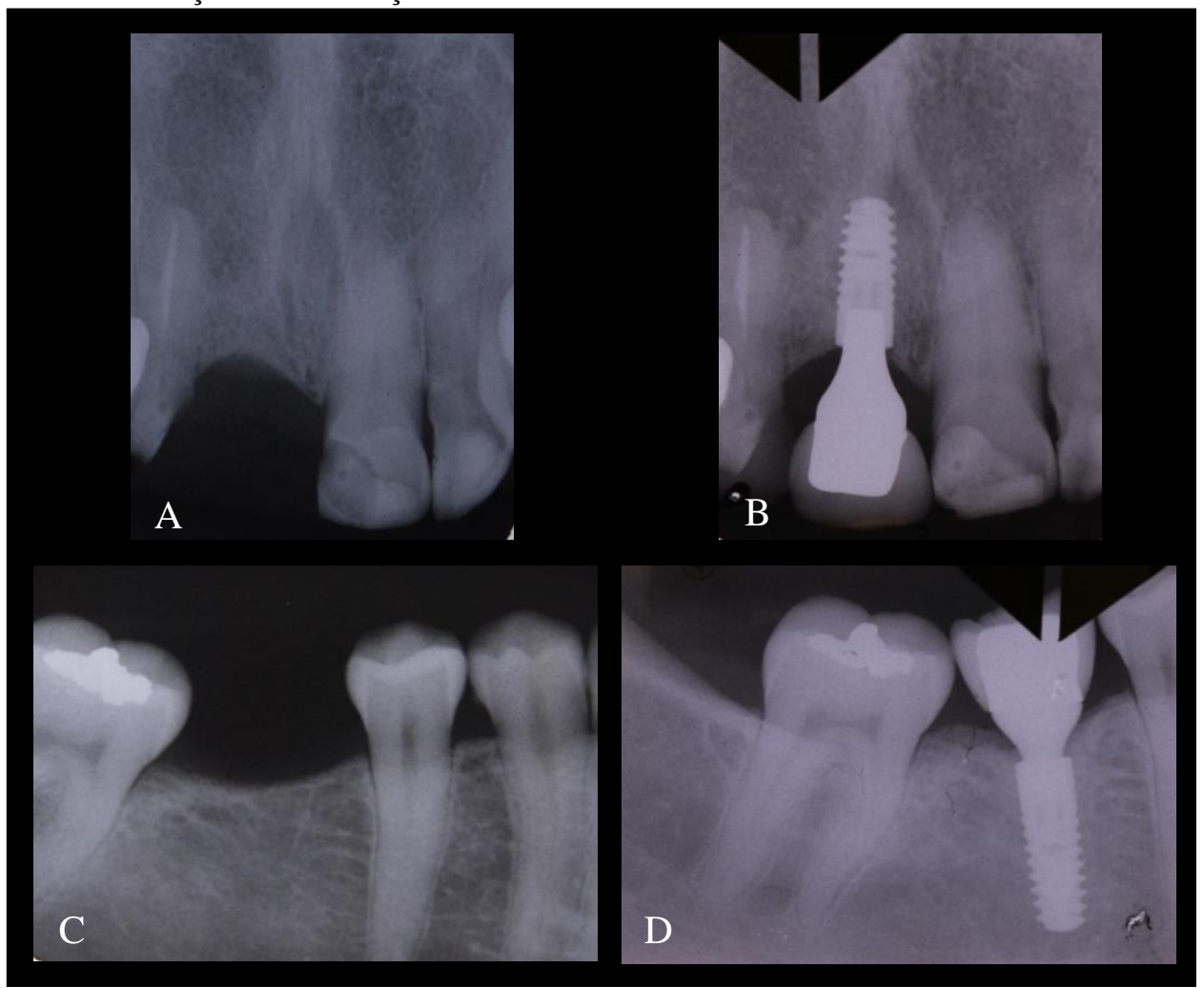


Tabela 1 - Distribuição do número de participantes considerando gênero, idade e número de sítios avaliados para cada variável clínica, por grupo (Titânio ou Zircônia), nos tempos investigados (DP: desvio-padrão).

\begin{tabular}{|c|c|c|c|c|c|c|c|c|}
\hline & \multicolumn{8}{|c|}{ Titânio } \\
\hline & \multicolumn{4}{|c|}{ Implante } & \multicolumn{4}{|c|}{ Dente contralateral } \\
\hline & T0 & $\mathrm{T} 1$ & $\mathrm{~T} 2$ & T3 & T0 & $\mathrm{T} 1$ & $\mathrm{~T} 2$ & T3 \\
\hline $\mathrm{N}^{\circ}$ Participantes & 10 & 7 & 7 & 7 & 10 & 7 & 7 & 7 \\
\hline Média de Idade (anos \pm DP) & $\begin{array}{c}48 \pm \\
3,6\end{array}$ & $\begin{array}{l}37 \pm \\
16,9\end{array}$ & $\begin{array}{l}37 \pm \\
16,9\end{array}$ & $\begin{array}{l}37 \pm \\
16,9\end{array}$ & $\begin{array}{c}48 \pm \\
3,6\end{array}$ & $\begin{array}{l}37 \pm \\
16,9\end{array}$ & $\begin{array}{l}37 \pm \\
16,9\end{array}$ & $\begin{array}{l}37 \pm \\
16,9\end{array}$ \\
\hline Gênero (Feminino/Masculino) & $9 / 1$ & $6 / 1$ & $6 / 1$ & $6 / 1$ & $9 / 1$ & $6 / 1$ & $6 / 1$ & $6 / 1$ \\
\hline \multirow[t]{4}{*}{ Sítios de amostragem } & 60 & 42 & 42 & 42 & 60 & 42 & 42 & 42 \\
\hline & \multicolumn{8}{|c|}{ Zircônia } \\
\hline & \multicolumn{4}{|c|}{ Implante } & \multicolumn{4}{|c|}{ Dente contralateral } \\
\hline & T0 & $\mathrm{T} 1$ & $\mathrm{~T} 2$ & T3 & T0 & $\mathrm{T} 1$ & $\mathrm{~T} 2$ & $\mathrm{~T} 3$ \\
\hline $\mathrm{N}^{\circ}$ Participantes & 10 & 7 & 7 & 7 & 10 & 7 & 7 & 7 \\
\hline Média de Idade (anos + DP) & $47 \pm$ & $44 \pm$ & $44 \pm$ & $44 \pm$ & $47 \pm$ & $44 \pm$ & $44 \pm$ & $44 \pm$ \\
\hline Media de ldade (anos \pm DP) & 4,2 & 16,0 & 16,0 & 16,0 & 4,2 & 16,0 & 16,0 & 16,0 \\
\hline Gênero (Feminino/Masculino) & $8 / 2$ & $5 / 2$ & $5 / 2$ & $5 / 2$ & $8 / 2$ & $5 / 2$ & $5 / 2$ & $5 / 2$ \\
\hline Sítios de amostragem & 60 & 42 & 42 & 42 & 60 & 42 & 42 & 42 \\
\hline
\end{tabular}

Como, frequentemente, os dados de parâmetros clínicos provenientes de avaliações longitudinais que incluem diversos fatores de variação apresentam medidas atípicas (outliers) e aumento da variabilidade ao longo do tempo, todos os dados obtidos neste estudo foram submetidos à análise estatística multifatorial com métodos não-paramétricos. Inicialmente, por meio do método Brunner-Langer Nonparametric Longitudinal Data in Factorial Experiments, foi realizada a análise da distribuição dos dados para cada grupo (por meio de gráficos do tipo Box Plot) e também foi analisado o efeito relativo dos fatores de variação dentro de um intervalo de confiança de $95 \%$. Para testar as hipóteses de ausência de interação entre os fatores "grupo" e "tempo", Wald-Type Statistic (WTS) e ANOVA-Type Statistic (ATS) foram aplicados. Posteriormente, para avaliar se a hipótese de ausência de interação deve ser rejeitada em cada período de investigação, comparações múltiplas foram realizadas por meio do teste de Friedman-Conover corrigido pelo pós-teste de Benjamini-Hochberg False Discovery Rate (FDR).

\subsection{Profundidade de Sondagem}

A Figura 8 ilustra os gráficos de Box Plot (esquerda) e do intervalo de confiança de 95\% para o efeito relativo do fator substrato (direita) avaliados em cada tempo separadamente. O Box Plot representa as medidas descritivas dos valores mínimo, $1^{\circ}$ quartil, mediana, $3^{\circ}$ quartil e valor máximo de profundidade de sondagem $(\mathrm{mm})$ para cada tempo, onde pode-se observar a distribuição levemente distorcida dos dados, principalmente relacionada ao fator substrato. No gráfico que avalia o efeito relativo dos fatores investigados, 
nota-se que a profundidade de sondagem, ao longo tempo, aumenta para o grupo titânio e diminui para o grupo zircônia. Diferentemente, para os grupos controle (dente), a profundidade de sondagem permanece praticamente constante ao longo do tempo. Para o titânio, os valores aumentam a partir do segundo período de avaliação (T1=12 meses), permanecendo constante até a avaliação final (T3=36 meses). Já para a zircônia, os valores permanecem constantes desde o carregamento dos implantes até o período de 24 meses (T2), a partir do qual apresenta leve redução. A falta de paralelismo das linhas ao longo do tempo sugere interação estatística entre os fatores substrato e tempo. Os resultados das análises dos efeitos substrato, tempo e suas interações estão representados na Tabela 2. Conforme apresentado na tabela, a hipótese de ausência de interações foi rejeitada, uma vez que tanto as

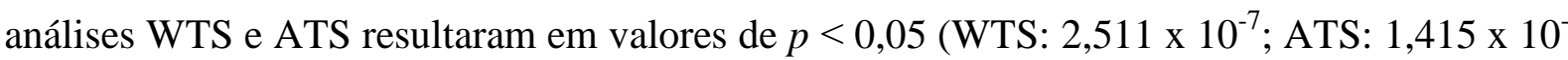
$\left.{ }^{6}\right)$.

Figura 8 - Gráfico Box Plot com os valores de mediana, intervalo interquartil e valores mínimo e máximo de profundidade de sondagem $(\mathrm{mm})$ e gráfico do intervalo de confiança de $95 \%$ para o efeito relativo dos fatores investigados. 0: baseline; 1: 12 meses; 2: 24 meses; 3: 36 meses.
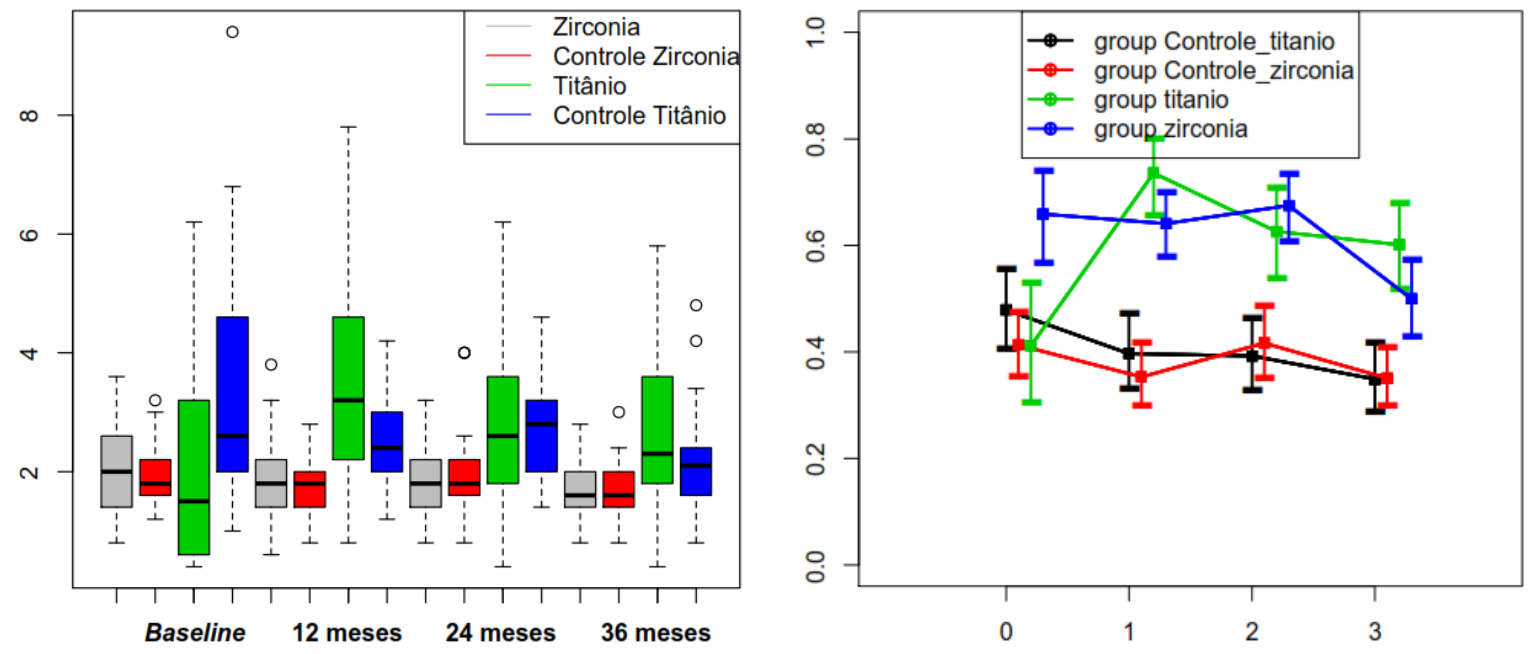

Tabela 2 - Análise dos efeitos relativos dos fatores substrato, tempo e suas interações na profundidade de sondagem (Statistic: valor da função estatística; df: graus de liberdade da análise).

Wald-Type Statistic (WTS) ANOVA-Type Statistic (ATS)

\begin{tabular}{lcccccc}
\hline Fator & Statistic & df & Valor $\boldsymbol{p}$ & Statistic & df & Valor $\boldsymbol{p}$ \\
Grupo & 77,57 & 3 & $1,01 \times 10^{-16}$ & 23,51 & 2,87 & $1,13 \times 10^{-14}$ \\
Tempo & 18,49 & 3 & $3,48 \times 10^{-4}$ & 4,50 & 2,54 & $6,02 \times 10^{-3}$ \\
Grupo: tempo & 48,03 & 9 & $2,51 \times 10^{-7}$ & 5,99 & 6,40 & $1,42 \times 10^{-6}$ \\
\hline
\end{tabular}


Os valores de $p$ resultantes das múltiplas comparações estão representados na Tabela 3 , onde pode-se observar que dentro do grupo titânio houve diferença significativa entre baseline (T0) e os demais tempos, mas não houve diferença comparando-se os tempos T1, T2 e T3. Ou seja, após o primeiro ano de função, existiu variação na profundidade de sondagem (aumento significativo) e, em seguida, esse parâmetro manteve-se constante até a avaliação final de 36 meses. No grupo zircônia, os valores de profundidade de sondagem tiveram leve aumento após os períodos de 12 e 24 meses, retornando após 36 meses aos valores registrados no baseline. A análise por múltiplas comparações também revelou variação significativa entre os grupos titânio e zircônia até o período de 12 meses. Após esse período, não houve diferença significativa entre os grupos. Os dentes contra-laterais apresentaram valores similares em todos os tempos T1, T2 e T3. Na Tabela 4, estão apresentados os valores de Mean ranks $\left(\mathrm{R}_{\mathrm{j}}\right)$ obtidos após as múltiplas comparações e as diferenças significantes (identificadas por diferentes letras) após a interação dos grupos e tempos. A Figura 9 ilustra o gráfico tipo Box Plot com a representação dos valores mínimo, $1^{\circ}$ quartil, mediana, $3^{\circ}$ quartil e valores máximos após as múltiplas comparações (interagindo os fatores substrato e tempo). 
Tabela 3 - Valores de $p$ para as múltiplas comparações por meio do método de Friedman-Conover corrigido pelo pós-teste de Benjamini-Hochberg FDR na profundidade de sondagem.

\begin{tabular}{|c|c|c|c|c|c|c|c|c|c|c|c|c|c|c|c|c|c|c|c|}
\hline \multicolumn{4}{|c|}{ Comparação } & \multirow{2}{*}{$\frac{\text { Valor } p}{2 \times 10^{-16}}$} & \multicolumn{4}{|c|}{ Comparação } & \multirow{2}{*}{$\frac{\text { Valor } p}{2 \times 10^{-16}}$} & \multicolumn{4}{|c|}{ Comparação } & \multirow{2}{*}{$\frac{\text { Valor } p}{5,5 \times 10^{-12}}$} & \multicolumn{4}{|c|}{ Comparação } & \multirow{2}{*}{$\begin{array}{l}\text { Valor } \boldsymbol{p} \\
0,2548\end{array}$} \\
\hline $\mathrm{A}$ & - & $\bar{B}$ & $<$ & & $\mathrm{C}$ & - & $\mathrm{E}$ & $<$ & & $\mathrm{E}$ & - & $\mathrm{L}$ & $<$ & & $\mathrm{H}$ & - & $\mathrm{O}$ & $=$ & \\
\hline A & - & $\mathrm{C}$ & $<$ & $2 \times 10^{-16}$ & $\mathrm{C}$ & - & $\mathrm{F}$ & $=$ & $1,4 \times 10^{-3}$ & $\mathrm{E}$ & - & M & $=$ & 0,4071 & $\mathrm{H}$ & - & $\mathrm{P}$ & $=$ & 0,9283 \\
\hline A & - & D & $<$ & $2 \times 10^{-16}$ & $\mathrm{C}$ & - & G & $=$ & $5,8 \times 10^{-4}$ & $\mathrm{E}$ & - & $\mathrm{N}$ & $=$ & $8,3 \times 10^{-7}$ & I & - & $\mathrm{J}$ & $=$ & $2,9 \times 10^{-4}$ \\
\hline A & - & $\mathrm{E}$ & $<$ & $3,6 \times 10^{-5}$ & $\mathrm{C}$ & - & $\mathrm{H}$ & $=$ & $2,8 \times 10^{-3}$ & $\mathrm{E}$ & - & $\mathrm{O}$ & $=$ & $9,1 \times 10^{-12}$ & I & - & $\mathrm{K}$ & $=$ & $8,8 \times 10^{-6}$ \\
\hline A & - & $\mathrm{F}$ & $<$ & $2 \times 10^{-16}$ & $\mathrm{C}$ & - & I & $=$ & $1,3 \times 10^{-3}$ & $\mathrm{E}$ & - & $\mathrm{P}$ & $=$ & $1,1 \times 10^{-8}$ & I & - & $\mathrm{L}$ & $=$ & 0,1531 \\
\hline A & - & G & $<$ & $2 \times 10^{-16}$ & $\mathrm{C}$ & - & $\mathrm{J}$ & $=$ & 0,7289 & $\mathrm{~F}$ & - & G & $=$ & 0,8531 & I & - & M & $=$ & $2,8 \times 10^{-10}$ \\
\hline A & - & $\mathrm{H}$ & $<$ & $2 \times 10^{-16}$ & $\mathrm{C}$ & - & $\mathrm{K}$ & $=$ & 0,2548 & $\mathrm{~F}$ & - & $\mathrm{H}$ & $=$ & 8,5558 & I & - & $\mathrm{N}$ & $=$ & 0,7198 \\
\hline A & - & I & $<$ & $2 \times 10^{-16}$ & $\mathrm{C}$ & - & $\mathrm{L}$ & $=$ & 0,1001 & $\mathrm{~F}$ & - & I & $=$ & 0,9841 & I & - & $\mathrm{O}$ & $=$ & 0,1752 \\
\hline A & - & $\mathrm{J}$ & $<$ & $2 \times 10^{-16}$ & $\mathrm{C}$ & - & M & $<$ & $2 \times 10^{-16}$ & $\mathrm{~F}$ & - & $\mathrm{J}$ & $=$ & $3,1 \times 10^{-4}$ & I & - & $\mathrm{P}$ & - & 0,7862 \\
\hline A & - & K & $<$ & $2 \times 10^{-16}$ & $\mathrm{C}$ & - & $\mathrm{N}$ & $=$ & $2,7 \times 10^{-4}$ & $\mathrm{~F}$ & - & K & $=$ & $9,4 \times 10^{-6}$ & $\mathrm{~J}$ & - & K & $=$ & 0,4851 \\
\hline A & - & $\mathrm{L}$ & $<$ & $2 \times 10^{-16}$ & $\mathrm{C}$ & - & $\mathrm{O}$ & $=$ & 0,0880 & $\mathrm{~F}$ & - & $\mathrm{L}$ & $=$ & 0,1576 & $\mathrm{~J}$ & - & $\mathrm{L}$ & - & 0,3899 \\
\hline A & - & $\mathrm{N}$ & $=$ & $1,4 \times 10^{-3}$ & $\mathrm{C}$ & - & $\mathrm{P}$ & $=$ & $3,9 \times 10^{-3}$ & $\mathrm{~F}$ & - & M & $=$ & $2,6 \times 10^{-10}$ & J & - & M & - & $2 \times 10^{-16}$ \\
\hline A & - & $\mathrm{N}$ & $<$ & $2 \times 10^{-16}$ & $\mathrm{D}$ & - & $\mathrm{E}$ & $=$ & $2 \times 10^{-16}$ & $\mathrm{~F}$ & - & $\mathrm{N}$ & $=$ & 0,7106 & $\mathbf{J}$ & - & $\mathrm{N}$ & $=$ & $4,5 \times 10^{-5}$ \\
\hline A & - & $\mathrm{O}$ & $<$ & $2 \times 10^{-16}$ & $\mathrm{D}$ & - & $\mathrm{F}$ & $=$ & $1,8 \times 10^{-3}$ & $\mathrm{~F}$ & - & $\mathrm{O}$ & $=$ & 0,1801 & $\mathrm{~J}$ & - & $\mathrm{O}$ & - & 0,0321 \\
\hline A & - & $\mathrm{P}$ & $<$ & $2 \times 10^{-16}$ & $\mathrm{D}$ & - & G & $=$ & $7,5 \times 10^{-4}$ & $\mathrm{~F}$ & - & $\mathrm{P}$ & $=$ & 0,7952 & $\mathrm{~J}$ & - & $\mathrm{P}$ & $=$ & 0,0010 \\
\hline B & - & $\mathrm{C}$ & $=$ & 0,098 & $\mathrm{D}$ & - & $\mathrm{H}$ & $=$ & $3,5 \times 10^{-3}$ & G & - & $\mathrm{H}$ & $=$ & 0,1 & $\mathbf{n}$ & - & $\mathrm{L}$ & $=$ & 0,0035 \\
\hline B & - & $\mathrm{D}$ & $=$ & 0,085 & $\mathrm{D}$ & - & I & $=$ & $1,7 \times 10^{-3}$ & G & - & I & $=$ & 0,8543 & K & - & M & 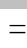 & $2 \times 10^{-16}$ \\
\hline B & - & $\mathrm{E}$ & $<$ & $2 \times 10^{-16}$ & $\mathrm{D}$ & - & $\mathrm{J}$ & $=$ & 0,6921 & G & - & $\mathrm{J}$ & $=$ & $1,1 \times 10^{-4}$ & K & - & $\mathrm{N}$ & $=$ & $9,9 \times 10^{-7}$ \\
\hline B & - & $\mathrm{F}$ & $=$ & $6,9 \times 10^{-7}$ & $\mathrm{D}$ & - & $\mathrm{K}$ & $=$ & 0,2260 & G & - & K & $=$ & $2,9 \times 10^{-6}$ & K & - & $\mathrm{O}$ & $=$ & $2,7 \times 10^{-3}$ \\
\hline B & - & G & $=$ & $1,9 \times 10^{-7}$ & $\mathrm{D}$ & - & $\mathrm{L}$ & $=$ & 0,1162 & G & - & $\mathrm{L}$ & $=$ & 0,9821 & K & - & $\mathrm{P}$ & $=$ & $4,2 \times 10^{-5}$ \\
\hline B & - & $\mathrm{H}$ & $=$ & $2,0 \times 10^{-6}$ & $\mathrm{D}$ & - & M & $<$ & $2 \times 10^{-16}$ & G & - & M & $=$ & $1,2 \times 10^{-9}$ & $\mathrm{~L}$ & - & M & $=$ & $4,7 \times 10^{-15}$ \\
\hline B & - & I & $=$ & $6,4 \times 10^{-7}$ & $\mathrm{D}$ & - & $\mathrm{N}$ & $=$ & $3,5 \times 10^{-4}$ & G & - & $\mathrm{N}$ & $=$ & 0,8555 & $\mathrm{~L}$ & - & $\mathrm{N}$ & - & 0,0631 \\
\hline B & - & $\mathrm{J}$ & $=$ & 0,2148 & $\mathrm{D}$ & - & $\mathrm{O}$ & $=$ & 0,1001 & G & - & $\mathrm{O}$ & $=$ & 0,1126 & $\mathrm{~L}$ & - & $\mathrm{O}$ & $=$ & 0,9445 \\
\hline B & - & K & $=$ & 0,6671 & $\mathrm{D}$ & - & $\mathrm{P}$ & $=$ & $5,1 \times 10^{-3}$ & G & - & $\mathrm{P}$ & $=$ & 0,6423 & $\mathrm{~L}$ & - & $\mathrm{P}$ & $=$ & 0,2701 \\
\hline B & - & $\mathrm{L}$ & $=$ & $5,8 \times 10^{-4}$ & $\mathrm{E}$ & - & $\mathrm{F}$ & $=$ & $7,3 \times 10^{-8}$ & $\mathrm{H}$ & - & I & $=$ & 0,8543 & M & - & $\mathrm{N}$ & $=$ & $4,6 \times 10^{-9}$ \\
\hline B & - & $\mathrm{N}$ & $<$ & $2,0 \times 10^{-16}$ & $\mathrm{E}$ & - & G & $=$ & $2,8 \times 10^{-7}$ & $\mathrm{H}$ & - & $\mathrm{J}$ & $=$ & $6,6 \times 10^{-4}$ & $\mathrm{M}$ & - & $\mathrm{O}$ & $=$ & $8,3 \times 10^{-15}$ \\
\hline B & - & $\mathrm{N}$ & $=$ & $6,0 \times 10^{-8}$ & $\mathrm{E}$ & - & $\mathrm{H}$ & $=$ & $2,2 \times 10^{-8}$ & $\mathrm{H}$ & - & K & $=$ & $2,5 \times 10^{-5}$ & M & - & $\mathrm{P}$ & $=$ & $3 \times 10^{-11}$ \\
\hline B & - & $\mathrm{O}$ & $=$ & $4,4 \times 10^{-4}$ & $\mathrm{E}$ & - & I & $=$ & $8,0 \times 10^{-8}$ & $\mathrm{H}$ & - & $\mathrm{L}$ & $=$ & 0,2260 & $\mathrm{~N}$ & - & $\mathrm{O}$ & $=$ & 0,0752 \\
\hline B & - & $\mathrm{P}$ & $=$ & $3,4 \times 10^{-6}$ & $\mathrm{E}$ & - & $\mathrm{J}$ & $<$ & $2 \times 10^{-16}$ & $\mathrm{H}$ & - & M & $=$ & $6,4 \times 10^{-11}$ & $\mathrm{~N}$ & - & $\mathrm{P}$ & $=$ & 0,4937 \\
\hline $\mathrm{C}$ & - & $\mathrm{D}$ & $=$ & 0,9445 & $\mathrm{E}$ & - & $\mathrm{K}$ & $<$ & $2 \times 10^{-16}$ & $\mathrm{H}$ & - & $\mathrm{N}$ & $=$ & 0,5729 & $\mathrm{O}$ & - & $\mathrm{P}$ & $=$ & 0,3055 \\
\hline
\end{tabular}

A - Titânio (T0); B - Titânio (T1); C - Titânio (T2); D - Titânio (T3); E - Controle Ti (T0); F - Controle Ti (T1); G - Controle Ti (T2); H Controle Ti (T3); I - Zircônia (T0); J - Zircônia (T1); K - Zircônia (T2); L - Zircônia (T3); M - Controle Zr (T0); N - Controle Zr (T1); O Controle $\mathrm{Zr}$ (T2); P - Controle Zr (T3). Números destacados em vermelho quando $p>0,05$. 
Tabela 4 - Mean ranks $(\mathrm{Rj})$ após múltiplas comparações na profundidade de sondagem. Letras diferentes (M) indicam diferenças significantes $(p<0,05)$ de acordo com FriedmanConover e FDR $(p<0,05)$. T0: baseline; T1: 12 meses; T2: 24 meses; T3: 36 meses.

\begin{tabular}{lccc}
\hline Substrato & Tempo & $\mathbf{R}_{\mathbf{j}}$ & $\mathbf{M}$ \\
\hline Titânio & $\mathrm{T}(0)$ & 241,9 & $\mathrm{a}$ \\
Titânio & $\mathrm{T}(1)$ & 614,4 & $\mathrm{~b}$ \\
Titânio & $\mathrm{T}(2)$ & 564,3 & $\mathrm{bc}$ \\
Titânio & $\mathrm{T}(3)$ & 556,9 & $\mathrm{bc}$ \\
Titânio (Controle) & $\mathrm{T}(0)$ & 349,7 & $\mathrm{~d}$ \\
Titânio (Controle) & $\mathrm{T}(1)$ & 457,9 & $\mathrm{e}$ \\
Titânio (Controle) & $\mathrm{T}(2)$ & 460,8 & $\mathrm{e}$ \\
Titânio (Controle) & $\mathrm{T}(3)$ & 444,1 & $\mathrm{e}$ \\
Zircônia & $\mathrm{T}(0)$ & 485,3 & $\mathrm{e}$ \\
Zircônia & $\mathrm{T}(1)$ & 599,2 & $\mathrm{~b}$ \\
Zircônia & $\mathrm{T}(2)$ & 621,9 & $\mathrm{~b}$ \\
Zircônia & $\mathrm{T}(3)$ & 537,5 & $\mathrm{ce}$ \\
Zircônia (Controle) & $\mathrm{T}(0)$ & 303,2 & $\mathrm{~d}$ \\
Zircônia (Controle) & $\mathrm{T}(1)$ & 467,5 & $\mathrm{e}$ \\
Zircônia (Controle) & $\mathrm{T}(2)$ & 505,6 & $\mathrm{ce}$ \\
Zircônia (Controle) & $\mathrm{T}(3)$ & 477,8 & $\mathrm{e}$ \\
\hline & & & \\
\hline
\end{tabular}

Figura 9 - Mediana, intervalo interquartil e valores mínimo e máximo de profundidade de sondagem (mm) após os testes de múltiplas comparações de Friedman-Conover corrigido por Benjamini-Hockberg FDR. Diferentes letras representam diferenças significantes entre os grupos $(\mathrm{p}<0,05)$. Ti: titânio; Zr: zircônia. T0: baseline; T1: 12 meses; T2: 24 meses; T3: 36 meses.

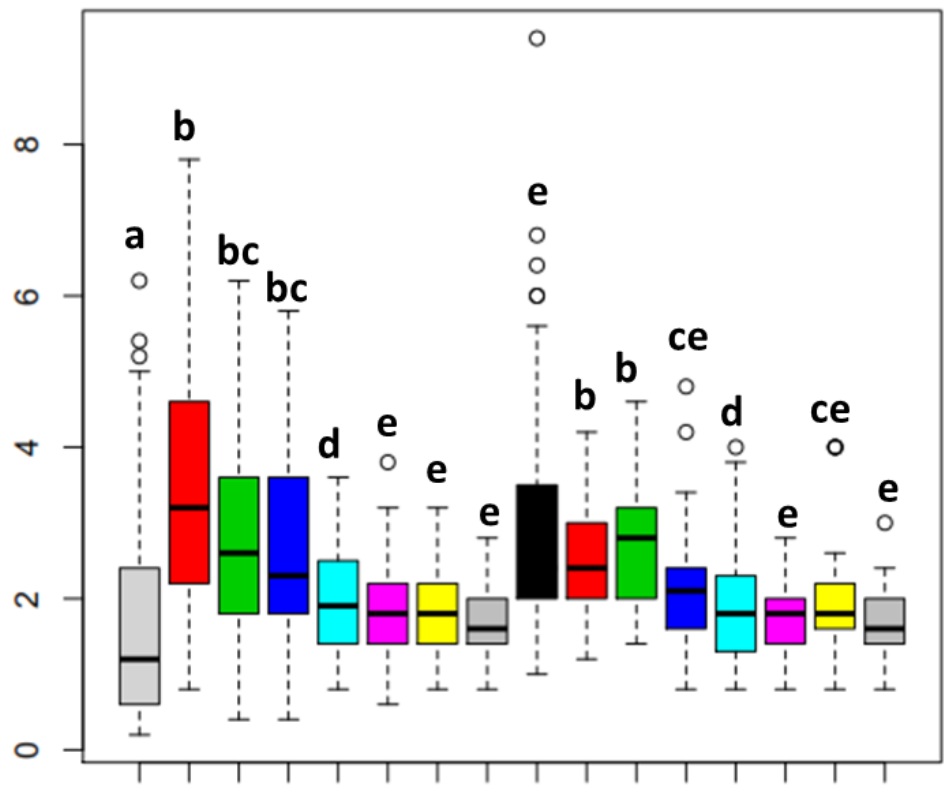

A - Titânio (TO)

B - Titânio (T1)

C - Titânio (T2)

D - Titânio (T3)

E - Controle Ti (TO)

F - Controle Ti (T1)

G - Controle Ti (T2)

$\mathrm{H}$ - Controle Ti (T3)

I - Zircônia (TO)

J - Zircônia (T1)

K - Zircônia (T2)

L - Zircônia (T3)

M - Controle Zr (TO)

$\mathrm{N}$ - Controle $\mathrm{Zr}$ (T1)

$\mathrm{O}$ - Controle $\mathrm{Zr}$ (T2)

$P$ - Controle Zr (T3)

A B C D E F G H I J K L M N O P 


\subsection{Nível clínico de inserção}

A Figura 10 ilustra os gráficos de Box Plot (esquerda) e do intervalo de confiança de 95\% para o efeito relativo do fator substrato (direita). O Box Plot representa os valores mínimo, $1^{\circ}$ quartil, mediana, $3^{\circ}$ quartil e valor máximo de nível clínico de inserção $(\mathrm{mm})$ para cada tempo separadamente, onde pode-se observar leve distorção dos dados, e também principalmente relacionada ao fator substrato, semelhante ao que ocorre na profundidade de sondagem. Alguns outliers foram registrados em cada período, confirmando a variabilidade de distribuição dos dados. No gráfico que avalia o efeito relativo dos fatores investigados, também observa-se a falta de paralelismo das linhas ao longo do tempo, com distribuição muito semelhante à que foi registrada para a profundidade de sondagem, também sugerindo uma interação estatística entre os fatores substrato e tempo para esta variável. Além disso, nota-se que o grupo titânio apresenta aumento no nível clínico de inserção a partir segundo período de avaliação (12 meses), permanecendo constante até a avaliação final (36 meses). Em contrapartida, no grupo zircônia os valores permanecem constantes desde o carregamento dos implantes até o período de 24 meses, a partir do qual apresenta diminuição. Os resultados das análises dos efeitos substrato, tempo e suas interações estão representados na Tabela 5. Conforme apresentado na tabela, a hipótese de ausência de interações foi rejeitada, uma vez que tanto as análises WTS e ATS resultaram em valores de $p<0,05$ (WTS: 3,583 x 10-8; ATS: $\left.3,788 \times 10^{-7}\right)$.

Figura 10 - Gráfico Box Plot com os valores de mediana, intervalo interquartil e valores mínimo e máximo de nível clínico de inserção $(\mathrm{mm})$ e gráfico do intervalo de confiança de $95 \%$ para o efeito relativo dos fatores investigados. 0: baseline; 1: 12 meses; 2: 24 meses; 3: 36 meses.
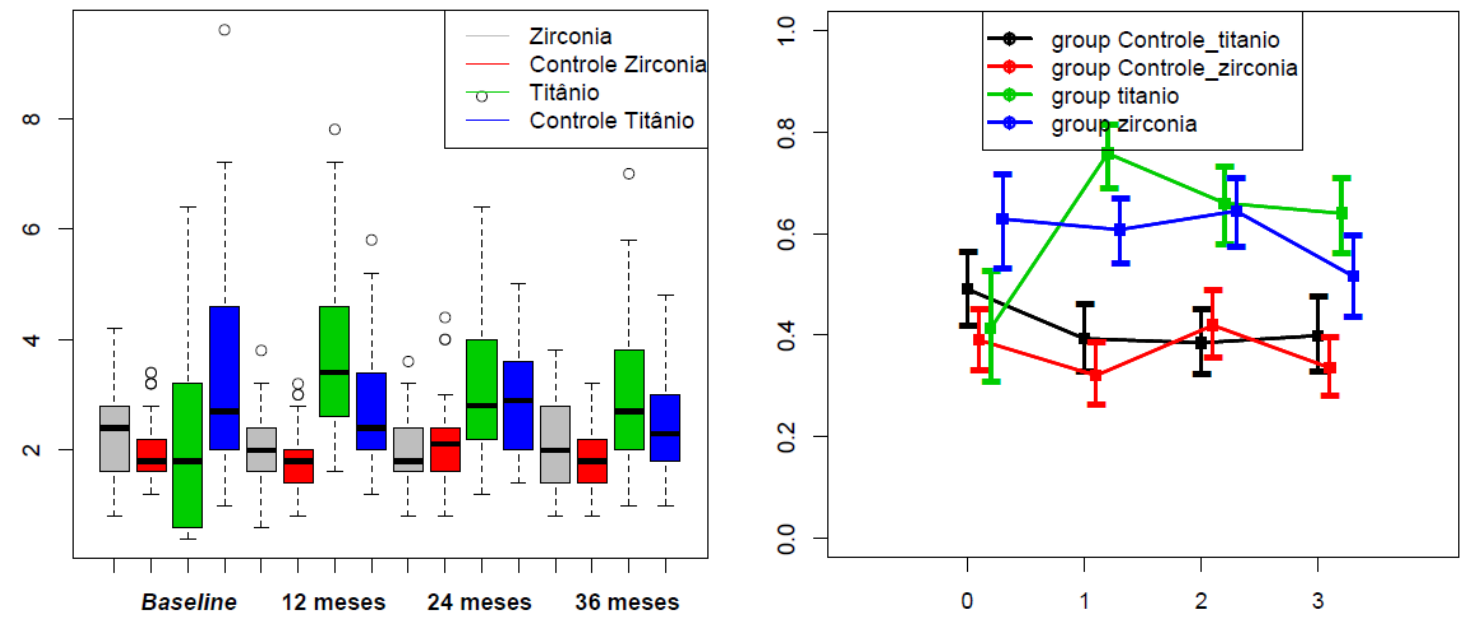
Tabela 5 - Análise dos efeitos relativos dos fatores substrato, tempo e suas interações no nível clínico de inserção (Statistic: valor da função estatística; df: graus de liberdade da análise).

Wald-Type Statistic (WTS) ANOVA-Type Statistic (ATS)

\begin{tabular}{lcccccc} 
Fator & Statistic & df & Valor $\boldsymbol{p}$ & Statistic & df & Valor $\boldsymbol{p}$ \\
Grupo & 84,70 & 3 & $2,99 \times 10^{-18}$ & 28,35 & 2,99 & $2,58 \times 10^{-18}$ \\
Tempo & 8,09 & 3 & $4,40 \times 10^{-2}$ & 2,21 & 2,44 & $9,77 \times 10^{-2}$ \\
Grupo: tempo & 52,53 & 9 & $3,58 \times 10^{-8}$ & 6,44 & 6,44 & $3,78 \times 10^{-7}$ \\
\hline
\end{tabular}

Os valores de $p$, obtidos após as múltiplas comparações entre os diversos fatores, estão representados na Tabela 6 , onde nota-se que ambos os grupos apresentaram diferença significativa entre baseline (T0) e os demais tempos investigados. No titânio, os valores aumentaram significativamente após a instalação dos implantes, enquanto que na zircônia os valores tiveram redução relevante. Não houve variação dos valores após a segunda coleta dos dados (12 meses) para os dois grupos, a partir do qual o nível clínico de inserção manteve-se constante. As múltiplas comparações interagindo os grupos titânio e zircônia revelou variação significativa até o tempo T1, após esse período não existe diferença significativa entre os grupos. Os dentes contra-laterais apresentaram valores de nível clínico de inserção similares entre 12 e 36 meses após a instalação da prótese em ambos os grupos. Na Tabela 7 estão apresentados os valores de Mean ranks $\left(\mathrm{R}_{\mathrm{j}}\right)$ obtidos após as múltiplas comparações e as diferenças significantes das interações entre os fatores investigados. A Figura 11 ilustra o gráfico tipo Box Plot com a representação dos valores mínimo, $1^{\circ}$ quartil, mediana, $3^{\circ}$ quartil e valores máximos após as múltiplas comparações (interagindo os fatores substrato e tempo). 
Tabela 6 - Valores de $p$ para as múltiplas comparações realizadas por meio do método de Friedman-Conover corrigido pelo pós-teste de Benjamini-Hochberg FDR no nível clínico de inserção.

\begin{tabular}{|c|c|c|c|c|c|c|c|c|c|c|c|c|c|c|c|c|c|c|c|}
\hline \multicolumn{4}{|c|}{ Comparação } & \multirow{2}{*}{$\frac{\text { Valor } p}{2 \times 10^{-16}}$} & \multicolumn{4}{|c|}{ Comparação } & \multirow{2}{*}{$\frac{\text { Valor } p}{2 \times 10^{-16}}$} & \multicolumn{4}{|c|}{ Comparação } & \multirow{2}{*}{$\frac{\text { Valor } p}{2 \times 10^{-13}}$} & \multicolumn{4}{|c|}{ Comparação } & \multirow{2}{*}{$\begin{array}{l}\text { Valor } \boldsymbol{p} \\
1,0000\end{array}$} \\
\hline $\mathrm{A}$ & - & B & $<$ & & $\mathrm{C}$ & - & $\mathrm{E}$ & $<$ & & $\mathrm{E}$ & - & $\mathrm{L}$ & $=$ & & $\mathrm{H}$ & - & $\mathrm{O}$ & $=$ & \\
\hline A & - & $\mathrm{C}$ & $<$ & $2 \times 10^{-16}$ & $\mathrm{C}$ & - & $\mathrm{F}$ & $=$ & $7,4 \times 10^{-5}$ & $\mathrm{E}$ & - & M & $=$ & 0,3296 & $\mathrm{H}$ & - & $\mathrm{P}$ & $=$ & 0,2583 \\
\hline A & - & $\mathrm{D}$ & $<$ & $2 \times 10^{-16}$ & $\mathrm{C}$ & - & G & $=$ & $5,9 \times 10^{-5}$ & $\mathrm{E}$ & - & $\mathrm{N}$ & $=$ & $4,2 \times 10^{-5}$ & I & - & $\mathrm{J}$ & $=$ & $4,4 \times 10^{-4}$ \\
\hline A & - & $\mathrm{E}$ & $=$ & $1,9 \times 10^{-5}$ & $\mathrm{C}$ & - & $\mathrm{H}$ & $=$ & 0,0301 & $\mathrm{E}$ & - & $\mathrm{O}$ & $=$ & $1,4 \times 10^{-11}$ & I & - & K & $=$ & $9,6 \times 10^{-6}$ \\
\hline A & - & $\mathrm{F}$ & $<$ & $2 \times 10^{-16}$ & $\mathrm{C}$ & - & I & $=$ & $2,2 \times 10^{-5}$ & $\mathrm{E}$ & - & $\mathrm{P}$ & $=$ & $3 \times 10^{-8}$ & I & - & $\mathrm{L}$ & $=$ & 0,0102 \\
\hline A & - & G & $<$ & $2 \times 10^{-16}$ & $\mathrm{C}$ & - & $\mathrm{J}$ & $=$ & 0,5004 & $\mathrm{~F}$ & - & $\mathrm{G}$ & $=$ & 0,9605 & I & - & M & $=$ & $8,9 \times 10^{-9}$ \\
\hline A & - & $\mathrm{H}$ & $<$ & $2 \times 10^{-16}$ & $\mathrm{C}$ & - & K & $=$ & 0,8641 & $\mathrm{~F}$ & - & $\mathrm{H}$ & $=$ & 0,0895 & I & - & $\mathrm{N}$ & $=$ & 0,5727 \\
\hline A & - & I & $<$ & $2 \times 10^{-16}$ & $\mathrm{C}$ & - & $\mathrm{L}$ & $=$ & 0,1145 & $\mathrm{~F}$ & - & I & $=$ & 0,7990 & I & - & $\mathrm{O}$ & $=$ & 0,0482 \\
\hline A & - & $\mathrm{J}$ & $<$ & $2 \times 10^{-16}$ & $\mathrm{C}$ & - & $\mathrm{M}$ & $<$ & $2 \times 10^{-16}$ & F & - & $\mathrm{J}$ & $=$ & 0,0013 & I & - & $\mathrm{P}$ & $=$ & 0,4286 \\
\hline A & - & K & $<$ & $2 \times 10^{-16}$ & $\mathrm{C}$ & - & $\mathrm{N}$ & $=$ & $1,2 \times 10^{-4}$ & F & - & K & $=$ & $3,3 \times 10^{-5}$ & $\mathrm{~J}$ & - & K & $=$ & 0,3928 \\
\hline A & - & $\mathrm{L}$ & $<$ & $2 \times 10^{-16}$ & $\mathrm{C}$ & - & $\mathrm{O}$ & $=$ & 0,0300 & F & - & $\mathrm{L}$ & $=$ & 0,0223 & $\mathrm{~J}$ & - & $\mathrm{L}$ & $=$ & 0,3928 \\
\hline A & - & $\mathrm{M}$ & $=$ & $1,3 \times 10^{-3}$ & $\mathrm{C}$ & - & $\mathrm{P}$ & $=$ & $6,9 \times 10^{-4}$ & F & - & M & $=$ & $1,6 \times 10^{-9}$ & $\mathrm{~J}$ & - & M & $<$ & $2 \times 10^{-16}$ \\
\hline A & - & $\mathrm{N}$ & $<$ & $2 \times 10^{-16}$ & $\mathrm{D}$ & - & E & $<$ & $2 \times 10^{-16}$ & $\mathrm{~F}$ & - & $\mathrm{N}$ & $=$ & 0,4006 & $\mathrm{~J}$ & - & $\mathrm{N}$ & $=$ & $3,6 \times 10^{-5}$ \\
\hline A & - & $\mathrm{O}$ & $<$ & $2 \times 10^{-16}$ & $\mathrm{D}$ & - & $\mathrm{F}$ & $=$ & $2,1 \times 10^{-5}$ & F & - & $\mathrm{O}$ & $=$ & 0,0895 & $\mathrm{~J}$ & - & $\mathrm{O}$ & $=$ & 0,1491 \\
\hline A & - & $\mathrm{P}$ & $<$ & $2 \times 10^{-16}$ & $\mathrm{D}$ & - & G & $=$ & $1,6 \times 10^{-5}$ & F & - & $\mathrm{P}$ & $=$ & 0,5995 & $\mathbf{J}$ & - & $\mathrm{P}$ & $=$ & 0,0084 \\
\hline B & - & $\mathrm{C}$ & $=$ & 0,2057 & $\mathrm{D}$ & - & $\mathrm{H}$ & $=$ & 0,0134 & G & - & $\mathrm{H}$ & $=$ & 0,0809 & K & - & $\mathrm{L}$ & $=$ & 0,0792 \\
\hline B & - & $\mathrm{D}$ & $=$ & 0,3335 & $\mathrm{D}$ & - & I & $=$ & $5,5 \times 10^{-6}$ & G & - & I & $=$ & 0,8396 & K & - & M & $<$ & $2 \times 10^{-16}$ \\
\hline B & - & $\mathrm{E}$ & $<$ & $2 \times 10^{-16}$ & $\mathrm{D}$ & - & $\mathrm{J}$ & $=$ & 0,3336 & G & - & $\mathrm{J}$ & $=$ & 0,0011 & $\mathrm{~K}$ & - & $\mathrm{N}$ & $=$ & $4,6 \times 10^{-7}$ \\
\hline B & - & $\mathrm{F}$ & $=$ & $1,2 \times 10^{-7}$ & $\mathrm{D}$ & - & K & $=$ & 0,9205 & G & - & K & $=$ & $2,6 \times 10^{-5}$ & $\mathrm{~K}$ & - & $\mathrm{O}$ & $=$ & 0,0184 \\
\hline B & - & G & $=$ & $9,1 \times 10^{-8}$ & $\mathrm{D}$ & - & $\mathrm{L}$ & $=$ & 0,0607 & G & - & $\mathrm{L}$ & $=$ & 0,0192 & $\mathrm{~K}$ & - & $\mathrm{P}$ & $=$ & $3,4 \times 10^{-4}$ \\
\hline B & - & $\mathrm{H}$ & $=$ & $4,2 \times 10^{-4}$ & $\mathrm{D}$ & - & M & $<$ & $2 \times 10^{-16}$ & G & - & M & $=$ & $2,2 \times 10^{-9}$ & $\mathrm{~L}$ & - & $\mathrm{M}$ & $<$ & $2 \times 10^{-16}$ \\
\hline B & - & I & $=$ & $2,5 \times 10^{-8}$ & $\mathrm{D}$ & - & $\mathrm{N}$ & $=$ & $2,6 \times 10^{-7}$ & G & - & $\mathrm{N}$ & $=$ & 0,4286 & $\mathrm{~L}$ & - & $\mathrm{N}$ & $=$ & 0,0014 \\
\hline B & - & $\mathrm{J}$ & $=$ & 0,0470 & $\mathrm{D}$ & - & $\mathrm{O}$ & $=$ & 0,0134 & G & - & $\mathrm{O}$ & $=$ & 0,0809 & $\mathrm{~L}$ & - & $\mathrm{O}$ & $=$ & 0,5765 \\
\hline B & - & K & $=$ & 0,2829 & $\mathrm{D}$ & - & $\mathrm{P}$ & $=$ & $2,1 \times 10^{-4}$ & G & - & $\mathrm{P}$ & $=$ & 0,5727 & $\mathrm{~L}$ & - & $\mathrm{P}$ & $=$ & 0,0837 \\
\hline B & - & $\mathrm{L}$ & $=$ & $3,5 \times 10^{-3}$ & $\mathrm{E}$ & - & $\mathrm{F}$ & $=$ & $6,2 \times 10^{-7}$ & $\mathrm{H}$ & - & I & $=$ & 0,0482 & M & - & $\mathrm{N}$ & $=$ & $2,8 \times 10^{-7}$ \\
\hline B & - & $\mathrm{M}$ & $<$ & $2 \times 10^{-16}$ & $\mathrm{E}$ & - & G & $=$ & $8,2 \times 10^{-7}$ & $\mathrm{H}$ & - & $\mathrm{J}$ & $=$ & 0,1491 & M & - & $\mathrm{O}$ & $=$ & $5,8 \times 10^{-15}$ \\
\hline B & - & $\mathrm{N}$ & $=$ & $5,9 \times 10^{-10}$ & $\mathrm{E}$ & - & $\mathrm{H}$ & $=$ & $1,4 \times 10^{-11}$ & $\mathrm{H}$ & - & K & $=$ & 0,0184 & M & - & $\mathrm{P}$ & $=$ & $4,1 \times 10^{-11}$ \\
\hline B & - & $\mathrm{O}$ & $=$ & $4,2 \times 10^{-4}$ & $\mathrm{E}$ & - & I & $=$ & $2,6 \times 10^{-6}$ & $\mathrm{H}$ & - & $\mathrm{L}$ & $=$ & 0,5765 & $\mathrm{~N}$ & - & $\mathrm{O}$ & $=$ & 0,0098 \\
\hline B & - & $\mathrm{P}$ & $=$ & $2,2 \times 10^{-6}$ & $\mathrm{E}$ & - & $\mathrm{J}$ & $<$ & $2 \times 10^{-16}$ & $\mathrm{H}$ & - & M & $=$ & $5,8 \times 10^{-15}$ & $\mathrm{~N}$ & - & $\mathrm{P}$ & $=$ & 0,1659 \\
\hline $\mathrm{C}$ & - & $\mathrm{D}$ & $=$ & 0,7901 & $\mathrm{E}$ & - & K & $<$ & $2 \times 10^{-16}$ & $\mathrm{H}$ & - & $\mathrm{N}$ & $=$ & 0,0098 & $\mathrm{O}$ & - & $\mathrm{P}$ & $=$ & 0,2583 \\
\hline
\end{tabular}

A - Titânio (T0); B - Titânio (T1); C - Titânio (T2); D - Titânio (T3); E - Controle Ti (T0); F - Controle Ti (T1); G - Controle Ti (T2); H Controle Ti (T3); I - Zircônia (T0); J - Zircônia (T1); K - Zircônia (T2); L - Zircônia (T3); M - Controle Zr (T0); N - Controle Zr (T1); O Controle Zr (T2); P - Controle Zr (T3). Números destacados em vermelho quando $p>0,05$. 
Tabela 7 - Mean ranks (Rj) após múltiplas comparações no nível clínico de inserção. Letras diferentes (M) indicam diferenças significantes $(p<0,05)$ de acordo com FriedmanConover e FDR ( $p<0,05)$. T0: baseline; T1: 12 meses; T2: 24 meses; T3: 36 meses.

\begin{tabular}{lccc}
\hline Substrato & Tempo & $\mathbf{R}_{\mathbf{j}}$ & $\mathbf{M}$ \\
\hline Titânio & $\mathrm{T}(0)$ & 238,4 & $\mathrm{a}$ \\
Titânio & $\mathrm{T}(1)$ & 626,2 & $\mathrm{~b}$ \\
Titânio & $\mathrm{T}(2)$ & 582,0 & $\mathrm{bc}$ \\
Titânio & $\mathrm{T}(3)$ & 576,8 & $\mathrm{bc}$ \\
Titânio (Controle) & $\mathrm{T}(0)$ & 358,7 & $\mathrm{~d}$ \\
Titânio (Controle) & $\mathrm{T}(1)$ & 456,1 & ef \\
Titânio (Controle) & $\mathrm{T}(2)$ & 456,9 & ef \\
Titânio (Controle) & $\mathrm{T}(3)$ & 470,3 & egh \\
Zircônia & $\mathrm{T}(0)$ & 459,7 & $\mathrm{f}$ \\
Zircônia & $\mathrm{T}(1)$ & 582,5 & $\mathrm{cg}$ \\
Zircônia & $\mathrm{T}(2)$ & 606,5 & $\mathrm{bc}$ \\
Zircônia & $\mathrm{T}(3)$ & 546,1 & $\mathrm{cgh}$ \\
Zircônia (Controle) & $\mathrm{T}(0)$ & 300,0 & $\mathrm{~d}$ \\
Zircônia (Controle) & $\mathrm{T}(1)$ & 450,7 & $\mathrm{f}$ \\
Zircônia (Controle) & $\mathrm{T}(2)$ & 507,2 & egh \\
Zircônia (Controle) & $\mathrm{T}(3)$ & 469,9 & efh \\
\hline
\end{tabular}

Figura 11 - Mediana, intervalo interquartil e valores mínimo e máximo de nível clínico de inserção (mm) após os testes de múltiplas comparações de Friedman-Conover corrigido por Benjamini-Hockberg FDR. Diferentes letras representam diferenças significantes entre os grupos $(\mathrm{p}<0,05)$. Ti: titânio; Zr: zircônia. T0: baseline; T1: 12 meses; T2: 24 meses; T3: 36 meses.

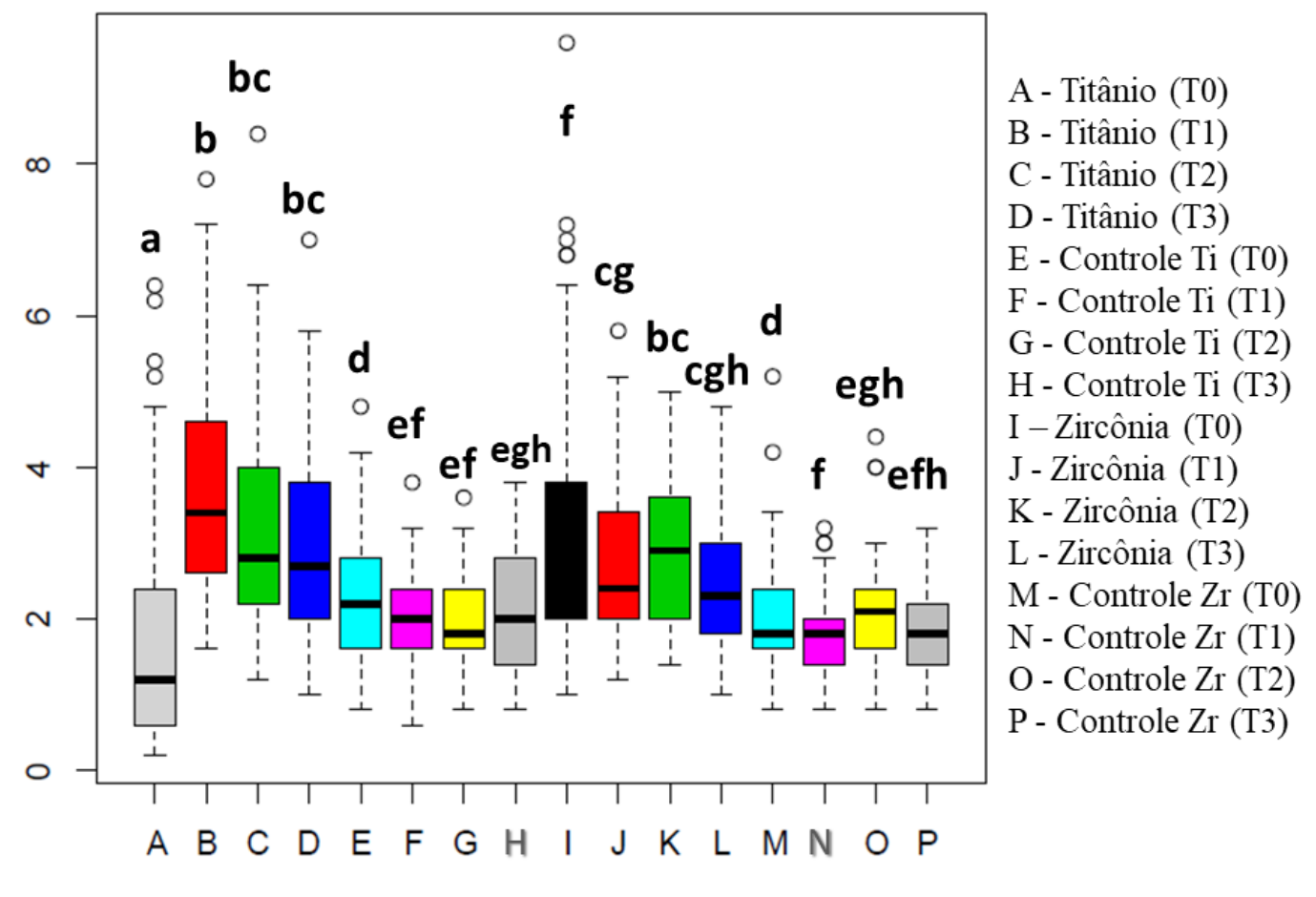




\subsection{Sangramento à sondagem}

A Figura 12 ilustra os gráficos de Box Plot (esquerda) e do intervalo de confiança de 95\% para o efeito relativo do fator substrato (direita) em cada tempo separadamente. O Box Plot representa os valores mínimo, $1^{\circ}$ quartil, mediana, $3^{\circ}$ quartil e valor máximo de sangramento à sondagem $(\mathrm{mm})$ para cada tempo separadamente. Para esta variável, tanto o gráfico de distribuição dos valores obtidos quanto o de interação entre os grupos ilustram grande distorção dos dados. O Box Plot demonstra uma grande variabilidade na distribuição das medianas. No gráfico que avalia o efeito relativo dos fatores investigados, nota-se que o sangramento à sondagem, ao longo tempo, aumenta tanto para o grupo titânio quanto para o grupo zircônia. Assim como já observado para a profundidade de sondagem e nível clínico de inserção, os dados dos grupos controles (dentes) permanecem praticamente constantes ao longo do tempo. Para o titânio, os maiores valores foram registrados no terceiro período de avaliação (24 meses), a partir do qual se observa leve redução. Já para a zircônia, ocorre ligeiro aumento após 12 meses e em seguida os valores permanecem constantes até o último período de avaliação (36 meses). A falta de paralelismo das linhas ao longo do tempo sugere interação estatística entre os fatores substrato e tempo em ambos os grupos. Os resultados das análises dos efeitos substrato, tempo e suas interações estão representados na Tabela 8. Conforme apresentado na tabela, a hipótese de ausência de interações foi rejeitada, uma vez que tanto as análises WTS e ATS resultaram em valores de $p<0,05$ (WTS: $1,8 \times 10^{-3}$; ATS: $\left.2,51 \times 10^{-2}\right)$.

Figura 12 - Gráfico Box Plot com os valores de mediana, intervalo interquartil e valores mínimo e máximo de sangramento à sondagem e gráfico do intervalo de confiança de $95 \%$ para o efeito relativo dos fatores investigados. 0: baseline; 1: 12 meses; 2: 24 meses; 3: 36 meses.
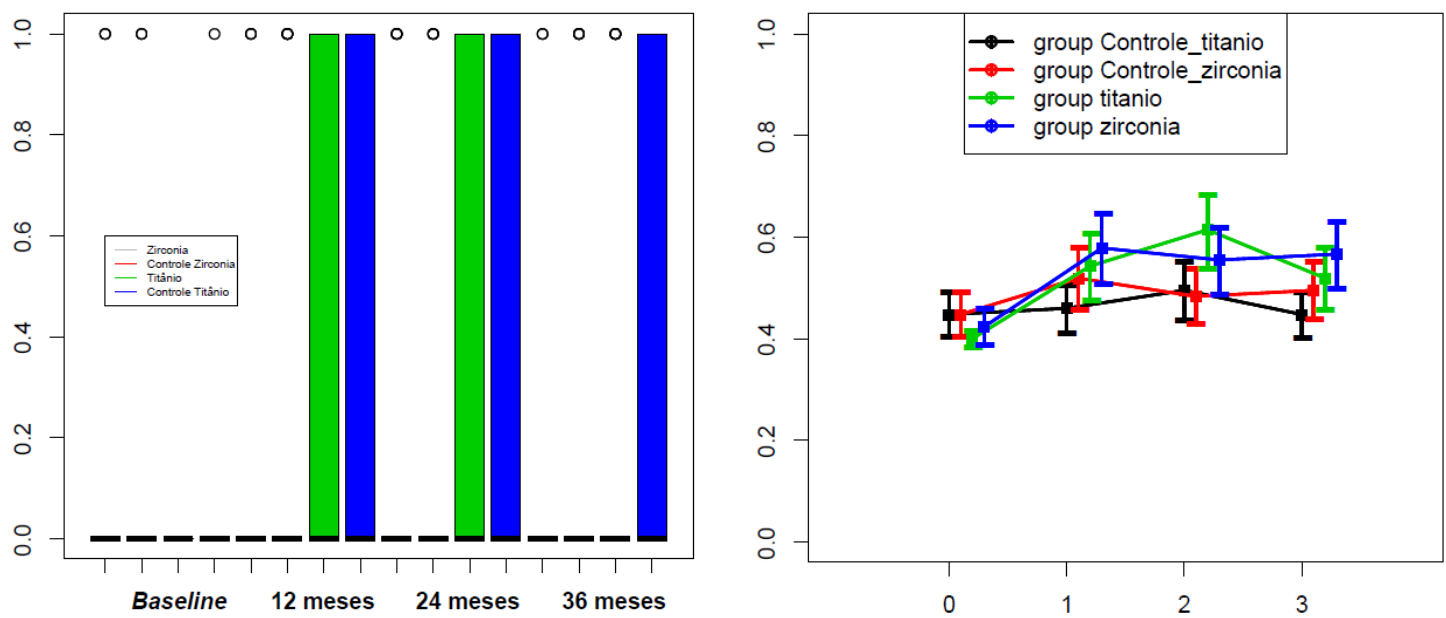
Tabela 8 - Análise dos efeitos relativos dos fatores substrato, tempo e suas interações no sangramento à sondagem (Statistic: valor da função estatística; df: graus de liberdade da análise).

Wald-Type Statistic (WTS) $\quad$ ANOVA-Type Statistic (ATS)

\begin{tabular}{lcccccc}
\hline Fator & Statistic & df & Valor $\boldsymbol{p}$ & Statistic & df & Valor $\boldsymbol{p}$ \\
Grupo & 10,41 & 3 & 0,0153 & 3,31 & 2,92 & 0,0200 \\
Tempo & 47,26 & 3 & $3,06 \times 10^{-10}$ & 11,69 & 2,84 & $2,22 \times 10^{-7}$ \\
Grupo: tempo & 26,32 & 9 & 0,0018 & 2,19 & 7,93 & 0,0251 \\
\hline
\end{tabular}

Os valores de $p$ relacionados às análises de múltiplas comparações estão representados na Tabela 9. Os resultados corroboram as análises de significância apontadas pelo teste de Brunner-Langer. Pode-se observar que o aumento no sangramento à sondagem apresentado no grupo zircônia após 12 meses em relação ao baseline (T0) é significativo e, após esse período, a taxa de sangramento manteve-se constante até o último período avaliado (36 meses). Já o grupo titânio apresenta variação significativa até o terceiro período de avaliação (24 meses). Além disso, é possível verificar que não existe diferença no sangramento à sondagem entre os grupos titânio e zircônia no momento de instalação dos pilares (T0), porém variações foram observadas nos períodos T1 e T3. Na Tabela 10 estão apresentados os valores de Mean ranks $\left(\mathrm{R}_{\mathrm{j}}\right)$ obtidos após as múltiplas comparações e um sumário das diferenças significantes entre os grupos investigados. A Figura 13 ilustra o gráfico tipo Box Plot com a representação dos valores mínimo, $1^{\circ}$ quartil, mediana, $3^{\circ}$ quartil e valores máximos após as múltiplas comparações (interagindo os fatores substrato e tempo). 
Tabela 9 - Valores de $p$ para as múltiplas comparações por meio do método de Friedman-Conover corrigido pelo pós-teste de Benjamini-Hochberg FDR no sangramento à sondagem.

\begin{tabular}{|c|c|c|c|c|c|c|c|c|c|c|c|c|c|c|c|c|c|c|c|}
\hline \multicolumn{4}{|c|}{ Comparação } & \multirow{2}{*}{$\frac{\text { Valor } \boldsymbol{p}}{2,9 \times 10^{-16}}$} & \multicolumn{4}{|c|}{ Comparação } & \multirow{2}{*}{$\frac{\text { Valor } p}{2 \times 10^{-16}}$} & \multicolumn{4}{|c|}{ Comparação } & \multirow{2}{*}{$\frac{\text { Valor } \boldsymbol{p}}{2 \times 10^{-16}}$} & \multicolumn{4}{|c|}{ Comparação } & \multirow{2}{*}{$\begin{array}{l}\text { Valor } \boldsymbol{p} \\
0,0223\end{array}$} \\
\hline $\mathrm{A}$ & - & $\mathrm{B}$ & $=$ & & $\mathrm{C}$ & - & $\mathrm{E}$ & $<$ & & $\mathrm{E}$ & - & $\mathrm{L}$ & $<$ & & $\mathrm{H}$ & - & $\mathrm{O}$ & $=$ & \\
\hline A & - & $\mathrm{C}$ & $<$ & $2 \times 10^{-16}$ & $\mathrm{C}$ & - & $\mathrm{F}$ & $=$ & $4,5 \times 10^{-3}$ & $\mathrm{E}$ & - & M & $=$ & 0,9496 & $\mathrm{H}$ & - & $\mathrm{P}$ & $=$ & $3 \times 10^{-4}$ \\
\hline A & - & $\mathrm{D}$ & $<$ & $2 \times 10^{-16}$ & $\mathrm{C}$ & - & G & $=$ & 0,3431 & $\mathrm{E}$ & - & $\mathrm{N}$ & $<$ & $2 \times 10^{-16}$ & I & - & $\mathrm{J}$ & $<$ & $2 \times 10^{-16}$ \\
\hline A & - & $\mathrm{E}$ & $=$ & 0,0839 & $\mathrm{C}$ & - & $\mathrm{H}$ & $=$ & 0,12858 & $\mathrm{E}$ & - & $\mathrm{O}$ & $<$ & $2 \times 10^{-16}$ & I & - & K & $<$ & $2 \times 10^{-16}$ \\
\hline A & - & $\mathrm{F}$ & $=$ & $5,9 \times 10^{-16}$ & $\mathrm{C}$ & - & I & $<$ & $2 \times 10^{-16}$ & $\mathrm{E}$ & - & $\mathrm{P}$ & $<$ & $2 \times 10^{-16}$ & I & - & $\mathrm{L}$ & $<$ & $2 \times 10^{-16}$ \\
\hline A & - & G & $<$ & $2 \times 10^{-16}$ & $\mathrm{C}$ & - & $\mathrm{J}$ & $=$ & 0,9341 & $\mathrm{~F}$ & - & G & $=$ & 0,0728 & I & - & M & $=$ & 0,3083 \\
\hline A & - & $\mathrm{H}$ & $<$ & $2 \times 10^{-16}$ & $\mathrm{C}$ & - & $\mathrm{K}$ & $=$ & 0,0507 & $\mathrm{~F}$ & - & $\mathrm{H}$ & $=$ & 0,2248 & I & - & $\mathrm{N}$ & $<$ & $2 \times 10^{-16}$ \\
\hline A & - & I & $=$ & 0,5279 & $\mathrm{C}$ & - & $\mathrm{L}$ & $=$ & 0,1026 & $\mathrm{~F}$ & - & I & $=$ & $1,1 \times 10^{-13}$ & I & - & $\mathrm{O}$ & $<$ & $2 \times 10^{-16}$ \\
\hline A & - & $\mathrm{J}$ & $<$ & $2 \times 10^{-16}$ & $\mathrm{C}$ & - & M & $<$ & $2 \times 10^{-16}$ & $\mathrm{~F}$ & - & $\mathrm{J}$ & & $3,1 \times 10^{-3}$ & I & - & $\mathrm{P}$ & $<$ & $2 \times 10^{-16}$ \\
\hline A & - & $\mathrm{K}$ & $<$ & $2 \times 10^{-16}$ & $\mathrm{C}$ & - & $\mathrm{N}$ & $=$ & 0,3904 & $\mathrm{~F}$ & - & $\mathrm{K}$ & & $7 \times 10^{-7}$ & $\mathrm{~J}$ & - & K & $=$ &, 0664 \\
\hline A & - & $\mathrm{L}$ & $<$ & $2 \times 10^{-16}$ & $\mathrm{C}$ & - & $\mathrm{O}$ & $=$ & 0,4678 & $\mathrm{~F}$ & - & $\mathrm{L}$ & & $4,1 \times 10^{6}$ & $\mathrm{~J}$ & - & $\mathrm{L}$ & $=$ & 0.1286 \\
\hline A & - & M & $=$ & 0,0944 & $\mathrm{C}$ & - & $\mathrm{P}$ & $=$ & 0,0598 & $\mathrm{~F}$ & - & M & & $2,3 \times 10^{-10}$ & $\mathrm{~J}$ & - & M & $<$ & $2 \times 10^{-16}$ \\
\hline A & - & $\mathrm{N}$ & $<$ & $2 \times 10^{-16}$ & $\mathrm{D}$ & - & $\mathrm{E}$ & $=$ & $4,7 \times 10^{-14}$ & $\mathrm{~F}$ & - & $\mathrm{N}$ & & $1,7 \times 10^{-4}$ & $\mathrm{~J}$ & - & $\mathrm{N}$ & $=$ & 0,4565 \\
\hline A & - & $\mathrm{O}$ & $<$ & $2 \times 10^{-16}$ & $\mathrm{D}$ & - & $\mathrm{F}$ & $=$ & 0,2401 & $\mathrm{~F}$ & - & $\mathrm{O}$ & & $2,8 \times 10^{-4}$ & $\mathrm{~J}$ & - & $\mathrm{O}$ & $=$ & 0,5397 \\
\hline A & - & $\mathrm{P}$ & $<$ & $2 \times 10^{-16}$ & $\mathrm{D}$ & - & $\mathrm{G}$ & $=$ & 6 & $\mathrm{~F}$ & - & $\mathrm{P}$ & & $1,0 \times 10^{-6}$ & $\mathrm{~J}$ & - & $\mathrm{P}$ & - & 0 \\
\hline B & - & C & $=$ & 0,0060 & $\mathrm{D}$ & - & $\mathrm{H}$ & $=$ & 0,9610 & G & - & $\mathrm{H}$ & & 0,5802 & K & - & $\mathrm{L}$ & $=$ & 0,7588 \\
\hline B & - & $\mathrm{D}$ & $=$ & 0,2757 & $\mathrm{D}$ & - & I & $<$ & $2 \times 10^{-16}$ & G & - & I & $<$ & $2 \times 10^{-16}$ & $\mathrm{~K}$ & - & M & $<$ & $2 \times 10^{-16}$ \\
\hline B & - & $\mathrm{E}$ & $=$ & $2 \times 10^{-10}$ & $\mathrm{D}$ & - & $\mathrm{J}$ & $=$ & 0,0943 & G & - & $\mathrm{J}$ & $=$ & 0,4 & K & - & $\mathrm{N}$ & $=$ & 0,4565 \\
\hline B & - & $\mathrm{F}$ & $=$ & 0,9459 & $\mathrm{D}$ & - & $\mathrm{K}$ & $=$ & $2 \times 10^{-4}$ & G & - & $\mathrm{K}$ & $=$ & 0,0 & $\mathrm{~K}$ & - & $\mathrm{O}$ & $=$ & 0,3 \\
\hline B & - & G & $=$ & 0,0877 & $\mathrm{D}$ & - & $\mathrm{L}$ & $=$ & $9 \times 10^{-4}$ & G & - & $\mathrm{L}$ & $=$ & 0,0080 & K & - & $\mathrm{P}$ & $=$ & 0,8103 \\
\hline B & - & $\mathrm{H}$ & $=$ & 0,2562 & $\mathrm{D}$ & - & M & $=$ & $2,9 \times 10^{-14}$ & G & - & M & $<$ & $2 \times 10^{-16}$ & $\mathrm{~L}$ & - & M & $<$ & $2 \times 10^{-16}$ \\
\hline B & - & I & $=$ & $5,5 \times 10^{-14}$ & $\mathrm{D}$ & - & $\mathrm{N}$ & $=$ & 0,0133 & G & - & $\mathrm{N}$ & $=$ & 0,0695 & $\mathrm{~L}$ & - & $\mathrm{N}$ & $=$ & 0,4565 \\
\hline B & - & $\mathrm{J}$ & $=$ & 0,0042 & $\mathrm{D}$ & - & $\mathrm{O}$ & $=$ & 0,0197 & $\mathrm{G}$ & - & $\mathrm{O}$ & $=$ & 0,0715 & $\mathrm{~L}$ & - & $\mathrm{O}$ & $=$ & 0,3801 \\
\hline B & - & K & $=$ & $1,1 \times 10^{-6}$ & $\mathrm{D}$ & - & $\mathrm{P}$ & $=$ & $3 \times 10^{-4}$ & G & - & $\mathrm{P}$ & $=$ & 0,0033 & $\mathrm{~L}$ & - & $\mathrm{P}$ & $=$ & 0,8103 \\
\hline B & - & $\mathrm{L}$ & $=$ & $6,4 \times 10^{-6}$ & $\mathrm{E}$ & - & $\mathrm{F}$ & $=$ & $3,6 \times 10^{-10}$ & $\mathrm{H}$ & - & I & $<$ & $2 \times 10^{-16}$ & M & - & $\mathrm{N}$ & $<$ & $2 \times 10^{-16}$ \\
\hline B & - & M & $=$ & $1,3 \times 10^{-10}$ & $\mathrm{E}$ & - & $\mathrm{G}$ & $=$ & $3,4 \times 10^{-16}$ & $\mathrm{H}$ & - & J & $=$ & 0,1026 & M & - & $\mathrm{O}$ & $<$ & $2 \times 10^{-16}$ \\
\hline B & - & $\mathrm{N}$ & $=$ & $2,4 \times 10^{-4}$ & $\mathrm{E}$ & - & $\mathrm{H}$ & $=$ & $3,4 \times 10^{-14}$ & $\mathrm{H}$ & - & K & $=$ & $3 \times 10^{-4}$ & M & - & $\mathrm{P}$ & $<$ & $2 \times 10^{-16}$ \\
\hline B & - & $\mathrm{O}$ & $=$ & $3,9 \times 10^{-4}$ & E & - & I & $=$ & 0,2815 & $\mathrm{H}$ & - & $\mathrm{L}$ & $=$ & 0,0011 & $\mathrm{~N}$ & - & $\mathrm{O}$ & $=$ & 0,9220 \\
\hline B & - & $\mathrm{P}$ & $=$ & $1,6 \times 10^{-6}$ & $\mathrm{E}$ & - & $\mathrm{J}$ & $<$ & $2 \times 10^{-16}$ & $\mathrm{H}$ & - & M & $=$ & $2,1 \times 10^{-14}$ & $\mathrm{~N}$ & - & $\mathrm{P}$ & $=$ & 0,3083 \\
\hline $\mathrm{C}$ & - & $\mathrm{D}$ & $=$ & 0,1187 & $\mathrm{E}$ & - & K & $<$ & $2 \times 10^{-16}$ & $\mathrm{H}$ & - & $\mathrm{N}$ & $=$ & 0,0151 & $\mathrm{O}$ & - & $\mathrm{P}$ & $=$ & 0,2562 \\
\hline
\end{tabular}

A - Titânio (T0); B - Titânio (T1); C - Titânio (T2); D - Titânio (T3); E - Controle Ti (T0); F - Controle Ti (T1); G - Controle Ti (T2); H Controle Ti (T3); I - Zircônia (T0); J - Zircônia (T1); K - Zircônia (T2); L - Zircônia (T3); M - Controle Zr (T0); N - Controle Zr (T1); O Controle $\mathrm{Zr}$ (T2); P - Controle Zr (T3). Números destacados em vermelho quando $p>0,05$. 
Tabela 10 - Mean ranks (Rj) após múltiplas comparações no sangramento à sondagem. Letras diferentes $(\mathrm{M})$ indicam diferenças significantes $(p<$ $0,05)$ de acordo com Friedman-Conover e FDR $(p<$ 0,05). T0: baseline; T1: 12 meses; T2: 24 meses; T3: 36 meses.

\begin{tabular}{lccc}
\hline Substrato & Tempo & $\mathbf{R}_{\mathbf{j}}$ & $\mathbf{M}$ \\
\hline Titânio & $\mathrm{T}(0)$ & 305,2 & $\mathrm{a}$ \\
Titânio & $\mathrm{T}(1)$ & 509,4 & $\mathrm{~b}$ \\
Titânio & $\mathrm{T}(2)$ & 551,9 & $\mathrm{cde}$ \\
Titânio & $\mathrm{T}(3)$ & 507,8 & $\mathrm{bc}$ \\
Titânio (Controle) & $\mathrm{T}(0)$ & 336,1 & $\mathrm{a}$ \\
Titânio (Controle) & $\mathrm{T}(1)$ & 482,2 & $\mathrm{~b}$ \\
Titânio (Controle) & $\mathrm{T}(2)$ & 515,1 & $\mathrm{bcd}$ \\
Titânio (Controle) & $\mathrm{T}(3)$ & 487,1 & $\mathrm{bc}$ \\
Zircônia & $\mathrm{T}(0)$ & 317,6 & $\mathrm{a}$ \\
Zircônia & $\mathrm{T}(1)$ & 560,6 & $\mathrm{cde}$ \\
Zircônia & $\mathrm{T}(2)$ & 584,6 & $\mathrm{e}$ \\
Zircônia & $\mathrm{T}(3)$ & 565,2 & $\mathrm{e}$ \\
Zircônia (Controle) & $\mathrm{T}(0)$ & 342,3 & $\mathrm{a}$ \\
Zircônia (Controle) & $\mathrm{T}(1)$ & 545,9 & $\mathrm{de}$ \\
Zircônia (Controle) & $\mathrm{T}(2)$ & 532,7 & $\mathrm{de}$ \\
Zircônia (Controle) & $\mathrm{T}(3)$ & 544,3 & $\mathrm{e}$ \\
\hline
\end{tabular}

Figura 13 - Mediana, intervalo interquartil e valores mínimo e máximo de sangramento à sondagem após os testes de múltiplas comparações de Friedman-Conover corrigido por Benjamini-Hockberg FDR. Diferentes letras representam diferenças significantes entre os grupos ( $<<0,05)$. Ti: titânio; Zr: zircônia. T0: baseline; T1: 12 meses; T2: 24 meses; T3: 36 meses.

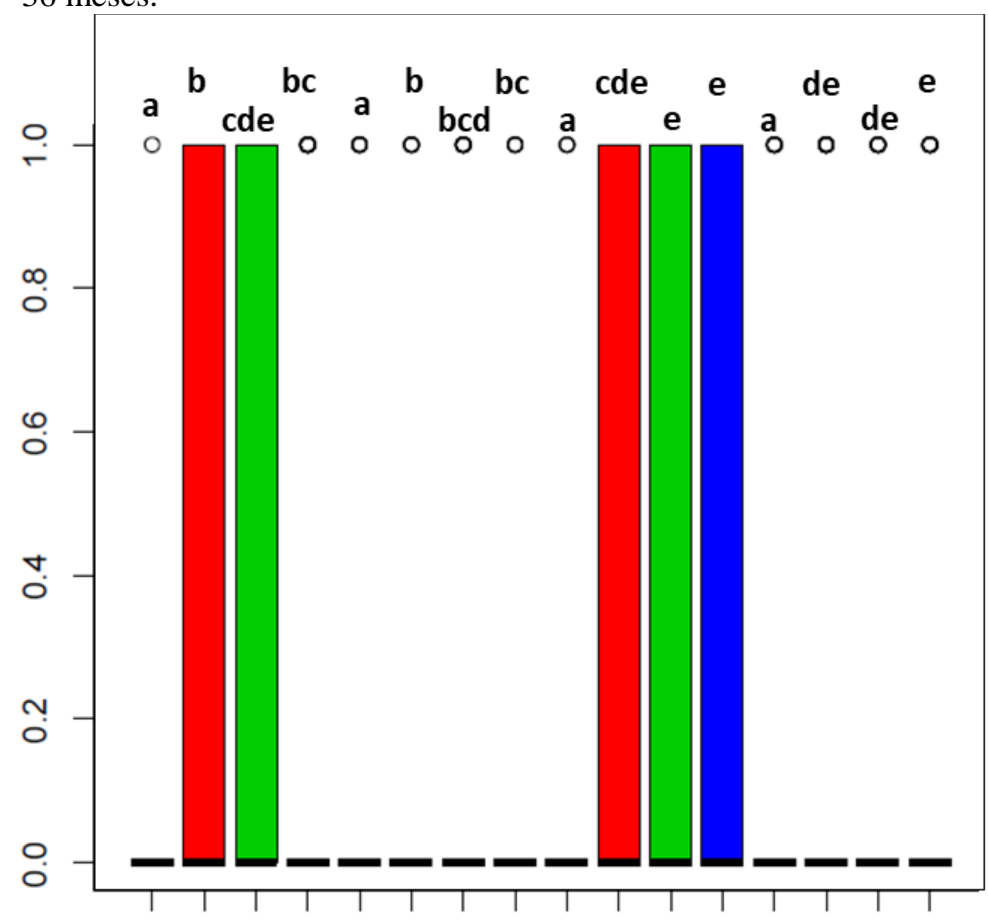

A - Titânio (T0)

B - Titânio (T1)

C - Titânio (T2)

D - Titânio (T3)

E - Controle Ti (T0)

F - Controle Ti (T1)

G - Controle Ti (T2)

$\mathrm{H}$ - Controle Ti (T3)

I - Zircônia (T0)

$\mathrm{J}$ - Zircônia (T1)

$\mathrm{K}$ - Zircônia (T2)

L - Zircônia (T3)

$\mathrm{M}$ - Controle $\mathrm{Zr}$ (T0)

$\mathrm{N}$ - Controle Zr (T1)

$\mathrm{O}$ - Controle $\mathrm{Zr}$ (T2)

$\mathrm{P}$ - Controle $\mathrm{Zr}(\mathrm{T} 3)$

A B C D E F G H I J K L M N O 


\subsection{Recessão gengival}

A Figura 14 ilustra os gráficos de Box Plot (esquerda) e do intervalo de confiança de 95\% para o efeito relativo do fator substrato (direita) em cada tempo separadamente. O Box Plot representa as medidas descritivas dos valores mínimo, $1^{\circ}$ quartil, mediana, $3^{\circ}$ quartil e valor máximo de recessão gengival $(\mathrm{mm})$, onde pode-se observar distribuição bastante distorcida dos dados, com grande quantidade de outliers. No gráfico que avalia o efeito relativo dos fatores investigados, nota-se que a recessão gengival, ao longo tempo, mantém-se praticamente constante em todos substratos investigados, diferentemente das demais variáveis descritas anteriormente, onde observou-se este comportamento somente para os grupos controles. Os resultados das análises dos efeitos substrato, tempo e suas interações estão representados na Tabela 11. Conforme apresentado na tabela, a hipótese de ausência de interações foi rejeitada somente para o fator grupo, uma vez que tanto as análises WTS e ATS resultaram em valores de $p<0,05$ (WTS: 0,007; ATS: 0,007).

Figura 14 - Gráfico Box Plot com os valores de mediana, intervalo interquartil e valores mínimo e máximo de recessão gengival $(\mathrm{mm})$ e gráfico do intervalo de confiança de $95 \%$ para o efeito relativo dos fatores investigados. 0: baseline; 1: 12 meses; 2: 24 meses; 3: 36 meses.
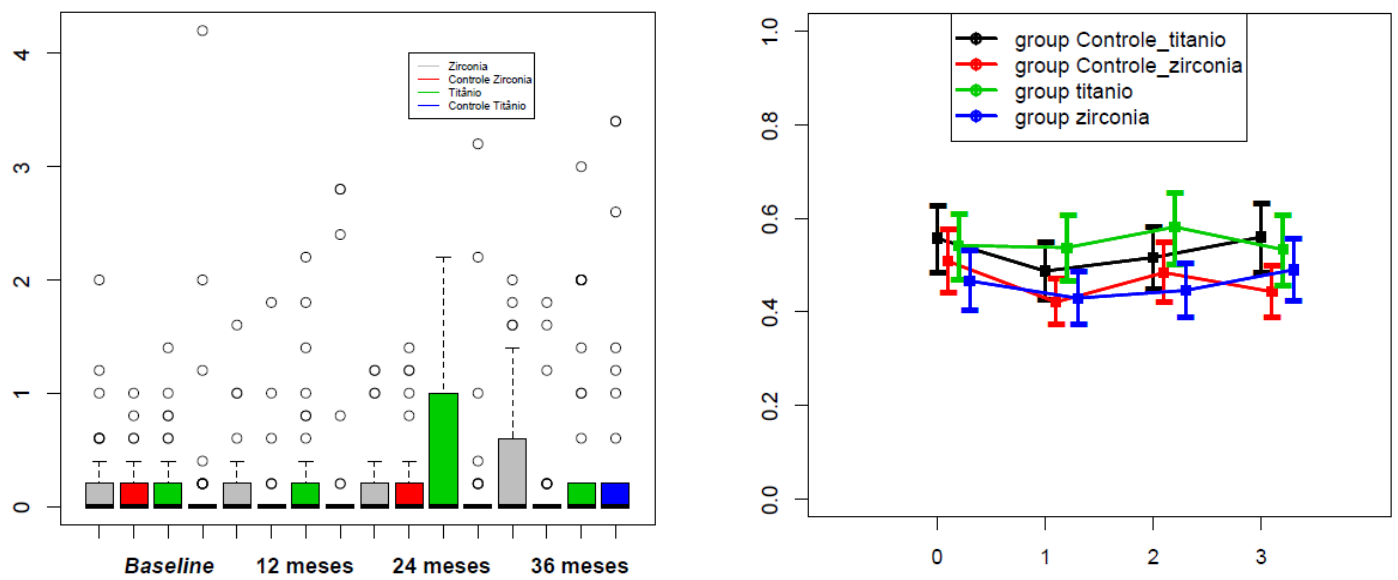

Tabela 11 - Análise dos efeitos relativos dos fatores substrato, tempo e suas interações na recessão gengival (Statistic: valor da função estatística; df: graus de liberdade da análise). Os valores destacados em vermelho representam ausência de interação entre os efeitos $(p>0,05)$.

\begin{tabular}{lcccccc}
\hline & \multicolumn{3}{c}{ Wald-Type Statistic (WTS) } & \multicolumn{3}{c}{ ANOVA-Type Statistic (ATS) } \\
\hline Fator & Statistic & df & Valor $\boldsymbol{p}$ & Statistic & df & Valor $\boldsymbol{p}$ \\
Grupo & 11,93 & 3 & 0,007 & 4,01 & 2,98 & 0,007 \\
Tempo & 7,48 & 3 & 0,057 & 1,89 & 2,70 & 0,133 \\
Grupo: tempo & 6,75 & 9 & 0,663 & 0,70 & 7,49 & 0,681 \\
\hline
\end{tabular}

Os valores de $p$, referentes às análises de múltiplas comparações para avaliar se a hipótese de ausência de interação também deve ser rejeitada em cada período de avaliação, estão representados na Tabela 12, onde podemos observar que os grupos titânio e zircônia 
apresentaram variação significativa da recessão 12 meses após o período de instalação dos conectores, sendo que os valores se mantiveram constantes nas demais avaliações em ambos os grupos. Os valores aumentaram após 12 meses para o titânio e reduziram no mesmo período para a zircônia. Ao compararmos a recessão gengival interagindo os grupos titânio e zircônia, nota-se que existe diferença significativa até o período de 12 meses, em seguida os valores são similares e mantêm-se constantes até o último período avaliado (36 meses). Os dentes contra-laterais apresentaram valores similares entre T1 e T3. Na Tabela 13 estão apresentados os valores de Mean ranks $\left(\mathrm{R}_{\mathrm{j}}\right)$ obtidos após as múltiplas comparações e as diferenças significantes entre os grupos investigados. A Figura 15 ilustra o gráfico tipo Box Plot com a representação dos valores mínimo, $1^{\circ}$ quartil, mediana, $3^{\circ}$ quartil e valores máximos após as múltiplas comparações (interagindo os fatores substrato e tempo). 
Tabela 12 - Valores de $p$ para as múltiplas comparações por meio do método de Friedman-Conover corrigido pelo pós-teste de Benjamini-Hochberg FDR na recessão gengival.

\begin{tabular}{|c|c|c|c|c|c|c|c|c|c|c|c|c|c|c|c|c|c|c|c|}
\hline \multicolumn{4}{|c|}{ Comparação } & \multirow{2}{*}{$\begin{array}{c}\text { Valor } \boldsymbol{p} \\
1,6 \times 10^{-6}\end{array}$} & \multicolumn{4}{|c|}{ Comparação } & \multirow{2}{*}{$\frac{\text { Valor } p}{8,7 \times 10^{-7}}$} & \multicolumn{4}{|c|}{ Comparação } & \multirow{2}{*}{$\frac{\text { Valor } \boldsymbol{p}}{1,3 \times 10^{-5}}$} & \multicolumn{4}{|c|}{ Comparação } & \multirow{2}{*}{$\begin{array}{l}\text { Valor } \boldsymbol{p} \\
0,0141\end{array}$} \\
\hline $\mathrm{A}$ & - & $\mathrm{B}$ & $=$ & & $\mathrm{C}$ & - & $\mathrm{E}$ & $=$ & & $E$ & - & $\mathrm{L}$ & $=$ & & $\mathrm{H}$ & - & $\mathrm{O}$ & $=$ & \\
\hline A & - & $\mathrm{C}$ & $=$ & $3 \times 10^{-9}$ & $\mathrm{C}$ & - & $\mathrm{F}$ & $=$ & 0,5819 & $\mathrm{E}$ & - & M & $=$ & 0,8697 & $\mathrm{H}$ & - & $\mathrm{P}$ & $=$ & 0,0157 \\
\hline A & - & $\mathrm{D}$ & $=$ & $1,7 \times 10^{-9}$ & $\mathrm{C}$ & - & $\mathrm{G}$ & $=$ & 0,4092 & $\mathrm{E}$ & - & $\mathrm{N}$ & $=$ & $6,1 \times 10^{-4}$ & I & - & $\mathrm{J}$ & $=$ & 0,0010 \\
\hline A & - & $\mathrm{E}$ & $=$ & 0,3620 & $\mathrm{C}$ & - & $\mathrm{H}$ & $=$ & 0,0044 & $\mathrm{E}$ & - & $\mathrm{O}$ & $=$ & $1,2 \times 10^{-7}$ & I & - & K & $=$ & $2,4 \times 10^{-6}$ \\
\hline A & - & $\mathrm{F}$ & $=$ & $1,1 \times 10^{-7}$ & $\mathrm{C}$ & - & I & $=$ & $3,7 \times 10^{-11}$ & $\mathrm{E}$ & - & $\mathrm{P}$ & $=$ & $9,8 \times 10^{-8}$ & I & - & $\mathrm{L}$ & $=$ & $1,3 \times 10^{-9}$ \\
\hline A & - & G & $=$ & $1,1 \times 10^{-11}$ & $\mathrm{C}$ & - & $\mathrm{J}$ & $=$ & $8,9 \times 10^{-4}$ & $\mathrm{~F}$ & - & $\mathrm{G}$ & $=$ & 0,1482 & I & - & M & $=$ & 0,1436 \\
\hline A & - & $\mathrm{H}$ & $<$ & $2 \times 10^{-16}$ & $\mathrm{C}$ & - & $\mathrm{K}$ & $=$ & 0,0651 & $\mathrm{~F}$ & - & $\mathrm{H}$ & $=$ & $4,6 \times 10^{-4}$ & I & - & $\mathrm{N}$ & $=$ & $1,9 \times 10^{-7}$ \\
\hline A & - & I & $=$ & 0,5165 & $\mathrm{C}$ & - & $\mathrm{L}$ & $=$ & 0,6179 & $\mathrm{~F}$ & - & I & $=$ & $1,7 \times 10^{-9}$ & I & - & $\mathrm{O}$ & $=$ & $3,1 \times 10^{-12}$ \\
\hline A & - & $\mathrm{J}$ & $=$ & 0,0118 & $\mathrm{C}$ & - & M & $=$ & $3,3 \times 10^{-7}$ & $\mathrm{~F}$ & - & $\mathbf{J}$ & $=$ & 0,0076 & I & - & $\mathrm{P}$ & $=$ & $2,7 \times 10^{-12}$ \\
\hline A & - & K & $=$ & $6,9 \times 10^{-5}$ & $\mathrm{C}$ & - & $\mathrm{N}$ & $=$ & 0,1698 & $\mathrm{~F}$ & - & K & $=$ & 0,2182 & $\mathrm{~J}$ & - & K & $=$ & 0,1901 \\
\hline A & - & $\mathrm{L}$ & $=$ & $8,1 \times 10^{-8}$ & $\mathrm{C}$ & - & $\mathrm{O}$ & $=$ & 0,7282 & $\mathrm{~F}$ & - & $\mathrm{L}$ & $=$ & 0,9570 & $\mathrm{~J}$ & - & $\mathrm{L}$ & $=$ & 0,0063 \\
\hline A & - & $\mathrm{M}$ & $=$ & 0,4499 & $\mathrm{C}$ & - & $\mathrm{P}$ & $=$ & 0,7015 & $\mathrm{~F}$ & - & M & $=$ & $7,7 \times 10^{-6}$ & $\mathrm{~J}$ & - & M & $=$ & 0,0999 \\
\hline A & - & $\mathrm{N}$ & $=$ & $7,7 \times 10^{-6}$ & $\mathrm{D}$ & - & $\mathrm{E}$ & $=$ & $5,1 \times 10^{-7}$ & $\mathrm{~F}$ & - & $\mathrm{N}$ & $=$ & 0,4499 & $\mathrm{~J}$ & - & $\mathrm{N}$ & $=$ & 0,0738 \\
\hline A & - & $\mathrm{O}$ & $=$ & $3,4 \times 10^{-10}$ & $\mathrm{D}$ & - & $\mathrm{F}$ & $=$ & 0,5165 & $\mathrm{~F}$ & - & $\mathrm{O}$ & - & 0,3704 & $\mathrm{~J}$ & - & $\mathrm{O}$ & $=$ & $2 \times 10^{-4}$ \\
\hline A & - & $\mathrm{P}$ & $=$ & $2,8 \times 10^{-10}$ & $\mathrm{D}$ & - & $\mathrm{G}$ & $=$ & 0,4592 & $\mathrm{~F}$ & - & $\mathrm{P}$ & $=$ & 0,3537 & $\mathrm{~J}$ & - & $\mathrm{P}$ & $=$ & $1,8 \times 10^{-4}$ \\
\hline B & - & C & $=$ & 0,2999 & $\mathrm{D}$ & - & $\mathrm{H}$ & $=$ & 0,0059 & G & - & $\mathrm{H}$ & $=$ & 0,0595 & $\mathrm{~K}$ & - & $\mathrm{L}$ & $=$ & 0,1957 \\
\hline B & - & $\mathrm{D}$ & $=$ & 0,2519 & $\mathrm{D}$ & - & I & $=$ & $2 \times 10^{-11}$ & G & - & I & $=$ & $6,2 \times 10^{-14}$ & $\mathrm{~K}$ & - & M & $=$ & 0,0019 \\
\hline B & - & $\mathrm{E}$ & $=$ & $1,8 \times 10^{-4}$ & $\mathrm{D}$ & - & $\mathrm{J}$ & $=$ & $6,1 \times 10^{-4}$ & G & - & $\mathrm{J}$ & $=$ & $1,9 \times 10^{-5}$ & $\mathrm{~K}$ & - & $\mathrm{N}$ & $=$ & 0,6587 \\
\hline B & - & $\mathrm{F}$ & $=$ & 0,6383 & $\mathrm{D}$ & - & K & $=$ & 0,0515 & G & - & K & $=$ & 0,0049 & K & - & $\mathrm{O}$ & $=$ & 0,0244 \\
\hline B & - & G & $=$ & 0,0495 & $\mathrm{D}$ & - & $\mathrm{L}$ & $=$ & 0,5564 & G & - & $\mathrm{L}$ & $=$ & 0,1647 & $\mathrm{~K}$ & - & $\mathrm{P}$ & $=$ & 0,0220 \\
\hline B & - & $\mathrm{H}$ & $=$ & $5,3 \times 10^{-5}$ & $\mathrm{D}$ & - & M & $=$ & $1,9 \times 10^{-7}$ & G & - & M & $=$ & $1,9 \times 10^{-9}$ & $\mathrm{~L}$ & - & M & $=$ & $5,9 \times 10^{-6}$ \\
\hline B & - & I & $=$ & $3,8 \times 10^{-8}$ & $\mathrm{D}$ & - & $\mathrm{N}$ & $=$ & 0,1436 & G & - & $\mathrm{N}$ & $=$ & 0,0211 & $\mathrm{~L}$ & - & $\mathrm{N}$ & $=$ & 0,4181 \\
\hline B & - & $\mathrm{J}$ & $=$ & 0,0341 & $\mathrm{D}$ & - & $\mathrm{O}$ & $=$ & 0,7919 & G & - & $\mathrm{O}$ & $=$ & 0,6281 & $\mathrm{~L}$ & - & $\mathrm{O}$ & $=$ & 0,4004 \\
\hline B & - & K & $=$ & 0,4685 & $\mathrm{D}$ & - & $\mathrm{P}$ & $=$ & 0,7652 & G & - & $\mathrm{P}$ & $=$ & 0,6485 & $\mathrm{~L}$ & - & $\mathrm{P}$ & $=$ & 0,3789 \\
\hline B & - & $\mathrm{L}$ & $=$ & 0,6078 & $\mathrm{E}$ & - & $\mathrm{F}$ & $=$ & $1,8 \times 10^{-5}$ & $\mathrm{H}$ & - & I & $<$ & $2 \times 10^{-16}$ & M & - & $\mathrm{N}$ & $=$ & $3,1 \times 10^{-4}$ \\
\hline B & - & M & $=$ & $8,1 \times 10^{-5}$ & $\mathrm{E}$ & - & G & $=$ & $5,5 \times 10^{-9}$ & $\mathrm{H}$ & - & $\mathrm{J}$ & $=$ & $4,8 \times 10^{-10}$ & M & - & $\mathrm{O}$ & $=$ & $4,6 \times 10^{-8}$ \\
\hline B & - & $\mathrm{N}$ & $=$ & 0,7652 & $\mathrm{E}$ & - & $\mathrm{H}$ & $=$ & $1,1 \times 10^{-14}$ & $\mathrm{H}$ & - & $\mathrm{K}$ & $=$ & $1,2 \times 10^{-6}$ & $\mathrm{M}$ & - & $P$ & $=$ & $3,8 \times 10^{-8}$ \\
\hline B & - & $\mathrm{O}$ & $=$ & 0,1529 & $\mathrm{E}$ & - & I & $=$ & 0,0999 & $\mathrm{H}$ & - & $\mathrm{L}$ & $=$ & $5,8 \times 10^{-4}$ & $\mathrm{~N}$ & - & $\mathrm{O}$ & $=$ & 0,0805 \\
\hline B & - & $\mathrm{P}$ & $=$ & 0,1436 & $\mathrm{E}$ & - & $\mathrm{J}$ & $=$ & 0,1436 & $\mathrm{H}$ & - & M & $=$ & $3,2 \times 10^{-15}$ & $\mathrm{~N}$ & - & $\mathrm{P}$ & $=$ & 0,0738 \\
\hline $\mathrm{C}$ & - & D & $=$ & 0,9307 & $\mathrm{E}$ & - & $\mathrm{K}$ & $=$ & 0,0036 & $\mathrm{H}$ & - & $\mathrm{N}$ & $=$ & $1,2 \times 10^{-5}$ & $\mathrm{O}$ & - & $\mathrm{P}$ & $=$ & 0,9660 \\
\hline
\end{tabular}

A - Titânio (T0); B - Titânio (T1); C - Titânio (T2); D - Titânio (T3); E - Controle Ti (T0); F - Controle Ti (T1); G - Controle Ti (T2); H Controle Ti (T3); I - Zircônia (T0); J - Zircônia (T1); K - Zircônia (T2); L - Zircônia (T3); M - Controle Zr (T0); N - Controle Zr (T1); O Controle $\mathrm{Zr}$ (T2); P - Controle Zr (T3). Números destacados em vermelho quando $p>0,05$. 
Tabela 13 - Mean ranks (Rj) após múltiplas comparações na recessão gengival. Letras diferentes (M) indicam diferenças significantes $(p<0,05)$ de acordo com Friedman-Conover e FDR ( $p<0,05)$. T0: baseline; T1: 12 meses; T2: 24 meses; T3: 36 meses.

\begin{tabular}{lccc}
\hline Substrato & Tempo & $\mathbf{R}_{\mathbf{j}}$ & $\mathbf{M}$ \\
\hline Titânio & $\mathrm{T}(0)$ & 371,3 & $\mathrm{a}$ \\
Titânio & $\mathrm{T}(1)$ & 506,0 & $\mathrm{bc}$ \\
Titânio & $\mathrm{T}(2)$ & 534,3 & $\mathrm{bcd}$ \\
Titânio & $\mathrm{T}(3)$ & 514,5 & $\mathrm{bcd}$ \\
Titânio (Controle) & $\mathrm{T}(0)$ & 396,1 & $\mathrm{ae}$ \\
Titânio (Controle) & $\mathrm{T}(1)$ & 496,1 & $\mathrm{bcd}$ \\
Titânio (Controle) & $\mathrm{T}(2)$ & 516,4 & $\mathrm{df}$ \\
Titânio (Controle) & $\mathrm{T}(3)$ & 544,9 & $\mathrm{f}$ \\
Zircônia & $\mathrm{T}(0)$ & 359,5 & $\mathrm{a}$ \\
Zircônia & $\mathrm{T}(1)$ & 481,7 & $\mathrm{eg}$ \\
Zircônia & $\mathrm{T}(2)$ & 506,4 & $\mathrm{bg}$ \\
Zircônia & $\mathrm{T}(3)$ & 524,7 & $\mathrm{bcd}$ \\
Zircônia (Controle) & $\mathrm{T}(0)$ & 393,3 & $\mathrm{ae}$ \\
Zircônia (Controle) & $\mathrm{T}(1)$ & 494,0 & $\mathrm{bcg}$ \\
Zircônia (Controle) & $\mathrm{T}(2)$ & 532,5 & $\mathrm{~cd}$ \\
Zircônia (Controle) & $\mathrm{T}(3)$ & 516,4 & $\mathrm{~cd}$ \\
\hline & & &
\end{tabular}

Figura 15 - Mediana, intervalo interquartil e valores mínimo e máximo de recessão gengival $(\mathrm{mm})$ após os testes de múltiplas comparações de Friedman-Conover corrigido por BenjaminiHockberg FDR. Diferentes letras representam diferenças significantes entre os grupos ( $<<$ 0,05). Ti: titânio; Zr: zircônia. T0: baseline; T1: 12 meses; T2: 24 meses; T3: 36 meses.

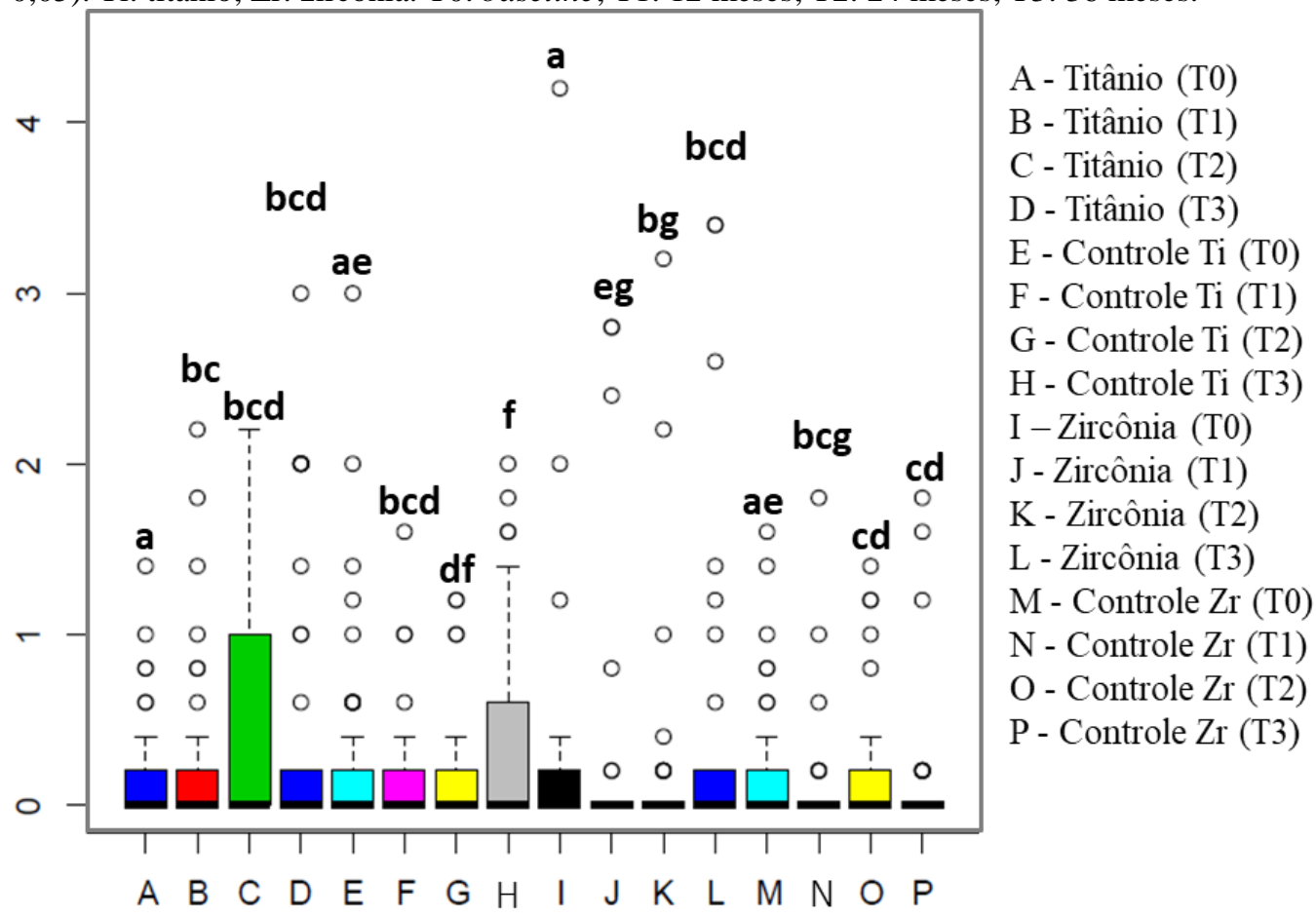




\subsection{Reabsorção óssea marginal}

A Tabela 14 mostra a perda óssea marginal (mm, média \pm DP) ao longo do tempo para cada tipo de substrato. Diante da distribuição normal dos dados, foram realizadas análises utilizando o teste Two-Way ANOVA. Nota-se que o titânio e a zircônia apresentaram valores similares de reabsorção óssea entre os períodos avaliados e sem diferença significante na perda óssea total ao final do período de 36 meses.

Tabela 14 - Reabsorção óssea marginal (mm, média \pm DP) ao redor dos implantes restaurados com conectores de titânio ou zircônia após 12, 24 e 36 meses de função.

\begin{tabular}{|c|c|c|c|c|}
\hline & \multicolumn{4}{|c|}{ Reabsorção Óssea Marginal } \\
\hline & $0-1$ ano & $1-2$ anos & $2-3$ anos & Perda óssea total \\
\hline Zircônia & $0,30 \pm 0,22$ & $0,34 \pm 0,33$ & $0,12 \pm 0,07$ & $0,76 \pm 0,21$ \\
\hline Titânio & $0,39 \pm 0,64$ & $0,26 \pm 0,32$ & $0,34 \pm 0,26$ & $0,98 \pm 0,41$ \\
\hline
\end{tabular}

0: Baseline - Instalação da prótese 60 dias após cirurgia

Não foram detectadas diferenças significantes pelo teste Two-Way ANOVA; $p<0,05$. 

6. Discussãa 



\section{DISCUSSÃO}

Em face à crescente utilização de componentes cerâmicos como estruturas de suporte para restaurações sobre implantes e devido à falta de resultados conclusivos, principalmente em longo prazo, sobre suas relações com os tecidos peri-implantares, este estudo teve por objetivo avaliar o desempenho clínico de dois tipos diferentes de conectores protéticos, os mais convencionalmente usados que são os fabricados em titânio e um conector anatomicamente semelhante fabricado em zircônia, ambos para restaurações unitárias. Os parâmetros clínicos utilizados foram a profundidade de sondagem, nível clínico de inserção, sangramento à sondagem e recessão gengival. Adicionalmente, também foi investigada a reabsorção óssea marginal dos implantes em função. O estudo foi conduzido por um período total de 36 meses, com avaliações a cada 12 meses. Nenhuma complicação clínica ou biológica foi observada nos períodos avaliados. Após os 3 anos não foram detectadas, em ambos os grupos, a presença de mobilidade nos implantes, radioluscência ao redor dos implantes, dor, desconforto ou infecção/inflamação na região do implante. Os valores de reabsorção óssea encontrados foram próximos às médias de valores reportadas na literatura após o primeiro ano de função. Além disso, foi observada estética satisfatória em todas as restaurações avaliadas, obtendo assim taxa de sucesso de 100\% em ambos os grupos.

A hipótese nula investigada de ausência de interações foi rejeitada para o fator grupo em todos os parâmetros avaliados, uma vez que nossos resultados apontaram diferenças relevantes entre os conectores de titânio e zircônia. Para o fator tempo, a hipótese nula somente não foi rejeitada para a variável recessão gengival; neste caso, o fator tempo não teve efeito significativo na recessão dos dois grupos. De forma geral, observou-se diferença entre os conectores de titânio e zircônia no primeiro e no terceiro ano de função; nos períodos intermediários o comportamento clínico entre eles é similar. O titânio apresentou aumento significativo na profundidade de sondagem e nível clínico de inserção após um ano de função, mantendo os valores constantes nos demais períodos até o final da investigação. Diferentemente, a zircônia apresentou valores constantes até 24 meses, quando apresentou redução significativa após 36 meses. Os valores de recessão e sangramento à sondagem foram mais constantes ao longo do estudo. Ambos os conectores apresentaram aumento de sangramento à sondagem em relação ao momento de instalação da prótese, e variação significativa foi observada entre eles, onde em alguns períodos a taxa de sangramento foi superior no grupo zircônia e em outros no grupo titânio. Em relação à recessão gengival, ambos os grupos apresentaram variação significativa da recessão entre o período de instalação 
do pilar (T0) e 12 meses, no qual o titânio apresentou leve aumento da recessão e a zircônia redução, após esse período os valores se mantiveram constantes em ambos os grupos. Os dados provenientes dos dentes contra-laterais foram utilizados neste estudo para servirem como parâmetro de comparação entre uma situação funcional de equilíbrio (dente) frente aos substratos investigados. Assim como esperado, seus valores foram constantes ao longo de todo o período do estudo para todas as variáveis avaliadas.

Os resultados obtidos nesta investigação estão de acordo com vários estudos descritos na literatura, onde altas taxas de sucesso e sobrevivência têm sido reportadas para restaurações utilizando conectores de titânio e zircônia em mais de 12 meses de função mastigatória (SAILER et al., 2009a; EKFELDT et al., 2011; HOSSEINI et al., 2011; ZEMBIC et al., 2013, 2015; PASSOS et al., 2016; EKFELDT et al., 2017). Isto é um fato relevante, já que a taxa média de sobrevivência reportada na literatura é de 95\%, enquanto nossos implantes apresentaram 100\% de sucesso, considerando os diversos fatores envolvidos como: restabelecimento da função mastigatória; ausência de dor ou infecção; estabilidade individual; e ausência de sinais radiográficos ou clínicos de patologia peri-implantar (BUSER et al., 2000; MISH et al., 2008). Além disso, a estética tem sido constantemente referida como fator importante para a obtenção de sucesso do tratamento e satisfação do paciente (ALBORNOZ et al., 2014). Os resultados similares entre os diferentes conectores de titânio e zircônia, observados neste estudo, podem ser atribuídos às propriedades físicas e mecânicas dos materiais investigados, como resistência à corrosão, alta capacidade de suportar cargas, biocompatibilidade e estabilidade dimensional. Propriedades estas que sempre foram o diferencial do titânio e que tiveram evolução muito grande nos últimos anos para os materiais cerâmicos (PICONI; MACCAURO, 1999; VAN BRAKEL et al., 2012; ALTUNA et al., 2016).

Apesar do desempenho satisfatório e similar ao do titânio, com alta taxa de sucesso e ausência de complicações biológicas e técnicas, existe a necessidade de acompanhar o desempenho clínico dos conectores de zircônia por um longo período de tempo, pois além de existirem estudos não conclusivos avaliando seu desempenho clínico longitudinalmente, a zircônia, assim como todas as cerâmicas, é propensa ao processo de degradação em baixas temperaturas, também conhecido como degradação hidrotérmica ou envelhecimento térmico. Este processo inicia-se na superfície, com incorporação de água nos grãos superficiais, preenchendo os espaços vazios de oxigênio, espalhando-se por toda superfície e chegando a afetar a estrutura interna do material. O resultado é o aumento da rugosidade superficial com o aparecimento de micro-trincas e diminuição da densidade do material, comprometendo suas 
propriedades mecânicas e podendo resultar em fratura (CHEVALIER et al., 2007). Apesar deste processo ocorrer lentamente em temperaturas orais, este mecanismo de degradação pode diminuir drasticamente as propriedades mecânicas do material, culminando na redução da resistência e tenacidade à fratura. Estudos in vitro demonstraram diminuição de $50 \%$ da tenacidade à fratura da zircônia durante simulações de processo de envelhecimento em ambiente úmido (STUDART et al., 2007; ALGHAZZAWI et al., 2012; MILITOV et al., 2016).

Outro fator que deve ser melhor investigado nos componentes cerâmicos é a capacidade de adesão dos micro-organismos sobre sua superfície. Estudos têm mostrado que o material utilizado na confecção de conectores protéticos tem grande impacto na formação e desenvolvimento do biofilme microbiano. Atualmente, sabe-se que não somente as suas características topográficas de rugosidade superficial interferem diretamente na formação do biofilme, mas também sua composição química e energia livre de superfície têm importante papel, muitas vezes seletivo, na adesão dos diversos micro-organismos presentes na cavidade oral (AVILA et al., 2016). Alguns autores sugerem que a rugosidade superficial é o fator que mais interfere na adesão microbiana em superfícies de titânio (ESPOSITO et al. 1998; QUIRYNEN et al., 2002), enquanto outros estudos atribuíram a energia livre de superfície como fator mais importante na formação inicial do biofilme em superfícies de zircônia (HAHNEL et al. 2009; BURGERS et al. 2010). No entanto, ainda existem limitações no conhecimento sobre possíveis diferenças nos mecanismos de adesão bacteriana a esses materiais, havendo, assim, a necessidade de melhor compreensão do papel do biofilme formado em cada componente na manutenção da saúde ou no desenvolvimento de potenciais lesões inflamatórias nos tecidos suportes peri-implantares, o que possibilitará o desenvolvimento de recomendações clínicas que possam evitar ou minimizar a proliferação dos microrganismos, desenvolvimento de doenças e consequente perda dos implantes.

Os resultados da primeira fase deste estudo, que investigou o impacto da colonização microbiana sobre os parâmetros clínicos dos implantes até um período de 6 meses de função, mostraram maior quantidade de micro-organismos colonizando os implantes restaurados com conectores de titânio. Também, os resultados sugerem colonização microbiana seletiva para titânio e zircônia, com o perfil microbiano variando entre os materiais. Foi identificada uma quantidade relevante de espécies ainda não classificadas ou caracterizadas nos implantes restaurados com titânio. Além disso, este grupo apresentou maior reabsorção óssea no período investigado (do NASCIMENTO et al., 2016). Os achados microbiológicos parecem não ter influenciado o sucesso dos implantes, uma vez que os conectores se comportaram de forma 
semelhante dentro da condição de saúde (do NASCIMENTO et al., 2016). Os resultados microbiológicos deste estudo preliminar são relevantes e devem se investigados por maior período de tempo, principalmente para avaliar como esta microbiota pode se comportar em longo prazo (se mantém ou se altera) e se ela pode ou não impactar nos resultados clínicos dos implantes. Talvez, essas diferenças relacionadas à microbiota encontradas na primeira fase do estudo (primeiros 6 meses) possam ainda ter se refletido nos resultados obtidos após os 12 primeiros meses de avaliação desta segunda etapa, onde, diferentemente da zircônia, os conectores de titânio apresentaram aumento na profundidade de sondagem e nível clínico de inserção.

A qualidade da união entre o tecido mole e o conector protético é outro fator que deve ser considerado, pois pode desempenhar papel importante na redução da colonização microbiana, uma vez que essa união funciona como barreira mecânica para a passagem de micro-organismos à região peri-implantar e componentes dos implantes (NOTHDURFT et al., 2015). Embora mudanças iniciais na saúde dos tecidos moles peri-implantares sejam difíceis de serem diagnosticadas, está bem estabelecido que o sangramento à sondagem é o método preferido para identificar a inflamação inicial da mucosa peri-implantar e a profundidade de sondagem e o nível clínico de inserção refletem a progressão da doença (JEPSEN et al., 2015). Ambos conectores apresentaram aumento no sangramento à sondagem após 12 meses de função, porém nenhum avanço para a condição de doença peri-implantar foi observada. Apesar do aumento, o maior valor de sangramento à sondagem mensurado no grupo zircônia (35,7\% no período T1) e no grupo titânio (42,9\% no período T2) são inferiores aos associados a locais com mucosite e peri-implantite, $67 \%$ e $91 \%$, respectivamente (SALVI et al., 2004).

A mucosa peri-implantar de espessura fina, não queratinizada, em conjunto com outros fatores etiológicos, como mal posicionamento dos implantes e remodelação fisiológica, podem ser fatores de risco para recessões da mucosa peri-implantar (FICKL et al., 2015). Semelhante aos nossos resultados, alguns estudos observaram que pequena recessão periimplantar $(<1 \mathrm{~mm})$ normalmente ocorre no primeiro ano após a inserção da restauração protética final, e nos anos subsequentes os valores tendem a se manterem constantes (BENGAZI et al., 1996; SMALL; TARNOW, 2000; CHANG et al., 2010). Bidra e Rungruanganunt (2013) ao avaliar o desempenho clínico dos conectores de titânio e cerâmicos na região anterior, por meio de revisão sistemática, observaram que a recessão periimplantar foi reportada predominantemente em estudos que utilizaram conectores de titânio pré-fabricados. Essa associação pode ser apenas coincidência ou está relacionada ao fato de que (1) conectores pré-fabricados fornecem menor suporte aos tecidos gengivais em 
comparação aos personalizados, (2) foram relatados em estudos que avaliaram por um período maior que os conectores cerâmicos, e (3) a recessão associada a conectores de titânio é identificada com maior facilidade.

Acredita-se que alterações iniciais da reabsorção óssea marginal podem influenciar a saúde dos tecidos moles peri-implantares e predispor ao desenvolvimento de doenças (SCHWARZ; SAHM e BECKER, 2012). São considerados limites aceitáveis perda óssea de aproximadamente 1,3 $\mathrm{mm}$ no primeiro ano e inferior a 0,1-0,2 $\mathrm{mm}$ por ano nos anos subsequentes (COX e ZARB 1987; PAPASPYRIDAKOS et al., 2012). A perda óssea marginal total observada no presente estudo, ao final de 36 meses, para os dois tipos de conectores avaliados foi inferior a $1 \mathrm{~mm}$, bem abaixo do limite preconizado na literatura, o que reflete condição favorável de saúde peri-implantar em ambos conectores. Porém, esses dados devem ser analisados com cautela, tendo em vista a dificuldade de padronização da metodologia de tomada radiográfica periapical. A radiografia periapical é a técnica mais aceita para avaliação em longo prazo de alterações ósseas marginais em regiões interproximais de implantes osseointegrados (BORNSTEIN et al., 2017). Porém, essa técnica radiográfica produz proporção elevada de falsos achados negativos, ou seja, tem baixa sensibilidade na detecção de mudanças precoces na remodelação óssea e/ou patológica (BRAGGER et al., 1998). Stokholm et al. (2016) observaram distância significativamente menor $(0,3 \mathrm{~mm})$ da perda óssea marginal peri-implantar quando medida nas radiografias digitais em comparação com a encontrada histologicamente. Apesar das limitações dessa metodologia, quando utilizamos a distância de um ponto fixo, como a plataforma do implante, para a crista óssea alveolar, este dado representa um parâmetro confiável para monitoramento em longo prazo na prática clínica (SALVI; LANG, 2004). Além disso, é indicada a realização de tomadas radiográficas por meio da técnica do paralelismo, a fim de minimizar distorções na imagem, realizar posicionamento da película radiográfica e angulação da irradiação o mais constante possível (LINDHE et al., 2010).

Os resultados apresentados no presente estudo trazem informações adicionais que podem ser consideradas relevantes e complementam aquelas já discutidas por investigações semelhantes, que sugerem que a zircônia pode apresentar melhor desempenho clínico em relação aos conectores de titânio. Os dados obtidos podem auxiliar no entendimento de algumas dúvidas pertinentes ao assunto e orientar no desenvolvimento de pesquisas futuras, atentando para a necessidade de investigações que se concentrem na avaliação em longo prazo destes componentes, correlacionando o biofilme bacteriano presente nos sulcos periimplantares e coroas protéticas. 

7. Conclusães 



\section{CONCLUSÕES}

De acordo com a metodologia utilizada e os resultados obtidos no estudo, pode-se concluir que:

1) Tanto os substratos investigados, titânio e zircônia, quanto os tempos de avaliação propostos tiveram um efeito relativo significante nos parâmetros de profundidade de sondagem, nível clínico de inserção e sangramento à sondagem; para recessão gengival, somente o fator grupo foi significante.

2) Os implantes restaurados com conectores de titânio apresentaram um aumento significante na profundidade de sondagem e nível clínico de inserção após os 12 primeiros meses de função, enquanto que a zircônia apresentou uma redução significante após 36 meses.

3) Os dois materiais apresentaram um aumento no sangramento à sondagem após os primeiros 12 meses, mas com valores inferiores aos reportados para doenças periimplantares.

4) Não houve diferença em relação à perda óssea total para os tipos de conectores ao final dos 36 meses de função. 

Referências 



\section{REFERÊNCIAS}

ABRAHAMSSON, I.; BERGLUNDH, T.; LINDHE, J. The mucosal barrier following abutment disreconnection. An experimental study in dogs. Journal of Clinical Periodontology. v. 24, p. 568-572, 1998.

ALBERTINI, M.; LÓPEZ-CERERO, L.; O'SULLIVAN, M.G.; CHEREGUINI, C.F.; BALLESTA, S.; RÍOS, V. Assessment of periodontal and opportunistic flora in patients with peri-implantitis. Clinical Oral Implants Research. v. 26, p. 937-941, 2015.

ALBORNOZ, A.C.; VIGNOLETTI, F.; FERRANTINO, L.C.; ARDENAS, E. de SANCTIS, M.; SANZ, M. A randomized trial on the aesthetic outcomes of implantsupported restorations with zirconia or titanium abutments. International Journal of Prosthodontics. p. 1-9, 2014. doi: $10.1111 /$ jcpe. 12312 .

ALGHAZZAWI TF, LEMONS J, LIU PR, ESSIG ME, BARTOLUCCI AA, JANOWSKI GM. Influence of low-temperature environmental exposure on the mechanical properties and structural stability of dental zirconia. Journal of Prosthodontics. v. 21, n. 5, p. 363-9, 2012.

ALTUNA, P.; TAULÉ, L.E.; ALBIOL G.J.; ÁLVAREZ F.O.; ALFARO H.F.; NART, J. Clinical evidence on titanium-zirconium dental implants: a systematic review and metaanalysis. International Journal of Oral and Maxillofacial Surgery. v. 45. p. 842-850, 2016.

ATIEH, M.A.; ALSABEEHA, N.H.; FAGGION JUNIOR, C.M.; DUNCAN, W.J. The frequency of peri-implant diseases: a systematic review and meta-analysis. Journal of Periodontology. v. 84, p. 1586-1598, 2013.

ATSUTA, I.; AYUKAWA, Y.; KONDO, R.; OSHIRO, W.; MATSUURA, Y.; FURUHASHI, A.; TSUKIYAMA, Y.; KOYANO, K. Soft tissue sealing around dental implants based on histological interpretation. Journal of Prosthodontic Research. v. 60, n. 1, p. 3-11, 2016.

AVILA, E.D.; AVILA-CAMPOS, M.J.; VERGANI, C.E.; SPOLIDÓRIO, D.M.P.; MOLLO, F.A. Structural and quantitative analysis of a mature anaerobic biofilm on different implant abutment surfaces. Journal of Prosthetic Dentistry. v. 115, p. 428-436, 2016.

BALAJI, S.M. Tobacco smoking and surgical healing of oral tissues:a review. Indian Journal of Dental Research. v. 19, p. 344-348, 2008.

BENGAZI, F.; WENNSTROM, J.L.; LEKHOLM, U. Recession of the soft tissue margin at oral implants. A 2-year longitudinal prospective study. Clinical Oral Implants Research. v. 7, p. 303-310, 1996.

BIDRA A.; RUNGRUANGANUNT, P. Clinical Outcomes of Implant Abutments in the Anterior Region: A Systematic Review. Journal of Esthetic and Restorative Dentistry. v. 25, n. 3, p. 159-176, 2013.

BLÁZQUEZ-HINAREJOS, M.; AYUSO-MONTERO, R.; JANÉ-SALAS, E.; LÓPEZ LÓPEZ, J. Influence of surface modified dental implant abutments on connective tissue attachment: A systematic review. Archives of Oral Biology. v. 80, p. 185-192, 2017. 
BORNSTEIN, M.M; HORNER, K.; JACOBS, R. Use of cone beam computed tomography in implant dentistry: current concepts, indications and limitations for clinical practice and research. Periodontology 2000. v. 73, p. 51-72, 2017.

BRÄGGER, U.; PASQUALI, L.; RYLANDER, H.; CARNES, D.; KORNMAN, K.S. Computer-assisted densitometric image analysis in periodontal radiography. Journal of Clinical Periodontology. v. 15, p. 27-37, 1988.

BRÄNEMARK, P. I.; ADELL, R.; BREINE, J. Intraosseous anchorage of dental prostheses. Experimental studies. Scandinavian Journal of Plastic and Reconstructive Surgery. v. 3, n. 2, p.81-100, 1969.

BRODBECK, U. The Zi Real Post: A new ceramic implant abutment. Journal of Esthetic and Restorative Dentistry. v. 15, p. 10-23, 2003.

BURGERS, R.; HAHNEL, S.; REICHERT, T.E.; ROSENTRITT, M.; BEHR, M.; GERHARD, T.; HANDEL, G.; GOSAU, M. Adhesion of Candida albicans to various dental implant surfaces and the influence of salivary pellicle proteins. Acta Biomaterialia. v. 6, p. 2307-2313, 2010.

BUSENLECHNER, D.; FÜRHAUSER, R.; HAAS, R.; WATZEK, G.; MAILATH, G.; POMMER, B. Long-term implant success at the Academy for Oral Implantology: 8-year follow-up and risk factor analysis. Journal of Periodontal \& Implant Science. v. 44, n. 3, p. 102-108, 20

BUSER, D.; ARX, T.; BRUGGENKATE, C.; WEINGART, D. Basic surgical principles with ITI implants. Clinical Oral Implants Research. v 11, p. 59-68, 2000.

BUSER, D.; MERICSKE-STERN, R.; BERNARD, J.P. Long-term evaluation of nonsubmerged ITI implants. Part 1: 8-year life table analysis of a prospective multicenter study with 2359 implants. Clinical Oral Implants Research. v. 8, p. 161- 172, 1997.

CHANG, M.; WENNSTRÖM, J.L. Peri-implant soft tissue and bone crest alterations at fixed dental prostheses: a 3-year prospective study. Clinical Oral Implants Research. v. 21, n. 5, p. $527-534,2010$.

CHEVALIER, J.; GREMILLARD, L.; DEVILLE, S. low temperature degradation of zirconia and implications for biomedical implants. Annual Review of Materials Research. v. 37, p. 1$32,2007$.

CHRCANOVIC, B.R.; ALBREKTSSON, T.; WENNERBERG, A. Reasons for failures of oral implants. Journal of Oral Rehabilitation. v. 41, n. 6, p. 443-476, 2014.

COATES, E.A.; BRENNAN, D.; LOGAN, R.M.; GOSS AN, SCOPACASA, B.; SPENCER, A.J.; GORKIC, E. Hepatitis $\mathrm{C}$ infection and associated oral health Problems. Australian Dental Journal. v. 45, p. 108-114, 2000.

COX, J.F.; ZARB, G.A. The longitudinal clinical efficacy of osseointegrated dental implants. The International Journal of Oral \& Maxillofacial Implants. v. 2, p. 91-100, 1987.

DABDOUB, S.M.; TSIGARIDA, A.A.; KUMAR, P.S. Patient-specificanalysis of periodontal and peri-implant microbiomes. Journal of Dental Research. v. 92, p. 168-175, 2013. 
DAUBERT, D.M.; WEINSTEIN, B.F.; BORDIN, S.; LEROUX, B.G.; FLEMMING, T.F. Prevalence and predictive factors for peri-implant disease and implant failure: a crosssectional analysis. Journal of Periodontology. v. 86, p. 337-347, 2015.

DAWSON, D.R; JASPER S. Key Systemic and Environmental Risk Factors for Implant Failure. Dental Clinics of North America. v. 59, p. 25-39, 2015.

DERKS, J.; TOMASI, C. Peri-implant health and disease. A systematic review of current epidemiology. Journal of Clinical Periodontology. v. 42, p. 158-171, 2015.

do NASCIMENTO, C., PITA, M.S., PEDRAZZI, V., DE ALBUQUERQUE JUNIOR, R.F. \& RIBEIRO, R.F. In vivo evaluation of Candida spp. adhesion on titanium or zirconia abutment surfaces. Archives of Oral Biology. v. 58, p. 853-861, 2013.

do NASCIMENTO, C.; MIANI, P.K.; PEDRAZZI, V.; MULLER, K.; de ALBUQUERQUE RF JR. Bacterial leakage along the implant-abutment interface: culture and DNA Checkerboard hybridization analyses. Clinical Oral Implants Research. v. 23, n. 10, p. 1168-72, 2012.

do NASCIMENTO, C.; MONESI, N.; ITO, I.Y.; ISSA, J.P.; de ALBUQUERQUE JUNIOR, R.F. Bacterial diversity of periodontal and implant-related sites detected by the DNA Checkerboard method. European Journal of Clinical Microbiology \& Infectious Diseases. v. 30, n. 12, p. 1607-13, 2011.

do NASCIMENTO, C.; PITA, M.S.; FERNANDES, F.H.; PEDRAZZI, V.; de ALBUQUERQUE JUNIOR, R.F.; RIBEIRO, R.F. Bacterial adhesion on the titanium and zirconia abutment surfaces. Clinical Oral Implants Research. v. 25, p. 337-43, 2014.

do NASCIMENTO, C.D.; PITA, M.S.; SANTOS, E.S.; MONESI, N.; PEDRAZZI, V.; ALBUQUERQUE JUNIOR, R.F.; RIBEIRO, R.F. Microbiome of titanium and zirconia dental implants abutments. Dental Materials. v. 32, n. 1, p. 93-101, 2016.

EICK, S.; RAMSEIER, C.A.; ROTHENBERGER, K.; BRÄGGER, U.; BUSER, D.; SALVI, G.E. Microbiota at teeth and implants in edentulous patients. A 10-year retrospective study. Clinical Oral Implants Research. v. 27, p. 218-225, 2016.

EKFELDT, A.; FURST, B.; GUNNAR, E.C. Zirconia abutments for single-tooth implant restorations: a 10- to 11-year follow-up study. Clinical Oral Implants Research. v. 28, p. 1303-1308, 2017.

ELEMAM, R.F.; PRETTY, I. Comparison of the success rate of endodontic treatment and implant treatment. International Scholarly Research Network. v. 2011, p. 1-8, 2011. doi: $10.5402 / 2011 / 640509$

EMECEN-HUJA, P.; HASAN, I.; MILLER, C.S. Biologic Markers of Failing Implants. Dental Clinics of North America, v. 59, p. 179-194, 2015.

ESPOSITO, M.; HIRSCH, J.M.; LEKHOLM, L.; THOMSEN, P. Fatores biológicos que contribuem para a falha de implantes orais osteointégrados. (II). Etiopatogenia. European Journal of Oral Sciences. v. 106, n. 3, p. 721-764, 1998. 
ESQUIVEL-UPSHAW, J.; MEHLER, A.; CLARK, A.; NEAL, D.; GONZAGA, L.; ANUSAVICE, K. Peri-implant complications for posterior endosteal implants. Clinical Oral Implants Research. v. 26, n. 12, p. 1390-6, 2014. doi: 10.1111/clr.12484.

FERREIRA, S.D.; SILVA, G.L.; CORTELLI, J.R.; COSTA, J.E.; COSTA, F.O. Prevalence and risk variables for peri-implant disease in Brazilian subjects. Journal of Clinical Periodontology. v. 33, p. 929-935, 2006.

FICKL, S. Peri-implant mucosal recession: Clinical significance and therapeutic opportunities. Quintessence Qnternational. v. 46, n. 8, p 671-676, 2015.

FÜRST, M.M.; SALVI, G.E.; LANG, N.P.; PERSSON, G.R. Bacterial colonization immediately after installation on oral titanium implants. Clinical Oral Implants Research. v. 18, p. 501-508, 2007.

GEHRKE, P.; DHOM, G.; BRUNNER, J.; WOLF, D.; DEGIDI, M.; PIATELLI, A. Zirconium implant abutments: Fracture strength and influence of cyclic loading on retaining screw loosening. Quintessence International. v. 37, p. 19-26, 2006.

GENS, K.D.; ELSHABOURY, R.H.; HOLT, J.S. Fecal microbiota transplantation and emerging treatments for Clostridium difficile infection. Journal of Pharmacy Practice. v. 26, p. 498-505, 2013.

GIBBS, C.H.; HIRSCHFELD, J.W.; LEE, J.G.; LOW， S.B.; MAGNUSSON, I.; THOUSAND, R.R.; YERNENI, P.; CLARK, W.B. Description and clinical evaluation of a new computerized periodontal probe - the Florida probe. Journal of Clinical Periodontology. v. 15, n. 2, p. 137-144, 1988.

GLAUSER R, SAILER I, WOHLWEND A, STUDER S, SCHIBLI M, SCHARER P. Experimental zirconia abutments for implant-supported single-tooth restorations in esthetically demanding regions: 4-year results of a prospective clinical study. The International Journal of Prosthodontics. v. 17, p. 285-90, 2004.

GOUVOUSSIS, J.; SINDHUSAKE, D.; YEUNG, S. Cross-infection from periodontitis sites to failing implants site in the same mouth. The International Journal of Oral \& Maxillofacial Implants. v. 12, p. 666-73, 1997.

GURGEL, B.C.V.; MONTENEGRO, S.C.L.; DANTAS, P.M.C.; PASCOAL, A.L.B.; LIMA, K.C.; CALDERON, P.S. Frequency of peri-implant diseases and associated factors. Clinical Oral Implants Research. v. 28, n. 10, p. 1211-1217, 2017.

HAHNEL, S.; ROSENTRITT, M.; HANDEL, G.; B€URGERS, R. In vitro evaluation of artificial ageing on surface properties and early Candida albicans adhesion to prosthetic resins. Journal of Materials Science: Materials in Medicine. v. 20, p. 249-255, 2009.

HEITZ-MAYFIELD, L.J. Peri-implant diseases: diagnosis and risk indicators. Journal of Clinical Periodontology. v. 35, n. 8, p. 292-304, 2008.

HOSSEINI, M.; WORSAAE, N.; SCHIDT, M; GOTFREDSEN, K. A 3-year prospective study of implant-supported, single-tooth restorations of all-ceramic and metal-ceramic materials in patients with tooth agenesis. Clinical Oral Implants Research. 2012. doi: 10.1111/j.1600-0501.2012.02514.x 
JEPSEN, S.; BERGLUNDH, T.; GENCO, R.; SERINO, G.; TOMASI,C.; ZITZMANN, N.U. Primary prevention of peri-implantitis: managing peri-implant mucositis. Journal of Clinical Periodontology. v. 42, 2015. doi: 10.1111/jcpe.12369.

JERVOE-STORM, P.M.; JEPSEN, S.; JÖHREN, P.; MERICSKE-STERN, R.; ENKLING, $\mathrm{N}$. Internal bacterial colonization of implants: association with peri-implant bone loss. Clinical Oral Implants Research. v. 26, n. 8, p. 957-963, 2015.

JUNG, R.; SAILER, I.; HAMMERLE, C.F.; ATTIN, T.; SCHMIDLIN, P. In vitro color changes of soft tissues caused by restorative materials. The International Journal of Periodontics \& Restorative Dentistry. v. 27, p. 251-257, 2007.

KAROUSSIS, I.K.; KOTSOVILIS, S.; FOURMOUSIS, I. A comprehensive and critical review of dental implant prognosis in periodontally compromised partially edentulous patients. Clinical Oral Implants Research. v. 18, p. 669-679, 2007.

KIM, A.; CAMPBELL, S.D.; VIANA, M.A.G.; KNOERNSCHILD, K.L. Abutment Material Effect on Peri-implant Soft Tissue Color and Perceived Esthetics. Journal of Prosthodontics. v. 00, p. 1-7, 2015. doi: 10.1111/jopr.12360.

KOCAR, M.; SEME, K.; HREN, N.I. Characterization of the normal bacterial flora in periimplant sulci of partially and completely edentulous patients. The International Journal of Oral \& Maxillofacial Implants. v. 25, p. 690-698, 2010.

KUMAR, P.S.; MASON, M.R.; BROOKER, M.R.; O’BRIEN, K. Pyrosequencing reveals unique microbial signatures associated with healthy and failing dental implants. Journal of Clinical Periodontology.v. 39, p. 425-433, 2012.

LEONHARDT, A.; RENVERT, S.; DAHLÉN, G.; Microbial findings at failing implants. Clinical Oral Implants Research. v. 10, p. 339-45, 1999.

LINDHE, J.; MEYLE, J. Peri-implant diseases: Consensus Report ofthe Sixth European Workshop on Periodontology. Journal of Clinical Periodontology. v. 35, p. 282-285, 2008.

LINDHE, J.; KARRING, T.; LANG, N.P. Tratado de periodontia clínica e implantologia oral. 5 ed, Rio de Janeiro: Guanabara Koogan, 2010. 590 p.

LINKEVICIUS, T.; VAITELIS, J. The effect of zirconia or titanium as abutment material on soft peri-implant tissues: A systematic review and meta-analysis. Clinical Oral Implants Research. v. 26, n. 11, p. 139-147, 2015.

LIU Y.; WANG, J. Influences of microgap and micromotion of implant-abutment interface on marginal bone loss around implant neck. Archives of Oral Biology. v. 83, p. 153-160, 2017.

LOPS D.; BRESSAN, E.; CHIAPASCO, M.; ROSSI, A.; ROMEO, E. Zirconia and titanium implant abutments for single-tooth implant protheses after 5 years of function in posterior regions. The International Journal of Oral \& Maxillofacial Implants. v. 28, n.1, p. 281$287,2013$.

MALO, P.A.; NOBRE, M.; LOPES, A.; MOSS, S.M.; MOLINA, G.J.A. A longitudinal study of the survival of all-on-4 implants in the mandible with up to 10 years of follow-up. The Journal of the American Dental Association. v. 142, p. 310-320, 2011. 
MERHEB, J.; VERCRUYSSEN, M.; COUCKE, W.; BECKERS, L.; TEUGHELS, W.; QUIRYNEN, M. The fate of buccal bone around dental implants. A 12-month postloading follow-up study. Clinical Oral Implants Research. v. 28, n. 1, p.. 103-108, 2017. doi: 10.1111/clr.12767.

MILITOV, G.; ANASTASSOVA-YOSHIDA, Y.; NOTHDURFT, F.P.; VON SEE, C.; POSPIECH, $P$. Influence of the preparation design and artificial aging on the fracture resistance of monolithic zirconia crowns. Journal of Advanced Prosthodontics. v. 8 , n. 1, p. 30-36, 2016.

MISCH, C.E.; PEREL, M.E.; SAMMARTINO, G.; GALINDO-MORENO, P.; STEIGMANN, M.; JOSEPH CHOUKROUN, J.; GUTIERREZ-PEREZ, J.L.; MARENZI, G.; VALAVANIS, D.K. Implant Success, Survival, and Failure: The International Congress of Oral Implantologists (ICOI) Pisa Consensus Conference. Implant Dentistry. v. 17, n. 1, / VOLUME 17, NUMBER 1 p. 5-15, 2008.

MOLIN, M.K.; KARLSSON, S.L. Five-year clinical prospective evaluation of zirconiabased Denzir 3-unit FPDs. The International Journal of Prosthodontics. v. 21, p. 223$227,2008$.

MOORE, W.E.C.; MOORE, L.V.H. The bacteria of periodontal disease. Periodontology 2000. v. 2000, n. 5, p. 66-77, 1994.

MORASCHINI, V.; POUBEL, L.A..; FERREIRA, V.F.; BARBOZA, E.S. Evaluation of survival and success rates of dental implants reported in longitudinal studies with a follow-up period of at least 10 years: a systematic review. International Journal of Oral and Maxillofacial Surgery. v. 44, n. 3, p. 377-388, 2015.

NEVES, J.; NOBRE, M.A.; OLIVEIRA, P.; SANTOS, J.M.; MALO, P. Risk factors for implant failure and peri-implant pathology in systemic compromised patients. Journal of Prosthodontics. v. 2, p. 1-7, 2016.

NOTHDURFT, E.P.; FONTANA, D.; RUPPENTHAL, S.; MAY, A.; MEHRAEIN, Y.; LIPP, P.; KAESTNER, L. Differential Behavior of Fibroblasts and Epithelial Cells on Structured Implant Abutment Materials: A Comparison of Materials and Surface Topographies. Clinical Implant Dentistry and Related Research. v. 17, n. 8, 2015.

OATES, T.W.; DOWELL, S. ROBINSON, M. et al: Glycemic control and implant stabilization in type 2 diabetes mellitus. Journal of Dental Research. v. 88, p. 367-371, 2009.

ONG, E.S.; NEWMAN, H.N.; WILSON, M. The occurrence of periodontitis - related microoganisms in relation to titanium implants. Journal of Periodontology. v. 63, p. 200-5, 1992.

PALMA-CARRIÓ, C.; MAESTRE-FERRÍN, L.; PENARROCHA-OLTRA D.; NARROCHA-DIAGO, M.A.; PENARROCHA-DIAGO, M. Risk factorsassociated with early failure of dental implants. A literature review. Medicina Oral, Patologia Oral Y Cirugia Bucal. v. 16, p. 514-517, 2011.

PAPASPYRIDAKOS, P.; CHEN, C.J.; SINGH， M.; WEBER， H.P.; GALLUCCI， G.O. Success criteria in implant dentistry: a systematic review. Journal of Dental Research. v. 91, n. 3, p. 241-248, 2012. 
PASSONI, B.B.; DALAGO, H.R.; SCHULDT FILHO, G.; SOUZA, J.G.O.; BENFATTI, C.A., MAGINI RDE, S.; BIANCHINI, M.A. Does the number of implants have any relation with peri-implant disease? Journal of Applied Oral Science. v. 22, p. 403-408, 2014.

PASSOS, S.P.; LINKE, B.; LARJAVA, H.; FRENCH, D. Performance of zirconia abutments for implant-supported single-tooth crowns in esthetic areas: a retrospective study up to 12year follow-up. Clinical Oral Implants Research. v. 27, p. 47-54, 2016.

PASTER, B.J.; BOCHES, S.K.; GALVIN, J.L.; ERICSON, R.E.; LAU, C.N.; LEVANOS, V.A.; SAHASRABUDHE, A.; DEWHIRST, F.E. Bacterial diversity in human subgingival plaque. Journal of Bacteriology. v. 183, p. 3770-3783, 2001.

PICONI, C.; MACCAURO, G. Zirconia as a ceramic biomaterial. Biomaterials. v. 20, p. 125, 1999.

POL, C.W.P.; RAGHOEBAR, G.M.; KERDIJK, W.; BOVEN, G.C.; CUNE, M.S.; MEIJER, H.J.A. A systematic review and meta-analysis of 3-unit fixed dental prostheses: Are the results of 2 abutment implants comparable to the results of 2 abutment teeth? Journal of Oral Rehabilitation. v. 23, 2017. doi: 10.1111/joor.12575.

QUIRYNEN, M.; DE, S.M.; VAN, S.D. Infectious risks for oral implants: a review of the literature. Clinical Oral Implants Research. v. 13, p. 1-19, 2002.

RENATUS, A.; TRENTZSCH, L.; SCHÖNFELDER, A.; SCHWARZENBERGER, F.; JENTSCH, H. Evaluation of an Electronic Periodontal Probe Versus a Manual Probe Journal of Clinical and Diagnostic Research. v. 10, n. 1, p. 3-7, 2016.

RUSTEMEYER, J.; BREMERICH, A. Patients' knowledge and expectations regarding dental implants: assessment by questionnaire. International Journal of Oral and Maxillofacial Surgery. v. 36, p. 814-817, 2007.

SAILER, I.; PHILIPP, A.; ZEMBIC, A.; PJETURSSON, B.E.; CHRISTOPH, H.F.H.; ZWAHLEN, M. A Systematic review of the performance of ceramic and metal implant abutments supporting fixed implant reconstructions. Clinical Oral Implants Research. v. 20, n. 4, p. 4-31, 2009a.

SAILER, I.; ZEMBIC, A.; JUNG, R. E.; SIEGENTHALER, D.; HOLDEREGGER, C.; HAMMERLE, C. H. Randomized controlled clinical trial of customized zirconia and titanium implant abutments for canine and posterior single-tooth implant reconstructions: Preliminary results at 1 year of function. Clinical Oral Implants Research. v. 20, p. 219-225, 2009b.

SAITO, A.; HOSAKA, Y.; SEKIGUCHI K, K.T.; ISOBE, S.; SHIBUKAWA, Y.; SUMII, H.; ITO, T.; NAKAGAWA, T.; YAMADA, S. Responses of peri-implants tissues to undisturbed plaque formation in dogs: clinical, radiographic and microbiological findings. The Bulletin of Tokyo Dental College. v. 38, p. 13-20, 1997.

SAKKA, S.; BAROUDI, K.; NASSANI, M.Z. Factors associated with early and late failure of dental implants. Journal of Investigative and Clinical Dentistry. v. 3, p. 258-261, 2012.

SALVI, G.E.; FÜRST, M.M..; LANG, N.P.; PERSSON, G.R. One-year bacterial colonization patterns of Staphylococcus aureus and other bacteria at implants and adjacent teeth. Clinical Oral Implants Research. v. 19, p. 242-8, 2008. 
SALVI, G.E.; LANG, N.P. Diagnostic Parameters for Monitoring Peri-implant Conditions. The International Journal of Oral \& Maxillofacial Implants. v. 19, p. 116-127, 2004.

SANZ-MARTÍN, I.; SANZ-SÁNCHEZ, I.; ALBORNOZ, A.C.; FIGUERO, E.; SANZ, M. Effects of modified abutment characteristics on peri-implant soft tissue health: A systematic review and meta-analysis. Clinical Oral Implants Research. p. 1-12, 2017. doi: 10.1111/clr.13097.

SASADA, Y.; COCHRAN, D.L. Implant-Abutment Connections: A Review of Biologic Consequences and Peri-implantitis Implications. The International Journal of Oral \& Maxillofacial Implants. v. 32, n. 6, p. 1296-1307, 2017. doi: 10.11607/jomi.5732.

SBORDONE, L.; BARONE, A.; RAMAGLIA, L.; CIAGLIA, R.N.; IACONO, V.J. Antimicrobial susceptibility of periodontopathic bacteria associated with failing implants. Journal of Periodontology. v. 66, p. 69-74, 1995.

SCHAUMANN, S.; STAUFENBIEL, I.; SCHERER, R.; SCHILHABEL, M.; WINKEL, A.; STUMPP, S.N.; EBERHARD, S.N.; STIESCH, M. Pyrosequencing of supra- and subgingival biofilms from inflamed peri-implant and periodontal sites. BMC Oral Health. v. 14, p. 157, 2014. doi: 10.1186/1472-6831-14-157.

SCHWARZ, F.; SAHM, N.; BECKER 2 J. Impact of the outcome of guided bone regeneration in dehiscence-type defects on the long-term stability of peri-implant health: clinical observations at 4 years. Clinical Oral Implants Research. v. 23, n. 2, p. 191-196, 2012.

SGOLASTRA, F.; PETRUCCI, A.; SEVERINO, M. et al: Smoking and the risk of periimplantitis. A systematic review and meta-analysis. Clinical Oral Implants Research. v. 26, p. 62-67, 2015.

SIMION, M.; KIM, D.M.K.; PIERONI, S.; NEVINS, M.; CSSINELLI, C. Bacterial biofilm Morphology on a failing implant with an oxidized surface: a scanning electron microscope study. Quintessence Publishing. v. 36, n. 4, p. 485-488, 2016.

SMALL, P.N.; TARNOW, D.P. Gingival Recession Around Implants: a 1-Year Longitudinal Prospective Study. The International Journal of Oral \& Maxillofacial Implants. v. 15, p. 527-532, 2000.

SMITH, D.E.; ZARB, G.A. Criteria for sucesso $f$ osseointegrated endosseous implants. Journal of Prosthetic Dentistry. v. 62, n.5, p. 567-572, 1989.

SOCRANSKY, S.S.; HAFFAJEE, A.D. Periodontal microbial ecology. Periodontology 2000. v. 38, p. 135-187, 2005.

SRIDHAR, S.; WILSON JUNIOR, T.G.; PALMER, K.L.; VALDERRAMA, P.; MATHEW, M.T.; PRASAD, S.; JACOBS, M.; GINDRI, I.M.; RODRIGUES, D.C. In vitro investigation of the effect of oral bacteria in the surface oxidation of dental implants. Clinical Implant Dentistry and Related Research, v. 17, n. 2, p. 562-575, 2015.

STOKHOLM, R.; SPIN-NETO, R.; NYENGAARD, J.R.; ISIDOR, F. Comparison of radiographic and histological assessment of peri-implant bone around oral implants. Clinical Oral Implants Research. v. 27, n. 7, p. 782-6, 2016. 
STUDART AR, FILSER F, KOCHER P, GAUCKLER LJ. Fatigue of zirconia under cyclic loading in water and its implications for the design of dental bridges. Dental Materials. v. 23, p. 106-114, 2017.

STUDER, S.; ZELLWEGER, U.; SCHARER, P. The aesthetic guidelines of the mucogingival complex for fixed prosthodontics. Practical Periodontics and Aesthetic Dentistry. v. 8, n. 342, p. 333-341, 1996.

TRUONG, V.K.; LAPOVOK, R.; ESTRIN, Y.S.; RUNDELL, S.; WANG, J.Y.; FLUKE, C.J.; CRAWFORD, R.J; IVANOVA, E.P. The influence of nano-scale surface roughness on bacterial adhesion to ultra-fine-grained titanium. Biomaterials. v. 31, p. 3674-3683, 2010.

VALENTE, N.A.; ANDREANA, S. Peri-implant disease: what we know and what we need to know. Journal of Periodontal \& Implant Science. v. 46, n. 3, p. 136-151, 2016.

VAN BRAKEL, R.; MEIJER, G.J.; VERHOEVEN, J.W.; JANSEN, J.; de PUTTER, C.; CUNE, M.S. Soft tissue response to zirconia and titanium implant abutments: an in vivo within-subject comparison. Journal of Clinical Periodontology. v. 39, n. 10, p. 995-1001, 2012 .

VAN BRAKEL, R.; NOORDMANS, H.J.; FRENKEN, J. et al. The effect of zirconia and titanium implant abutments on light reflection of the supporting soft tissues. Clinical Oral Implants Research. v. 22, p. 1172-1178, 2011.

VECHIATO-FILHO, A.J.; PESQUEIRA, A.A.; DE SOUZA, G.M.; DOS SANTOS, D.M.; PELLIZZER, E.P.; GOIATO, M.C. Are Zirconia Implant Abutments Safe and Predictable in Posterior Regions? A Systematic Review and Meta-Analysis. The International Journal of Prosthodontics. v. 29, n. 3, p. 233-44, 2016.

WASSMANN, T.; KREIS, S.; BEHR, M.; BUERGERS, R. The influence of surface texture and wettability on initial bacterial adhesion on titanium and zirconium oxide dental implants. International Journal of Implant Dentistry. v. 3, n. 32, p 1-11, 2017.

WATKIN, A.; KERSTEIN, R.B. Improving darkened anterior peri-implant tissue color with zirconia custom implant abutments. Compendium of Continuing Education in Dentistry. v. 29, p. 238-40, 2008.

WEINLANDER, M.; KRENNMAIR, G.; PIEHSLINGER, E. Implant prosthodontic rehabilitation of patients with rheumatic disorders: a case series report. The International Journal of Prosthodontics. v. 23, p. 22-28, 2010.

WELANDER, M.; ABRAHAMSSON, I.; BERGLUNDH, T. The mucosal barrier at implant abutments of different materials. Clinical Oral Implants Research. v. 19, p. 635-41, 2008.

ZEMBIC, A.; SAILER, I.; JUNG, R.E.; HAMMERLE, C.H. Randomized controlled clinical trial of customized zirconia and titanium implant abutments for single-tooth implants in canine and posterior regions: 3-year results. Clinical Oral Implants Research. v. 20, p. 802-808, 2009. 
ZEMBIC, A.; BOSCH, A.; JUNG, R. E.; HAMMERLE, C. H.; SAILER, I. Five-year results of a randomized controlled clinical trial comparing zirconia and titanium abutments supporting single-implant crowns in canine and posterior regions. Clinical Oral Implants Research. v. 24, p. 384-390, 2013.

ZEMBIC, A.; PHILIPP, A.O.H; HÄMMERLE, C.H.F.; WOHLWEND, A.; SAILER,I. Eleven-year follow-up of a prospective study of zirconia implant abutments supporting single all-ceramic crowns in anterior and premolar regions. Clinical Implant Dentistry and Related Research. v. 17, n. 2, 2015. 
Anexa 



\section{ANEXO A - Aprovação do Comitê de Ética}

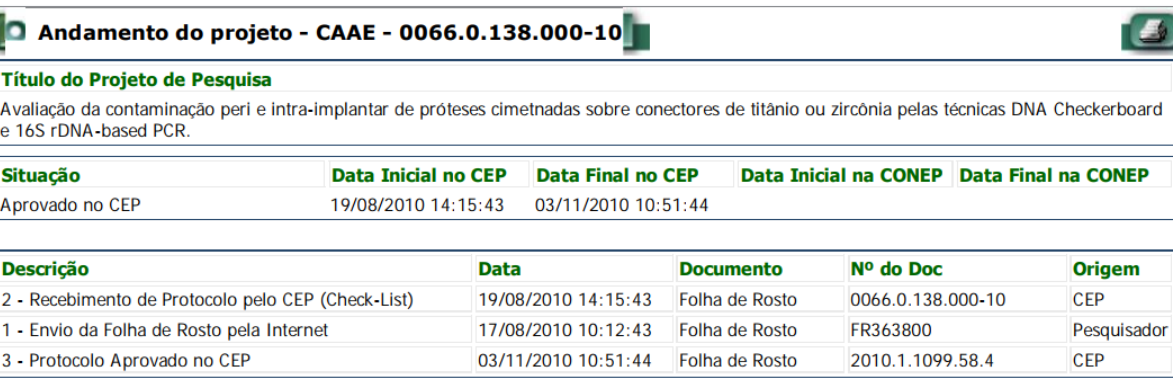



Apêndice 



\title{
APÊNDICE A - Termo de Consentimento Livre e Esclarecido
}

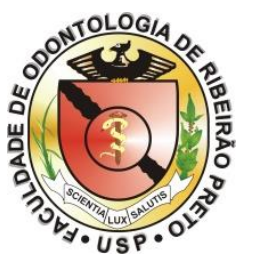

\author{
UNIVERSIDADE DE SÃO PAULO
}

FACULDADE DE ODONTOLOGIA DE RIBEIRÃO PRETO

TERMO DE CONSENTIMENTO LIVRE E ESCLARECIDO

(Capítulo IV, itens 1 a 3 da Resolução 196/96 - Conselho Nacional de Saúde)

Nós, Prof. Dr. Ricardo Faria Ribeiro (pesquisador responsável) e Cássio do Nascimento, convidamos você,

a participar da pesquisa "Avaliação da contaminação peri e intra-implantar de próteses cimentadas sobre conectores de titânio ou zircônia pelas técnicas DNA Checkerboard e 16S rDNA-based PCR".

A utilização de implantes dentários de dois componentes tem sido amplamente utilizada nas clínicas odontológicas para a reposição de dentes ausentes. Sobre o implante colocado no osso, são usados conectores para a colocação final da prótese (dente artificial). Uma das principais causas de complicações neste tipo de tratamento é a imperfeita adaptação entre o implante e seus componentes. Esta pesquisa tem como objetivo avaliar, utilizando técnicas de diagnósticos moleculares (identificação por DNA), a possível passagem de espécies bacterianas presentes na cavidade oral por meio da junção entre implantes e seus componentes protéticos fabricados em dois diferentes tipos de materiais atualmente disponíveis no mercado brasileiro, titânio ou zircônia.

Os pacientes participantes do projeto de pesquisa serão tratados com implantes e próteses unitárias (dentes) cimentadas. O paciente não terá nenhuma despesa ao participar deste estudo. Após a colocação dos implantes, serão colhidas amostras de placa bacteriana dos sulcos periodontais, peri-implantares (gengiva) e interior dos implantes no momento da reabertura dos implantes (instalação da coroa provisória) e após 3 e 6 meses da instalação das coroas provisórias. O período estabelecido para a colheita das amostras não trará complicações nem prejuízos para o paciente, uma vez que servirá para avaliar o comportamento biomecânico da prótese previamente à cimentação da coroa definitiva, possibilitando a realização de ajustes que garantam o sucesso da prótese definitiva.

Apesar dos baixos índices de complicações durante a cirurgia de colocação dos implantes, o paciente deve estar ciente da possibilidade dos riscos de perda do implante. Nestes casos, serão avaliadas as causas do insucesso para a possibilidade de realizar novamente a cirurgia de implante.

O paciente deverá comparecer à FORP-USP todas as vezes em que houver solicitação do dentista ou dos pesquisadores desse projeto.

Todos os dados relacionados com você serão confidenciais e sua identidade será mantida em sigilo. A divulgação dos resultados será realizada, preservando a sua identidade, pois não serão publicadas fotografias, nomes e/ou documentos dos participantes, nos artigos a serem publicados ou apresentados na forma de painel científico. 
A sua participação não é obrigatória, e você poderá desistir a qualquer momento, retirando o seu consentimento. A não participação neste projeto de pesquisa não trará prejuízo algum em sua relação com os pesquisadores ou com a Faculdade de Odontologia de Ribeirão Preto - USP.

Você receberá uma cópia deste termo, com o endereço e telefone dos pesquisadores e da secretaria do comitê de ética em Pesquisa da FORP/USP. Caso tenha alguma dúvida você poderá entrar em contato pelos telefones e endereços abaixo.

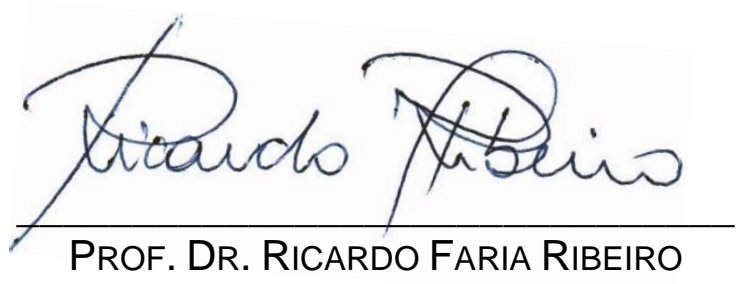

Telefones para contato: (16) 3602-4046 / 3602-3983 E-mail: rribeiro@forp.usp.br

\section{Cássio do Nascimento}

Telefones para contato: (16) 3602-4095 / 8192-4729 E-mail:

\section{cassionasc@forp.usp.br}

Nome do Secretário do CEP: Sr. Daniel Mesquita de Moraes

Endereço e telefone do CEP: Seção de Apoio Acadêmico, Prédio da Administração FORP/USP. Fone (16) 3602-4129

Declaro que entendi os objetivos, riscos e benefícios de minha participação na pesquisa e concordo em participar.

RG:

Sujeito da pesquisa

Telefone:( )

Endereço: 